Florida International University FIU Digital Commons

3-9-2012

\title{
The Effect of Young Adult Literature on Adolescents' Rape Myth Acceptance
}

Victor Malo-Juvera

Florida International University,vmalo001@fiu.edu

DOI: $10.25148 /$ etd.FI12041115

Follow this and additional works at: https://digitalcommons.fiu.edu/etd

\section{Recommended Citation}

Malo-Juvera, Victor, "The Effect of Young Adult Literature on Adolescents' Rape Myth Acceptance" (2012). FIU Electronic Theses and Dissertations. 564.

https://digitalcommons.fiu.edu/etd/564

This work is brought to you for free and open access by the University Graduate School at FIU Digital Commons. It has been accepted for inclusion in FIU Electronic Theses and Dissertations by an authorized administrator of FIU Digital Commons. For more information, please contact dcc@fiu.edu. 


\section{FLORIDA INTERNATIONAL UNIVERSITY \\ Miami, Florida}

\section{THE EFFECT OF YOUNG ADULT LITERATURE ON ADOLESCENTS' RAPE MYTH ACCEPTANCE}

A dissertation submitted in partial fulfillment of

the requirements for the degree of

DOCTOR OF EDUCATION

in

CURRICULUM AND INSTRUCTION

by

Victor Malo-Juvera

2012 
To: Dean Delia C. Garcia

College of Education

This dissertation, written by Victor Malo-Juvera, and entitled The Effect of Young Adult Literature on Adolescents' Rape Myth Acceptance, having been approved in respect to style and intellectual content, is referred to you for judgment.

We have read this dissertation and recommend that it be approved.

Patricia Barbetta

Leonard Bliss

Rebecca Powell

Laurie Shrage

Linda Spears-Bunton, Major Professor

Date of Defense: March 9, 2012

The dissertation of Victor Malo-Juvera is approved.

Dean Delia C. Garcia

College of Education

Dean Lakshmi N. Reddi

University Graduate School

Florida International University, 2012 


\section{DEDICATION}

With love to my wife Debbie, who has been beyond patient throughout this entire process. Without her love and support, none of this would have been possible. 


\section{ACKNOWLEDGMENTS}

I would like to express my gratitude to the many people who helped me throughout this project. Dr. Linda Spears-Bunton provided mentoring since my first class in a master's program and she has gone far beyond being my major professor. Without her help and guidance, this and so much more would have never been possible. Dr. Leonard Bliss shared with me his knowledge and love of research methods and statistics over the years and without his expertise this project would never have come to fruition. Whenever there was a question, Dr. Bliss had the correct answer. Dr. Laurie Shrage generously shared her knowledge of feminist theory and women's studies that were critical in completing this work. I would also like to thank Dr. Patricia Barbetta and Dr. Rebecca Powell for joining this journey in the later stages and I would like to thank Dr. Mohommed Farouk for being there in the beginning.

Aside from my committee, there are numerous others whose assistance was invaluable in getting me across the finish line. Dr. Linda Bliss read numerous drafts and provided copious notes that significantly improved the quality of this work. Dr. Isadore Newman shared his expertise in factor analysis and provided feedback on several chapters. Dr. Robert Farrell allowed me to investigate my interests in his class where I was able to write a first draft of my review of literature. Caprilla Almeida in the COE OGS office was always there to answer my questions and to make sure that I did not get tangled up in the red tape. Adam Koivisto provided critical help throughout the study. Juan Rodriguez is a librarian par excellence. Phillip Bolton in the UGS ETD office generously shared his time in helping me prepare the final submission. 
Finally, I would like to thank the Assembly on Literature for Adolescents of the National Council of Teachers of English for providing a research grant that paid for all the novels used in this study. 


\section{ABSTRACT OF THE DISSERTATION \\ THE EFFECT OF YOUNG ADULT LITERATURE ON ADOLESCENTS' RAPE MYTH ACCEPTANCE}

by

Victor Malo-Juvera

Florida International University, 2012

Miami, Florida

\section{Professor Linda Spears-Bunton, Major Professor}

This quasi-experimental study $(N=139)$ measured the effect of a reader response based instructional unit of the novel Speak on adolescents' rape myth acceptance. Participants were eighth grade language arts students at a Title I middle school in a major metropolitan school district. Seven classes were randomly assigned to treatment $(n=4)$ or control $(n=3)$ condition. Two teachers participated in the study and both taught both treatment and control classes. The study lasted a period of five weeks. Participants were pretested using the Rape Myth Acceptance Scale (Burt, 1980) and a researcher created scale, the Adolescent Date Rape Scale (ADRMS).

Analysis of pretests showed the ADRMS to be a reliable and valid measure of rape myth acceptance in adolescents. Factor analysis revealed it to have two major components: "She Wanted It" and "She Lied." Pretests supported previous studies which found girls to have significantly lower initial levels of rape myth acceptance than boys ( $p$ $<.001)$. A 2 (group) x 2 (instructor) x 2 (sex) ANCOVA using ADRMS pretest as a covariate and ADRMS posttest as a dependent variable found that treatment was effective in reducing rape myth acceptance $\left(p<.001, \dot{\eta}^{2}=.15\right)$. Boys with high rape myth 
acceptance as demonstrated by pretest scores of 1 standard deviation above the mean on ADRMS did not have a backlash to treatment. Extended analysis revealed that participants had significantly lower scores posttest on Factor 1, "She Wanted It" ( $p<$ $\left..001, \eta^{2}=.27\right)$, while scores on Factor 2, "She Lied" were not significantly lower ( $p=$ .07). This may be because the content of the novel primarily deals with issues questioning whether the main characters assault was a rape rather than a false accusation. Attrition rates were low $(N=15)$ and attrition analysis showed that drop outs did not significantly alter the treatment or control groups. Implications for reader response instruction of young adult literature, for research on rape myth acceptance in secondary schools, and for statistical analysis of effect size using pretests as filters are discussed. 


\section{TABLE OF CONTENTS}

CHAPTER

PAGE

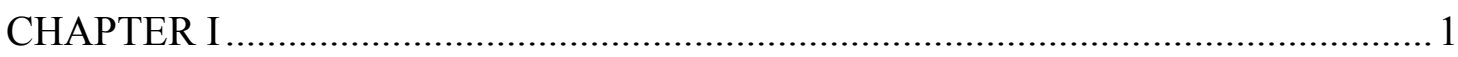

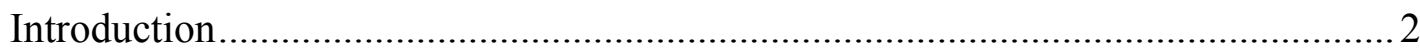

The Problem with Educational Literacy ………………............................................

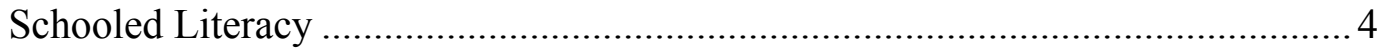

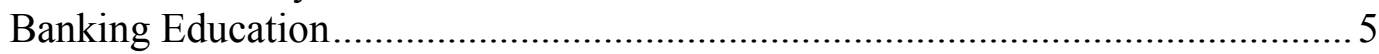

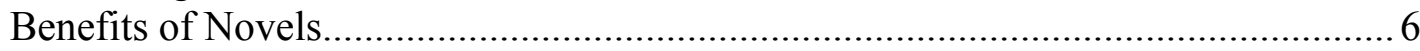

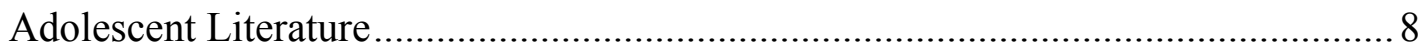

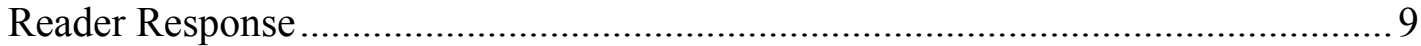

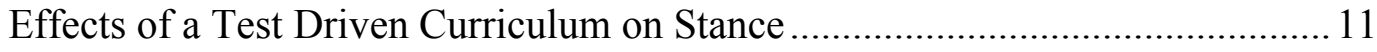

Benefits of Aesthetic Stance ........................................................................... 12

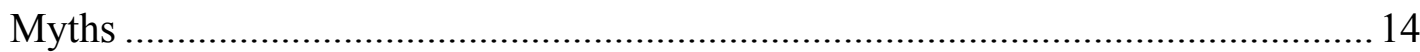

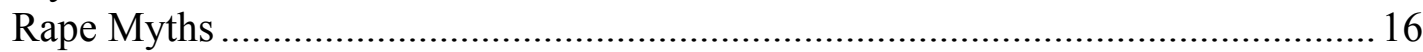

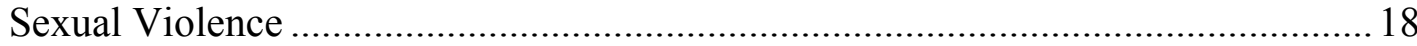

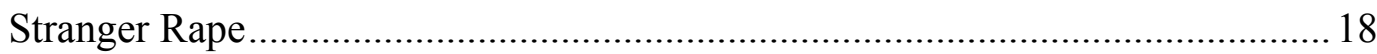

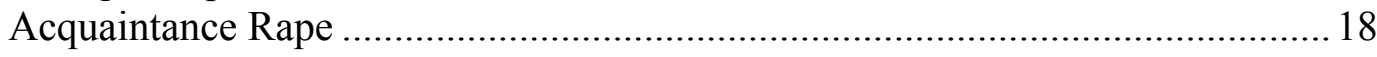

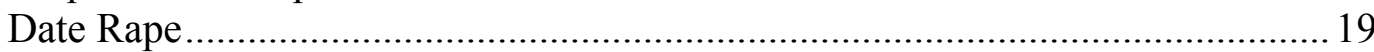

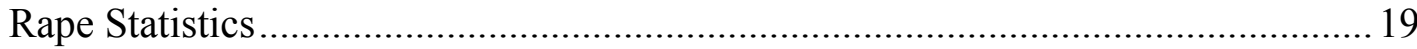

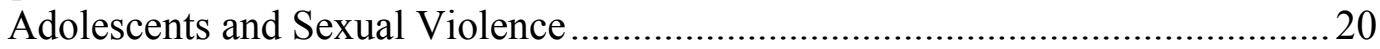

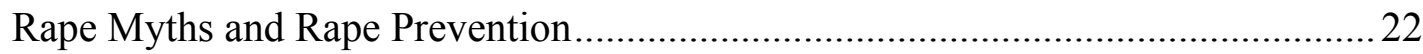

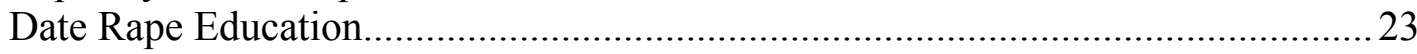

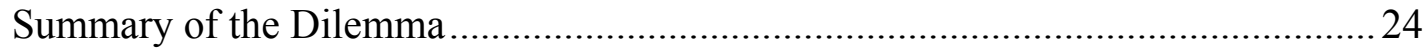

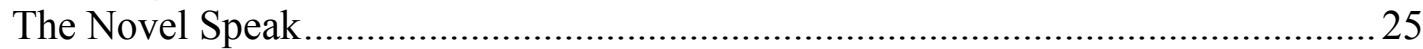

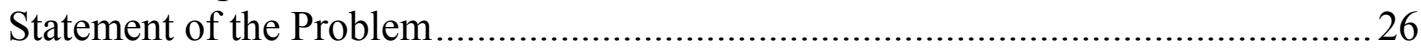

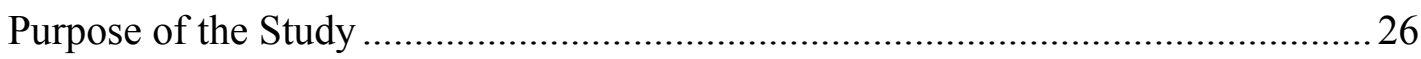

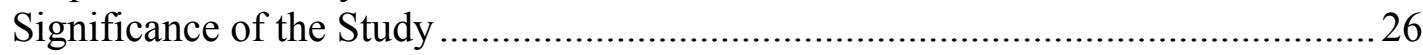

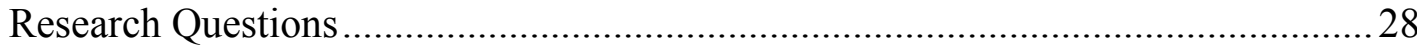

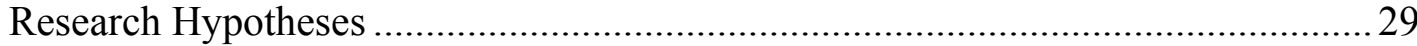

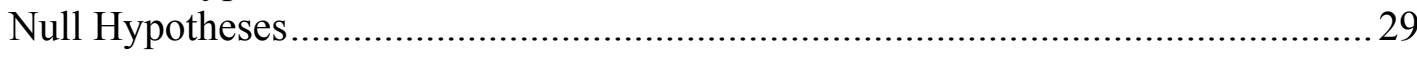

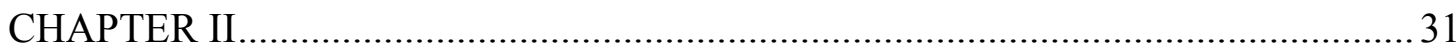

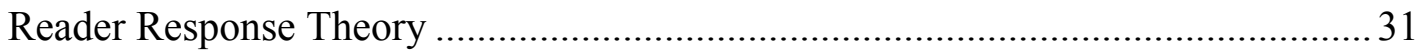

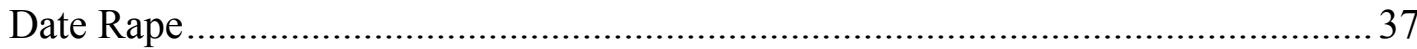

Research on Rape Myth Acceptance and Rape Proclivity......................................... 41

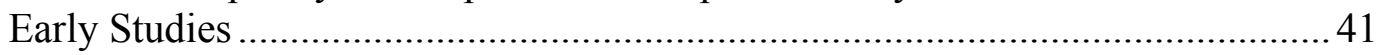

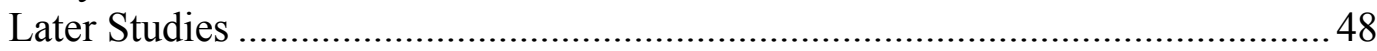

Conclusions about Rape Myth Acceptance and Rape Proclivity............................60

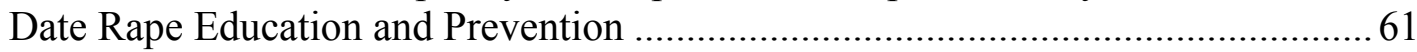

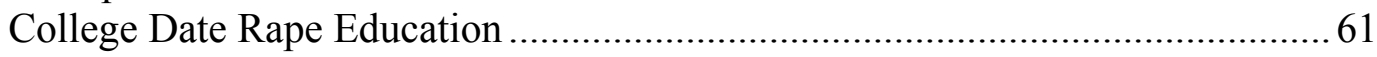

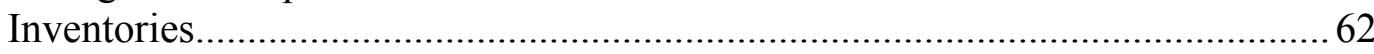

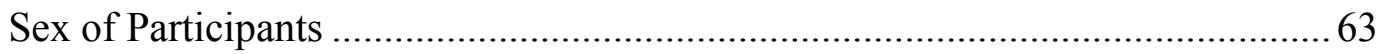

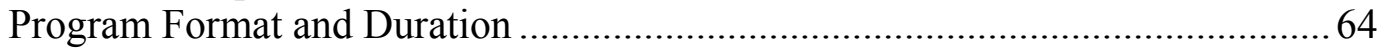




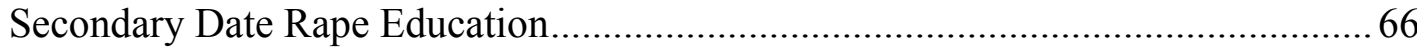

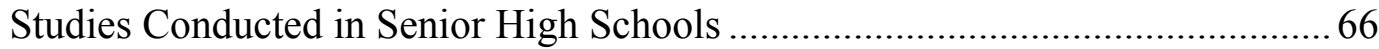

High Attrition Studies ..................................................................................... 70

Studies Using Pretests as Filters for Statistical Analysis..................................... 74

Studies Conducted in Middle or Junior High Schools............................................ 79

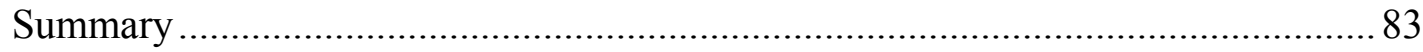

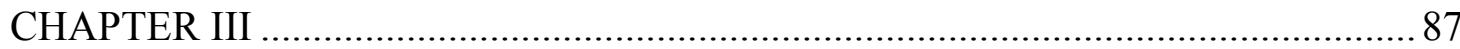

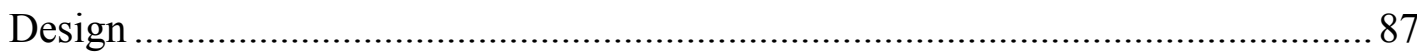

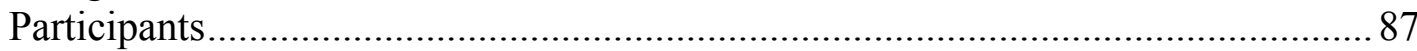

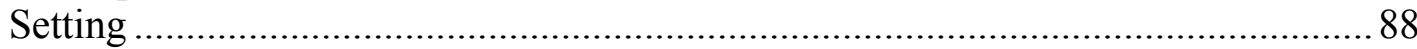

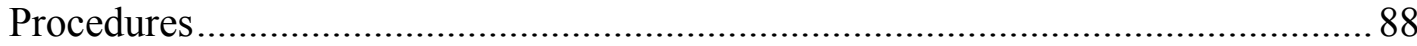

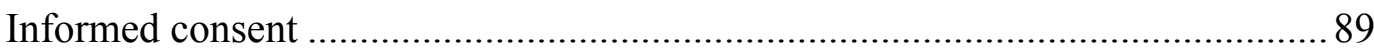

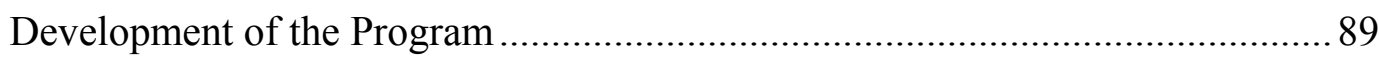

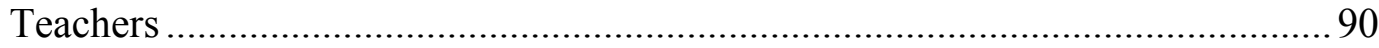

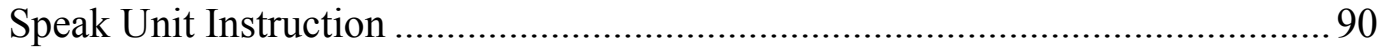

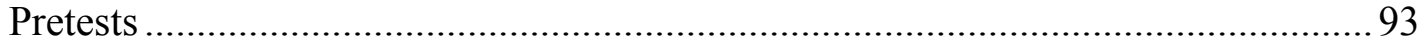

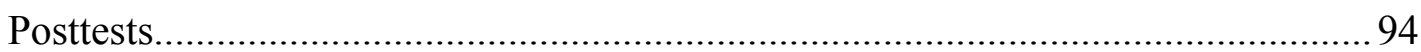

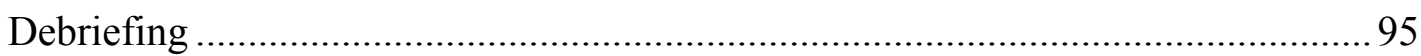

Wait List Control Group ...................................................................................99

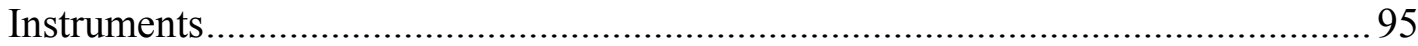

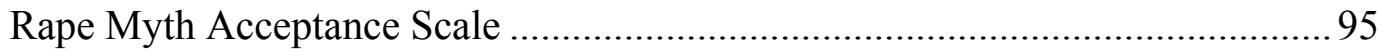

Adolescent Date Rape Myth Acceptance Scale.....................................................97

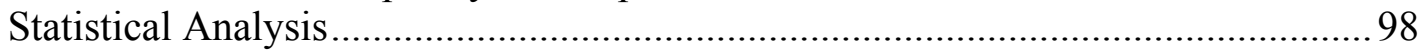

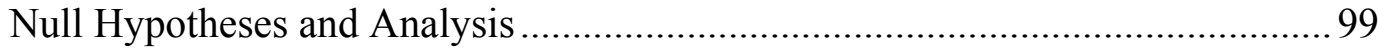

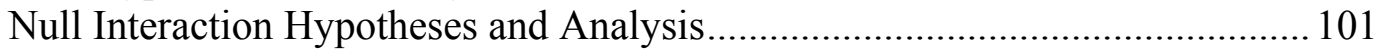

Statistical Analysis of Adolescent Date Rape Myth Scale .................................. 101

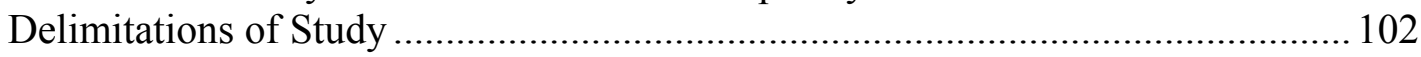

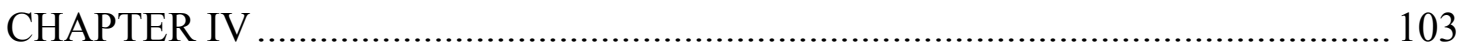

Sample

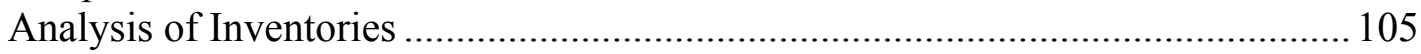

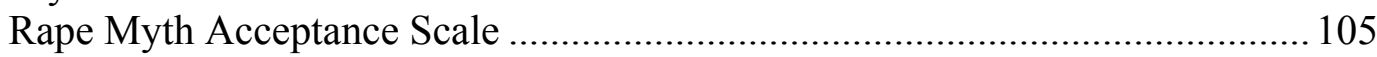

Adolescent Date Rape Myth Acceptance Scale ................................................ 105

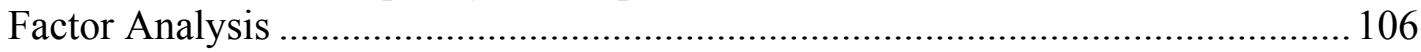

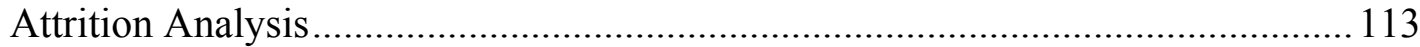

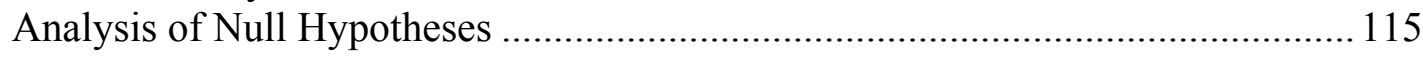

Post-Hoc Analysis of Factor Analysis Components 1 and 2 ................................. 119

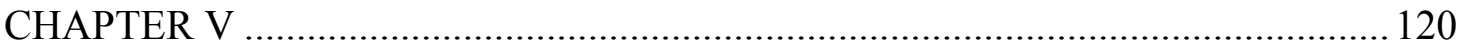

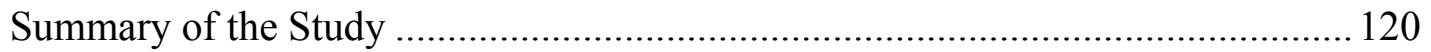

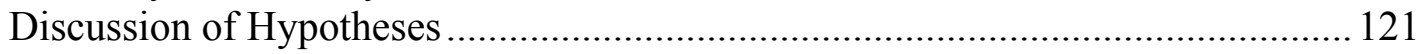

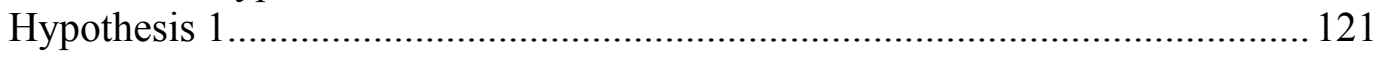

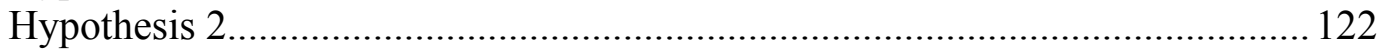

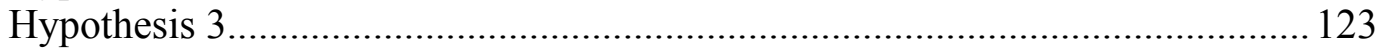




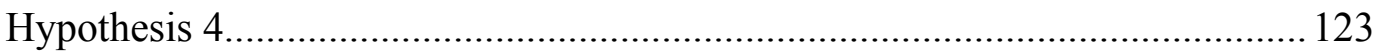

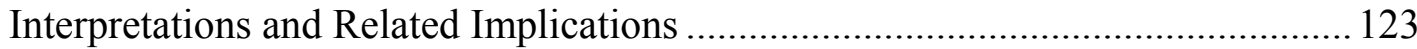

Main Effects for Teacher, Sex, and Interaction Hypotheses .............................. 127

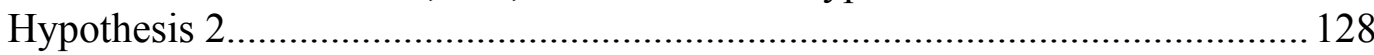

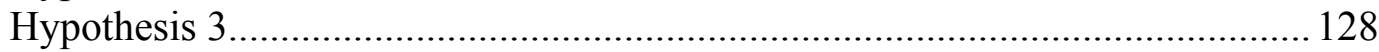

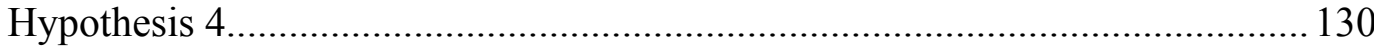

Attrition Analysis.......................................................................................... 130

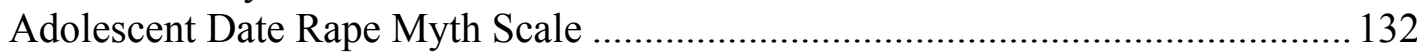

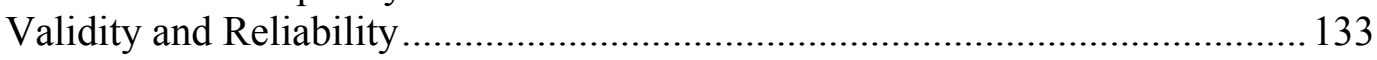

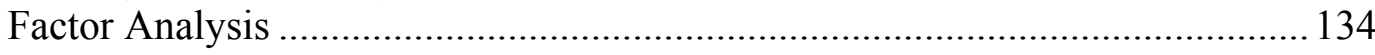

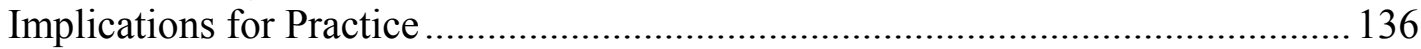

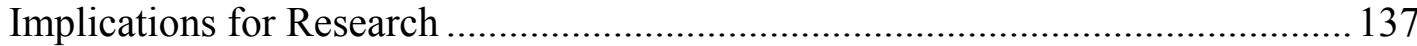

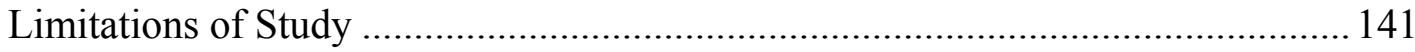

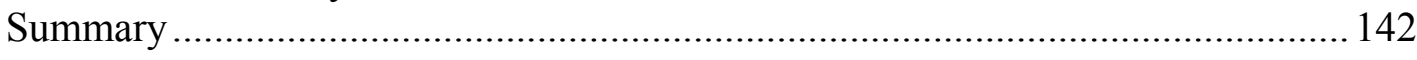

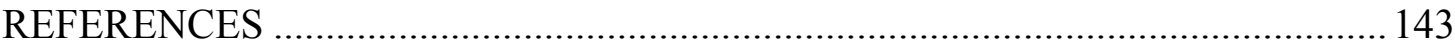

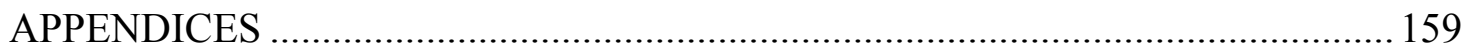

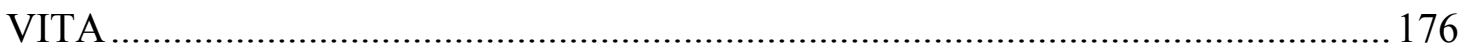




\section{LIST OF TABLES}

TABLE

PAGE

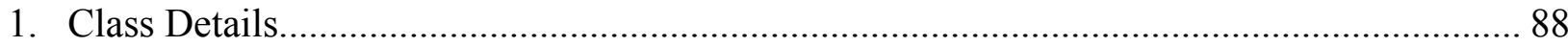

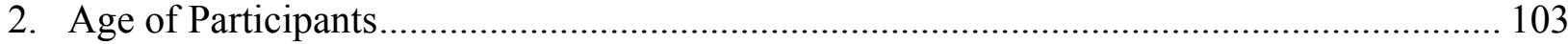

3. Summary of Exploratory Factor Analysis Results for Adolescent Date Rape Myth Acceptance Scale Using Principal Components Extraction and Varimax Rotation............ 108

4. Items Included in Component 1: She Wanted It .......................................................... 109

5. Items Included in Component 2: She Lied ........................................................ 110

6. Summary of Random Half Factor Analysis Results for Adolescent Date Rape Myth Acceptance Scale Using Principal Components Extraction and Varimax Rotation. 


\section{CHAPTER I}

\section{INTRODUCTION}

The purpose of this study was to examine the relationship between reading young adult novels and rape myth acceptance. This chapter establishes the theoretical foundations underlying the current drive in data driven literacy instruction which results in schooled literacy and a banking education model. These models reward teaching practices that create an environment which discourages aesthetic readings of literature. Aesthetic reading emphasizes the experience of reading while efferent readings emphasize information to be gathered from the reading event (Rosenblatt, 1938). Reader response theory is utilized to show the limitations of efferent reading transactions and to show the benefits of providing students with opportunities to engage in aesthetic reading transactions through young adult novels. Among the benefits of aesthetic reading that are shown is the ability for readers to identify with characters that are different from themselves and to experience events that would normally be impossible. These experiences can help teens reevaluate their beliefs in cultural myths that are dangerous, such as rape myths.

Rape myth acceptance is discussed in detail, especially the relationship between rape myth acceptance and likelihood of committing sexual assault. This chapter then chronicles the sobering statistics of sexual assault and shows how adolescents are overrepresented both as victims and as perpetrators of acquaintance rape and date rape. The relatively recent emergence of date rape prevention education in colleges and secondary schools is chronicled and the efficacy of interventions is examined. The shortcomings of some interventions such as equivocal results and participant backlash are 
discussed as well as the role that young adult literature may be able to play in addressing these deficiencies. Finally, this chapter proposes using a young adult novel, Speak, to investigate the relationship between reading a novel and adolescents' rape myth acceptance.

\section{Introduction}

What makes reading a novel different from other types of adolescent reading experiences? The definition of a novel is a point that literary scholars have debated and while for eons the definition may be ever changing; there are some persistent characteristics that classify narrative works as novels. The most accepted aspect of a novel that delineates it from other forms of fictional narrative is length: the novel is longer than other types of narrative such as short stories or novellas which may be read in a single sitting. Furthermore, the plots found in novels generally deal with multiple events, issues and ideas, and are generally too long to be focused on only one incident (Probst, 1988). In novels there are often more characters with mixed degrees of development. Thus, a major distinction between the experience involved with a novel and other types of narrative is that reading a novel is a longer and more involved process which allows readers time with complex human issues along with the possibility of an intimate personal reading experience. Because of the amount of time reading a novel requires, the amount of experience many students have with novels in the classroom is diminishing.

Curricula in language arts and English classrooms have been directly influenced by the passage of No Child Left Behind, which requires testing in reading and mathematics for students in Grades 3-8 and once in high school; the signing on to 
Common Core Standards by many states, which will lead to a national reading test so states can be compared in performance; and by the implementation of the Race to the Top competition, which coerces states to use performance pay that bases teacher salary on student test scores. These events have placed a premium on students' ability to answer questions based on short reading passages as part of high stakes standardized tests. Novels do not generally appear on standardized tests and when excerpts do appear, the majority of questions related to the passages are concerned with reading comprehension and do not generally require the test taker to analyze, interpret, evaluate or make any personal connections to the text (Purves, 1990). The recent marginalizing of novels in English/Language Arts curricula may be attributed to the diminished appearance and/or absence in standardized testing.

The threat that the use of novels may disappear from curricula is perceived as real enough that the National Council of Teachers of English (NCTE) has prepared an ad hoc task force to gather evidence about the benefits of teaching literature (Atwell, 2010). The push from NCTE to keep novels in the curriculum presents two compelling questions: (a), If students are not reading novels, what are they reading in school?; (b), what are the benefits of reading novels for adolescents?

\section{The Problem with Educational Literacy}

The culture of testing that has come to dominate the educational landscape has fed the wildfire of scripted curricula programs designed to increase student performance on reading tests (Mathews, 2000). Scripted curricula are commercially produced instructional programs that require teachers to follow scripts in varying degrees of fidelity (Moustafa \& Land, 2002). Rarely do these programs include novels as novels do not 
appear on standardized tests. Furthermore, companies producing scripted curricula do not realize profit from the sales of novels (Atwell, 2010). The absence of novels as part of standardized exams and the eschewing of novels from prefabricated scripted curricula has marginalized and sometimes even eliminated the reading of novels as part of curriculum in many public schools. Without novels as part of a literacy curriculum, reading experiences for students are of much shorter length and may lack cohesion. Reading multiple excerpts does not allow for the same experience as does the continuous reading of novel because they are fragmented experiences that do not provide an opportunity to establish an ongoing connection to the text.

\section{Schooled Literacy}

The predominant literacy curricula most public school students find themselves in consists of interactions with textbooks, standardized reading materials and pre-packaged literacy programs. Emphasis is placed on the ability of students to master "basic skills" and "comprehension" of texts via the completion of worksheets, workbook pages and standardized test practice, while any meaningful or authentic uses of print are eschewed (Edelsky, 1991; Irvine \& Larson, 2007). Reading comprehension is the ability to connect discrete bits of information from a text in order to construct meaning (Goodman, 1982). For students of lower socio-economic status and for students of color, this kind of curriculum is nothing new. In a seminal study, Anyon (1980) chronicled the curriculum in what she called working class schools and described language arts classrooms where there is little room for personal choices in reading or writing and an over reliance on worksheets. Brophy (1990) described this as a drill and test curriculum which disproportionately affects students who are members of minority groups or of lower 
socio-economic status. These types of literacy events are merely exercises rather than genuine opportunities for communication. Furthermore, these types of readings promote an input/output ideology (Edelsky, 1991; Powell, 2009). An example of these types of exercises are the ubiquitous practice standardized tests which require reading a passage and answering multiple choice questions that posit questions such as "what would be a good title for this passage" or "how was this passage organized." The information in the text is deposited into the students' minds for withdrawal at a later date and "promote ritualized mechanical responses that have little to do with student's lived experiences" (Powell, p. 9, 2009). Spears-Bunton and Powell (2009) described this type of literacy instruction as "schooled literacy," which encourages students to conform to instructional materials and emphasizes a singular accurate response. Students are not unaware that the primary purpose of their literacy events is to evaluate them and often do not see the relevance of these experiences for their lives (Powell, 2009). Thus, many students robotically move through their education without seeing how it is connected to their own lives, perfunctorily trying to provide the right answers to questions they do not see as worthy of inquiry.

\section{Banking Education}

These mechanical responses are the end result of what Freire described as "banking education" (1970). Banking education is the traditional model of teaching that deposits information in the minds of students in order to be withdrawn later for a test. It emphasizes surface level comprehension and facts which can be gleaned from the passage. The static and predefined knowledge that is deposited into students' minds is determined by so called experts and is unresponsive to variations in students' 
membership of different cultures, races, classes or sex. Powell argues that "students rarely read and write about things that really matter to them; their own ideas and perspectives are seen as irrelevant to the entire educational enterprise" $(2009$, p. 12). This marginalization of students is a dehumanizing process because it neglects to acknowledge people as "the primary actors in the construction of reality and the world" (Hochstrasser-Fickel, p. 43, 2009). While a standardized curriculum may seem desirable to those who are on a quest for higher standardized tests scores, schooled literacy promotes passivity and acquiescence and hides many forms of oppression such as racism, classism, and sexism (Powell, 2009). Curricula based on schooled literacy and banking education leave students feeling that the educational opportunities provided to them are disconnected from the reality of their lives.

Research has shown that the curriculum students are exposed to in school have a long term effect on students' ability and willingness to read; moreover, the way reading is experienced may not foster a love of reading (Cullinan, 2000). In fact, Irving (1980) found that many students make no connection between reading and pleasure. By presenting reading as an event with punitive measures tied to it, it is easy to understand why so many students come to the conclusion that reading is not enjoyable. While the oppressive and disenfranchising effects of current literacy curricula are clear, we must look at the alternative, providing genuine literacy experiences in the curricula. One of the ways to achieve this is by the use of novels.

\section{Benefits of Novels}

Because of the length of novels, interactions with these texts are much longer and more intimate than the interactions most students encounter with excerpts in school. 
Novels provide complete experiences and a range of emotions which are designed to make readers feel, think and care. The use of novels as part of the curriculum encourages reading at home as Anderson, Fielding, and Wilson (1988) found that students who commence reading a novel in school are more likely to engage in reading at home than students who do not read novels in school. Encouraging students to read at home is critical because reading for extended periods of time has been shown to be related to growth in vocabulary, reading comprehension, verbal fluency, and general information (Anderson, Fielding, \& Wilson, 1988; Greaney, 1980; Guthrie \& Greaney, 1991; Taylor, Frye, \& Maruyama, 1990). Furthermore, independent reading achievement correlates with academic success, including achievement tests, and an increase in quantity of independent reading (Anderson et al., 1988; Cunningham \& Stanovich, 1991; Guthrie \& Greaney, 1991; Krashen 1993; Stanovich \& Cunningham, 1993). The incorporation of novels into the curriculum has been shown to have far ranging measurable benefits for students as long as they are novels that students will be interested in reading outside of school.

A critical decision in any literacy program is deciding which novels to include and Probst (1988) argues that the interests and satisfactions of the reader should take precedence when choosing titles. Furthermore, if the text a student reads presents experiences and ideas that are highly relevant to the student, he or she will become highly engaged and that engagement may allow the reader to overcome difficulties in language and to comprehend a challenging text (Rosenblatt, 1938). Thus, the novels introduced in school should be appealing to a wide variety of students. The genre of literature that best 
satisfies that requirement is adolescent literature. In this study, the terms "literature" and "novel" will be used interchangeably.

\section{Adolescent Literature}

Adolescent literature is a genre of literature that features adolescent protagonists and/or may have an adolescent narrator (Probst, 1988). Many works of adolescent literature are written primarily for teen audiences; however, many other titles are not, but appeal to adolescents and have become part of the genre such as Lord of the Flies and The Catcher in the Rye. The subject matter of adolescent fiction is vast and may cover topics such as coming of age, homosexuality, racism, suicide, self-mutilation, cancer, death, mental illness, rape, child abuse, divorce, war, friendship, love and may take place in a variety of settings such as the Holocaust, the Middle Passage, on other planets, in the future - the possibilities are endless. Regardless of the subject, adolescent novels are experienced or viewed through the lenses of an adolescent protagonist or narrator.

Traditionally adolescent literature has also been shorter than adult literature running generally between 100 and 200 pages (Probst, 1988); however, popular series such as Harry Potter and The Twilight Series contain works in lengths of closer to 1000 pages. Their popularity is a testament to the fact that when a novel speaks to matters important to young adults, an adolescent will read it regardless of the length. The differences between student engagement in reading as a part of schooled literacy and reading novels are not just of time and length, the actual experience of reading is different depending on the reader's purpose for engaging the text. This difference forms the basis of reader response theory (Rosenblatt, 1938). 


\section{Reader Response}

Reader response theory, developed by Louise M. Rosenblatt (1938) argues that the interpretation of texts will differ between readers based on their own experiences, world views, biases, current preoccupations, and even their purpose for reading the text. When reading a text, readers participate in a negotiation and collaboration with the author and use their prior knowledge to create meaning (Rosenblatt, 1938). Logically, students who engage a text knowing that the reading experience will be short and that they will face multiple choice reading comprehension questions at the end of the event will engage the text in a much different way than they would engage the very same text if they were reading it for enjoyment and/or personal interest.

The differences in these two types of reading transactions are at the heart of Rosenblatt's reader response theory. During any transaction, a particular reader and a particular text engage in a dynamic situation where meaning is not fixed in the text, but is created by the interchange between the reader and the text (Rosenblatt, 1938). The transaction is moderated by the reader's motivations to engage the text, which Rosenblatt labels stance (Rosenblatt, 1938). Imagine that an adolescent is reading the latest book of the Twilight saga in a classroom during silent reading time, then, imagine that same teen is reading the same page of text on a single sheet of paper in the same classroom, but this time, the reader knows that a multiple choice reading comprehension test awaits her/him

at the end of the passage. The reader's stances towards these two transactions would lead to very different reading experiences. Rosenblatt labels the former example as an aesthetic reading and the latter example as an efferent reading. 
Aesthetic reading is a predominantly literary reading event in which the reader's main focus is on what happens during the actual reading (Rosenblatt, 1938). That is, primary importance is placed on ideas, thoughts, and emotions invoked in the reader during the event. "In aesthetic reading, the reader's attention is centered directly on what he is living through during his relationship with that particular text" (Rosenblatt, 1938, p. 25). The experience of the reading event is at the center of an aesthetic reading and what is activated in a reader's mind by the text is much more important than any specific information which remains after the event. Most of what people would call "reading for enjoyment" would be classified as aesthetic reading.

On the other hand, efferent reading is a predominantly nonliterary reading event in which the reader is focused on getting information from the text that can be assimilated for use after reading. The residue of information that remains after the reading event is more important than the experience of the reading event and efferent readers screen out all information except that which the reader has determined is necessary. Efferent reading requires attention mostly to public aspects of meaning and often marginalizes, eliminates or precludes activation of personal ideas or feelings (Rosenblatt, 1994). In fact, an efferent reading stance does not require reading - another person could read the material and simply provide the information needed to another who needed it. The student reading an excerpt of Twilight for an exam that may determine placement in class levels, whether electives are lost for intensive reading classes, and even whether or not he/she will receive a standard diploma, will most likely engage the text in with an efferent stance. 


\section{Effects of a Test Driven Curriculum on Stance}

When students are aware they will be continuously tested on factual aspects of a text, an aesthetic reading is prevented. The efferent transaction which ensues will focus on retaining information long enough to provide correct answers to questions. Once the required task is complete, the material and experience are quickly forgotten. These efferent reading experiences are part of schooled literacy and a banking curriculum model which marginalizes students. Adolescents in schools that embrace schooled literacy and banking curriculum are cognizant that they will be tested primarily on factual aspects of the works they read, most often in the form of multiple choice questions that are designed to replicate those on state standardized tests. This knowledge marginalizes the reader's personal ideas and feelings, and prevents adolescent readers from entering into an aesthetic reading transaction with the text (Rosenblatt, 1938). The elimination of aesthetic reading from the experience of many public school students precludes learning to think deeply and to reflect beyond the surface level. Readers are not able to picture themselves in another's situation and there is no opportunity to develop empathy with others. The lack of aesthetic reading also prevents students from attaining many of the benefits of independent reading. Rosenblatt argues that the elicitation of aesthetic readings from students should be the goal of literacy curricula (1938). Aesthetic readings encourage literacy beyond the surface level both affectively and intellectually, while efferent readings promote mechanical comprehension which is intellectually and mechanically detached. 


\section{Benefits of Aesthetic Stance}

The majority of the benefits of reading novels and independent reading described by Cullinan (2000) are due to students engaging in aesthetic transactions with texts. When a student begins reading a novel at school and continues reading it at home, it is reasonable to conclude that the student is engaged in an aesthetic transaction with the text. These aesthetic transactions lead to increases in vocabulary, reading comprehension, verbal fluency, and overall academic success (Anderson et al., 1988; Cunningham \& Stanovich 1991; Greaney 1980; Guthrie \& Greaney 1991; Krashen 1993; Stanovich \& Cunningham, 1993; Taylor et al., 1990). There are other benefits for the student who engages in aesthetic readings.

Aristotle was perhaps the earliest to refer to the humanizing emotional benefits of literature. In Politics he described katharsis (catharsis) and the capacity for music to purge religious frenzy. In Poetics he described the ability of tragedy to inspire fear and pity in the audience and he continues that tragedy and tragic pleasure can lead to a purgation of these emotions. Tragedy is not the only form of art that provides the opportunity for catharsis. Rosenblatt (1938) argues that literature provides an outlet for antisocial ideas, repressed urges and even anti-authoritarian desires to strike back at those who create social restrictions. Catharsis is possible because literature allows readers to exercise their senses more intensely than they would normally be able to do and because it provides readers the opportunity to safely experience events that would normally be impossible or unwise to experience. The ability to sympathize or identify with the experience of characters in literature is the basis of the cathartic benefits of literature; in order to achieve this, a primarily aesthetic reading is required. While catharsis in and of 
itself is a worthy benefit, there are numerous other benefits to aesthetic transactions that students can experience.

Nussbaum (1990) investigated numerous facets of reading and avers that the reader of a novel should examine and evaluate the elements of a story as to whether they are "elements of or impediments to a good human life" (p. 51). She concurred with Wollheim (1983) who believes that novels make important contributions to a reader's sense of morality by examining conflicts in ways that are not possible from didactic moral treatises. According to Nussbaum (1990), the writer of a novel is an indispensable guide who provides readers with an experience that allows for self-understanding in order for society as a whole to realize itself more fully. More than just the purging of an emotion, literature can spur readers to reexamine their attitudes and beliefs. Taken together, the works of Aristotle, Nussbaum, and Wollheim, vividly paint the picture of aesthetic reading experiences that provide readers with opportunities for moral and emotional growth that efferent reading simply cannot.

Rosenblatt (1938) argues that literature may suggest to readers more socially approved channels for the expression of desires. This may be because literature allows readers to engage in a "process of imaginative trial and error" (Rosenblatt, p. 190, 1938). Readers can vicariously experience what characters do and this may broaden their emotional, intellectual and cultural horizons. It may also provide them with a broader sense of possibilities when faced with situations which are similar to those they have read about. For many adolescent readers who feel isolated this may be a chance to find solace in knowing they are not alone. Aesthetic transactions may allow adolescent readers to identify with characters who are of different age, socio-economic status, race, religion, 
gender, sexual orientation, geographic location; and the possibilities go on ad infinitum. These experiences may extend beyond perceptions of self and may encourage adolescents' to reexamine themselves and their perceptions of others.

Aesthetic transactions with literature can show students how their ideals may have been unconsciously internalized representations of the dominant cultural ideals that surround them (Rosenblatt, 1938). Unfortunately, these ideals may support adherence to beliefs such as rape myths. By showing students how their beliefs are influenced by their surroundings, literature may give students a choice in whether to continue embracing ideals, such as rape myth acceptance, that may be morally unacceptable. Rosenblatt argues that readers can come to understand themselves and the world around them better through examination of their emotional responses to literature. According to Rosenblatt (1938), aesthetic readings of literature may either strengthen or weaken attitudes adolescents have adopted and/or internalized through other social influences. While parents and educational institutions are often thought to be the major transmitters of culture to adolescents, there is a myriad of propaganda, images and ideals that modern adolescents are bombarded with which shapes their view of themselves, the world around them and their place in it. Whether it is through television, print-mediums, movies, music, music-videos, commercials or the Internet, adolescents are indoctrinated with many myths, not all of which are beneficial for adolescents to embrace.

\section{Myths}

Myths play an important role in transmitting cultural ideals and norms to adolescents; however, there are various definitions of myth. Joseph Campbell (1976) described myths as having functions that are mystical, cosmological, sociological, and 
pedagogical. Some theologians would add that myths are sacred stories which are part of a religion; from the field of psychoanalysis, Jung would define myths as expressions of the psyche and collective unconsciousness that arise from archetypical images. Lonsway and Fitzgerald (1994) examined the term from various disciplines such as psychology, anthropology, philosophy, and sociology. They found three common characteristics of myths: (a), "they are false or apocryphal beliefs that are widely held"; (b), "they explain some important cultural phenomenon"; and (c), "they serve to justify existing cultural arrangements" (Lonsway \& Fitzgerald, 1994, p.134). Adolescents are bombarded with myths that indoctrinate them into a cultural hegemony that maintains the status quo. For example, many students in of poverty are indoctrinated with the belief that college is too expensive for them and that they will be burdened with student loans if they decide to attend. This myth helps maintain the current social order where people of color are less educated than European Whites and helps reduce upward economic mobility for lower classes. There are myths that have served to keep African-Americans, Latino/as, Native Americans and recently Muslims disenfranchised and in subservient positions in society by being relegated to low wage jobs, being overrepresented in non-college bound and special education courses, and by historically being denied civil rights which are enjoyed by the dominant class. Educational institutions are not exempt from myths as Hochstrasser-Fickel (2009) argues that the banking education curriculum that is pandemic in education conceals facts and events that are threatening to those in power and portrays the "status quo as the "natural' order of the world" (p. 44). According to Spears-Bunton and Powell (2009) one of the by-products of cultural myths in America for cultural minorities has been internalized oppression which is the "belief and 
acceptance of one's inferior status" (p. 35). Conversely, members of the dominant culture experience internalized supremacy, which is a sense of entitlement that the privileges of a dominant group have been legitimately earned (Goodman, 2001). Among the many myths adolescents are exposed to, myths concerning the place of women in society have served to keep women in a subservient position in America for hundreds of years. Women were the last minority group to be granted voting rights and even today women still do not enjoy equal pay for equal labor as their male counterparts in the workplace (National Organization for Women, 2012). Of the many myths that have disenfranchised women over the years, rape myths are perhaps the most dangerous for adolescent girls.

\section{Rape Myths}

In a seminal study where the first rape myth inventory was created, the Rape Myth Acceptance Scale (RMAS), Burt (1980) defines rape myths as "prejudicial, stereotyped, or false beliefs about rape, rape victims, and rapists" that create an environment hostile to rape victims (p. 217). In a subsequent study, Lonsway and Fitzgerald (1994) define rape myths as "attitudes and beliefs that are generally false but are widely and persistently held, and that serve to deny and justify male aggression against women" (p. 134). The socio-cultural construct of rape myths appeared in the 1970s from the work of sociologists and feminist scholars who described "a complex set of cultural beliefs thought to support and perpetuate male sexual violence toward women" (Payne, Lonsway \& Fitzgerald, 1999, p. 27). Rape myths demean victims of rape, "only bad girls get raped"; blame victims for their own assault, "if she didn't want sex she shouldn't have gone to his room"; absolve perpetrators of guilt, "if a man is sexually excited he can get 
carried away"; and question whether the victim truly did not want to engage in sex with the perpetrator, "any healthy woman can resist a rapist." The acceptance of rape myths influences how a person defines rape and the definition of rape one subscribes to may be broad or narrow.

Acceptance of rape myths may lead to a more restrictive definition of rape and therefore is rape supportive because it rejects the reality of many rapes, silences women's voices, and challenges a woman's authority over her body (Lonsway \& Fitzgerald, 1994). Denying that these rapes are real perpetuates a rape supportive culture. On the other hand, the rejection of rape myths may contribute to a wider definition of rape and to an acknowledgement of actual rapes. The rejection of rape myths reduces the degree to which a culture is rape supportive. These assumptions are supported by a study which looked at subjects' likelihood of defining rape vignettes as rape and the willingness to convict the perpetrator in the vignette (Burt \& Albin, 1981). Subjects who had higher scores on the Adversarial Sexual Belief scale (ASBS), Acceptance of Interpersonal Violence scale (AIVS) and the Rape Myth Acceptance (RMAS) scale were less likely to identify vignettes as rape and convict assailants as those subjects who had lower scores on the same inventories (Burt \& Albin, 1981). While rape myths have been investigated in order to gain knowledge about how people view rape, it is also useful to study rape myth acceptance as a possible precursor of sexual assault.

Rape myth acceptance has been associated with coercive sexual behaviors and rapists have been found to have more tolerant attitudes toward rape than others (Ward, 1995). Rape myth acceptance and the likelihood of committing a rape has been documented in adult males (Malamuth, 1981), in college males (Ward, 1995), and in 
adolescent males (Lanier, 1980). These studies are important because if rape myth acceptance can be reduced, there could be a possible concomitant drop in perpetration of sexual assaults. For adolescents, this is of critical importance because teens are at elevated risk of being victims or perpetrators of sexual assault (Avery-Leaf, Cascardi, O’Leary, \& Cano, 1997; Noonan \& Charles, 2009).

\section{Sexual Violence}

There are many different types of sexual assault and the term sexual violence encompasses any type of sexual activity that occurs without a person's freely given consent. Rape may be further divided into stranger rape, acquaintance rape, date rape, marital rape, and gang rape.

\section{Stranger Rape}

Stranger rape is defined as nonconsensual sex between individuals who did not know each other before the sex act. Stranger rape is what most people refer to when using the term "rape" which is often legally referred to as sexual battery. According to Florida law, "Sexual battery" means oral, anal, or vaginal penetration by, or union with, the sexual organ of another or the anal or vaginal penetration of another by any other object; however, sexual battery does not include an act done for a bona fide medical purpose" (Florida Statutes, 1997).

\section{Acquaintance Rape}

Acquaintance rape is defined as nonconsensual sex between individuals who knew each other before the sex act. Their relationship may be of many varieties such as coworkers, classmates, or familial relationship. 


\section{Date Rape}

Date rape is a subset of acquaintance rape where nonconsensual sex occurs between two people who are in a romantic relationship. Examples of a romantic relationship may be two people who are on a formal date, on an impromptu date, or who meet at a party and are romantically interested in each other. The term "date rape" was coined by Susan Brownmiller (1975) in her book Against Our Will: Men, Women and Rape (Post, Maxwell, Smith \& Korzeniewski, 2006).

\section{Rape Statistics}

Rape is pandemic in America. The United States leads the world in number of rapes committed and leads all industrialized nations in rapes per capita ("Rapes by Country," 2010). Statistics show that one out of six women has been the victim of a rape or an attempted rape during her lifetime and 17.7 million American women have been the victims of an attempted or completed rape (U.S. Department of Justice, 1998). Studies of college students show that between 24 and $50 \%$ of women will be or have been sexually victimized (Fisher, Cullen, \& Turner, 2000; Koss, Dinero, Seibel, \& Cox, 1988; Messman-Moore, Coates, Gaffey, \& Johnson, 2008). Women are not the only victims as one in 33 men will experience an attempted or completed rape during their lifetime (U.S. Department of Justice, 1998). Dating violence also extends to same sex relationships as $40 \%$ of self-identified gay, lesbian and bisexual adolescents have suffered abuse at the hands of a same sex partner (Freedner, Freed, Yang \& Austin, 2002). Another study of gay, lesbian and bisexual adolescents found teens in same sex relationships suffered dating violence at the same rate as teens in opposite sex relationships (Halpern, Young, Waller, Martin \& Kupper, 2004). 
An underreported crime, Burt and Albin (1981) cite Los Angeles police reports that showless than $10 \%$ of rapes are reported. Of those reported, fewer than $5 \%$ are prosecuted (Burt \& Albin, 1981). Other sources show that $60 \%$ of rapes and sexual assaults go unreported (Bureau of Justice Statistics, 2000; U.S. Department of Justice, 2005). The figures are unchanged when it comes to adolescent victims. Sixty percent choose not to report or seek help for dating violence (Ashley \& Foshee, 2005). When adolescents do report or seek help for dating violence, they are more likely to turn to friends and family members for support rather than professionals (Ashley \& Foshee, 2005). These statistics could show that rape myth acceptance not only is a factor for men in influencing sexual assault but also for women and men who are victimized (Frese, Moya, \& Megías, 2004). Rape myth acceptance may cause victims to question whether the rapes they suffered were indeed rapes and may also cause victims to blame themselves for their victimization.

\section{Adolescents and Sexual Violence}

The statistics for adolescents and preteens suffering rape are shocking. Specific numbers vary between sources but most show adolescents as a high risk group for sexual assault. According to Greenfield (1997) $44 \%$ of rape and sexual assault victims are under the age of $18 ; 29 \%$ are age $12-17$, and $15 \%$ are under the age of 12 . Other studies show that $25 \%$ of women will experience a rape or an attempted rape before the age of 14 (Koss, 1997; Parrot, 1991). Crime reports collected by law enforcement agencies in 12 states showed that adolescents under the age of 18 represented $67 \%$ of reported sexual assault victims. Middle and high school age adolescents (12-17) represented 33\% of known sexual assault victims, $34 \%$ of forcible rape victims, $24 \%$ of forcible sodomy 
victims, $26 \%$ of victims sexually assaulted with an object and $34 \%$ of sexual fondling victims (Snyder, 2000). One study found that the greatest proportion of both victims and perpetrators of sexual assaults is accounted for by middle school aged 14 year olds, who are more than four times as likely as an adult to be a victim or a perpetrator of sexual violence (Snyder \& Sickmund, 1999; U.S. Department of Justice, 2004). The prevalence of sexual victimization and perpetration of teens is a product of a rape supportive culture. Young boys and girls are indoctrinated with myths that portray males as conquerors and misogynistic views that paint women as objects without a voice who are waiting to be taken (Dill \& Thill, 2007). This combination helps create an environment where date rape may be viewed as acceptable behavior by both boys and girls. The myth of stranger rape as the primary form of sexual assault ignores and marginalizes the majority of threats an adolescent may face.

Of juvenile sexual assault victims, $93 \%$ knew their attacker, $34.2 \%$ of perpetrators were family members and $58.7 \%$ of perpetrators were acquaintances (U.S. Bureau of Justice Statistics, 2000). By the time a woman is of college age, $25 \%$ to $50 \%$ will have experienced at least one act of sexual coercion (submitting to sexual advances against their will) in a dating relationship (Kanin, 1957; Korman \& Leslie, 1982; Koss, Gidycz, \& Wisniewski, 1987). Forced sexual intercourse between people who know each other most often happens between the ages of 16 and 24 (Parrot, 1985). Clearly, adolescents are at high risk of suffering sexual assault at the hands of someone they know.

During the adolescent years, most teens begin to date; for many adolescents this is a time for sexual experimentation. A study found that by the $11^{\text {th }}$ grade, the average teen has had six to eight dating partners with 12 being the average age for adolescents to begin 
entering dating relationships (Slep, Cascardi, Avery-Leaf, \& O’Leary, 2001). The prevalence of dating in secondary school aged adolescents puts teens at unique risk for being victims of sexual assault and given that adolescents and preteens representing such a disproportionately large percentage of rape victims and sexual assault perpetrators, various educational programs have been created with the intent of reducing rape and sexual assault (Post et al., 2006).

\section{Rape Myths and Rape Prevention}

Educators have created numerous programs that attempt to change the attitudes of both men and women toward rape myth acceptance with the belief that reducing rape myth acceptance will reduce attempted rapes. There have been many studies on the effects of educational programs on changing attitudes toward dating violence in college students (e.g., Foubert \& Perry, 2007; Hanson \& Gidycz, 1993; Heppner, Humphrey, Hillebrand-Gunn, \& DeBord, 1995; Johansson-Love \& Geer, 2003). Some researchers believe that educational programs dealing with sexual violence should be conducted before children develop their dating behaviors and preferences (Mandelblatt, 1999; Ackard \& Neumark-Sztainer, 2001). Because adolescents of secondary school age are at the highest risk for victimization and perpetration of sexual assaults, secondary schools are a logical place for date rape prevention education (Fay \& Medway, 2006).

Furthermore, because the majority of secondary school students do not progress on to college, secondary school based date rape education is more appropriate since it would reach a greater portion of the population at risk. Finally, because 14-year olds have been found in one study (Snyder \& Sickmund, 1999) to be the highest risk for both 
perpetration and victimization of sexual assaults, middle school may be the ideal setting for date rape prevention education.

\section{Date Rape Education}

Educators have created numerous programs that attempt to change the attitudes of both male and female students toward acquaintance rape. The majority of programs examined have been instituted on college campuses and have focused on reducing college students' rape myth acceptance (e.g., Feltey, Ainslie, \& Geib, 1991; Foubert \& Perry, 2007; Hanson \& Gidycz, 1993; Harrison, Downes, \& Williams, 1991; Heppner, Humphrey, \& Hillebrand-Gunn, 1995; Johansson-Love \& Geer, 2003; Lee, 1987; Nelson $\&$ Torgler, 1990). There are fewer studies that focus on secondary school students (Cornelius \& Resseguie, 2006). Those that do are similar in didactic elements to the programs used in colleges (Avery-Leaf, Cascardi, O’Leary, \& Cano, 1997; Foshee, Bauman \& Greene, 2000; Hickman, Jaycox, \& Aronoff, 2004; Jaffe, Suderman, Reitzel, \& Kellip, 1992; Lavoie, Vezina, Piche, \& Boivin, 1995). The majority of both college and secondary school interventions seem to rely on didactic methods to change participants' acceptance of rape myths in order reduce future sexual assaults. Interventions have shown various levels of effectiveness in reducing rape myth acceptance and even in reducing future sexual assaults (Anderson, Fielding, \& Whiston, 2005; Brecklin \& Forde, 2001; Flores \& Hartlaub, 1998). Unfortunately, an unintended consequence of some programs has been a backlash in male participants where rape myth acceptance actually increased for some post intervention (Jaffe et al., 1992). This backlash could be caused by a variety of factors. For example, students with high initial levels of rape myth acceptance may react defensively to didactic interventions where they 
may feel they are being attacked. Furthermore, the short term duration of many interventions may not provide the opportunity for all participants to develop empathy for victims of sexual assault. For many readers, a prolonged aesthetic transaction with adolescent literature provides some remedy to this problem.

\section{Summary of the Dilemma}

Sexual violence is a serious problem affecting adolescents across the globe. Date rape is a subset of acquaintance rape where the victim and perpetrator know each before the assault occurs. Rape myth acceptance is the degree to which a person adheres to rape supportive ideas and higher levels of rape myth acceptance have been shown to be related to likelihood of committing sexual assault. As teens generally begin dating at age 12 and that the highest incidence for date rape victimization and perpetration occurs at age 14, date rape education is a necessary subject for students in middle school and senior high school. With these factors in mind, educators have created programs designed to reduce students' acceptance of rape myths in order to reduce sexual assaults. Most programs are primarily didactic in nature and have shown varying degrees of efficacy. A major concern has been the occurrence of a backlash effect where male participants' acceptance of rape myths increases post intervention. This backlash effect may be reduced or eliminated by providing participants with an intervention that affords them the time and opportunity to develop emotional sympathy and empathy with victims of sexual assault. Extended aesthetic reading transactions with adolescent novels which tackle the topic of rape may allow adolescents the time to vicariously experience what a rape victim endures and thereby reduce rape myth acceptance. One of the most popular young adult novels 
written in the last 10 years deals with the aftermath of a date rape from the point of view of a ninth grade girl.

\section{The Novel Speak}

Speak, by Laurie Halse Anderson, is a young adult novel that deals with the aftermath of a date rape. The main character, Melinda Sordino, is raped by a male high school student whom she meets at a party during the summer before her freshman year of high school. She is under the influence of alcohol at the party and during the rape. While she consents to kissing her assailant while taking a walk in the woods, she does not agree to engage in intercourse. She does not report the rape to authorities nor to anyone else, and throughout the novel she questions whether or not she was actually raped. The novel chronicles her efforts to remain in denial about the rape even though the boy who raped her not only attends the same high school she does, but dates one of her friends.

The novel was a New York Times and a Publishers Weekly bestseller and was a Printz Honor book in 1999. Recently, it was ranked the number one young adult novel of the last 10 years by members of the National Council of Teachers of English Assembly on Literature for Adolescents. It was made into a Showtime television movie in 2004. Speak is taught by teachers in language arts and English classrooms in both middle and high school levels and it is read by adolescents around the world in many languages. There are entries for various lessons to teach Speak at WebEnglishTeacher.com and there are numerous web sites geared toward students who are studying the novel with chapter summaries, character analyses, and discussion questions. Because of the popularity with both teachers and students in dealing with the subject of date rape, Speak would be an 
excellent choice to use with adolescents in order to determine if reading literature can aide in reducing rape myth acceptance.

\section{Statement of the Problem}

Considering the paucity of research into the relationship between reader response based classroom instruction of fictional literature and adolescents' rape myth acceptance, this investigation was undertaken to examine the relationship between reading a novel, Speak, and adolescents' acceptance of rape myths.

\section{Purpose of the Study}

The purpose of this study was to investigate whether the use of young adult novels, specifically Speak, has an effect on adolescents' rape myth acceptance. This study attempted to determine the benefits from reading novels that can be measured outside of the realm of standardized reading proficiency exams. This study adds to the discussion about the role of novels in education and supports the argument that novels should be maintained as part of the curriculum in English/Language Arts classes.

\section{Significance of the Study}

Statistics show that adolescents suffer acquaintance rape at high levels and that the belief in rape myths by both perpetrators and victims leads to the continuation of this crime on a widespread level. Further this study adds to the literature that examines adolescents' acceptance of rape myths and to the literature that examines the efficacy of programs designed to reduce adolescents' acceptance of rape myths.

The use of young adult novels as part of acquaintance/date rape education for adolescents is an uncharted territory in research and it was hoped that this study would lead to future studies that examine how young adult novels could be integrated into 
educational programs that attempt to reduce adolescents' rape myth acceptance. No other previous studies on reducing rape myth acceptance in adolescents known to the researcher have been conducted in English/Language Arts classes nor have any examined aesthetic reading experiences as part of the intervention. It was also hoped that future research may replicate the structure of this study and examine the relationship of other young adult novels on adolescents' beliefs such as acceptance of bullying, acceptance of students with alternative sexual orientations, acceptance of racist attitudes, or acceptance of sexist attitudes.

This study supported the use of contemporary young adult novels that deal with sensitive issues and may increase the inclusion of such titles into the official curriculum of secondary language arts, reading and English classes. The incorporation of novels in the curriculum would provide a wider reading experience for students that could lead to an increase in at home reading.

This study provided an empirically supported challenge to the banking education model and educational reforms which are marginalizing and often completely eliminating the use of novels from the official curriculum in many schools. In fact, if left unchallenged, so called "reforms" such as Race to the Top may eliminate entirely the type of instruction this study examines. Given quantitative evidence of the benefits that literary instruction provides, it was hoped the results of this study would support the retention and/or re-inclusion of novels and opportunities for aesthetic readings into the curriculum. There are numerous issues of poverty, racism, classism, homophobia and sexism that can be addressed as part of an English/Language Arts curriculum. Students who are in schools which are shackled by the banking model of curriculum, schooled 
literacy, and educational reforms, are those who most often face social inequalities and are those most in need of a curriculum that address these issues. In the current trend where studies in the humanities is becoming extinct for lower socio-economic status students, this study provides evidence that a traditional liberal arts education including literature and full length novels should be available for all students, regardless of poverty and/or academic ability.

Finally, and perhaps most importantly, it was hoped that this study would add impetus to involve teachers as societal change agents to better the educational experience of all students.

\section{Research Questions}

The following questions were addressed by this study:

1. Do participants who read the novel Speak have lower rape myth acceptance than participants who do not read the novel Speak?

a. After reading Speak, do participants who show a high level of pretest rape myth acceptance show a lower level of posttest rape myth acceptance?

b. After reading Speak, do boys who show a high level of pretest rape myth acceptance demonstrate a backlash to treatment and show higher levels of posttest rape myth acceptance?

c. After reading Speak, do participants who show a low level of pretest rape myth acceptance show a difference in posttest rape myth acceptance? 


\section{Research Hypotheses}

1. When adjusted for pretest rape myth acceptance, the mean posttest rape myth acceptance for participants who have read Speak will be significantly lower than the mean posttest rape myth acceptance of participants who do not read $\operatorname{Speak}(p<.05)$.

a. After reading Speak, participants who show a high level of pretest rape myth acceptance will show a significant decrease in posttest rape myth acceptance $(p<.05)$.

b. After reading Speak, boys who show a high level of pretest rape myth acceptance will show either no difference or a decrease in posttest rape myth acceptance $(p<.05)$.

c. After reading Speak, participants who show a low level of pretest rape myth acceptance will not show a significant difference in posttest rape myth acceptance $(p<.05)$.

\section{Null Hypotheses}

1. When adjusted for pretest rape myth acceptance, the mean posttest rape myth acceptance for participants who have read Speak will be greater than or equal to the mean posttest rape myth acceptance of participants who do not read Speak $(p<.05)$.

a. After reading Speak, participants who show a high level of pretest rape myth acceptance and read Speak will show either no difference or a significant increase in posttest rape myth acceptance compared to 
participants with a high level of pretest rape myth acceptance who do not read Speak $(p<.05)$.

b. After reading Speak, boys who show a high level of pretest rape myth acceptance will show a significant increase in posttest rape myth acceptance compared to boys with a high level of pretest rape myth acceptance who do not read Speak $(p<.05)$.

c. After reading Speak, participants who show a low level of rape myth acceptance will show no significant difference in posttest rape myth acceptance $(p<.05)$.

2. In the population, there will be no interaction between group and sex in posttest rape myth acceptance $(p<.05)$.

3. In the population, there will be no interaction between group and instructor in posttest rape myth acceptance $(p<.05)$.

4. In the population, there will be no interaction between sex and instructor in posttest rape myth acceptance $(p<.05)$. 


\section{CHAPTER II}

\section{REVIEW OF LITERATURE}

The review of literature begins by establishing the theoretical foundations of the study based on reader response theory and examines the phenomenon of aesthetic transactions in depth. The review then examines research which has investigated the role literature can play in changing readers' attitudes toward socio-cultural constructs such as racism and perception of disability. Rape myths and the development of rape myth inventory scales are then explored. Finally, the review provides a detailed review of date rape education programs that have been implemented in colleges and secondary schools.

\section{Reader Response Theory}

Reader response theory (Rosenblatt, 1938) was originally espoused in the seminal work, Literature as Exploration. Reader response theory considers reading events as transactions which involved a reader, a text and the stance which the reader takes when reading a text. Reader response theory is antithetical to New Criticism, which was the dominant theory of literary instruction until the 1980's (Beach, 1993). It is important to understand New Criticism in order to get a better understanding of reader response. New Criticism placed the text at the center of all transactions with literature. The role of the teacher was to show the student how to analyze the text through a close reading to glean the meanings of the text which were accepted as objective knowledge. Presumably, there was a specific meaning each text provided and differences between readers did not alter the meaning of the text. Rather, meaning was understood to be a fixed an unquestioned state. In opposition to New Criticism, reader response theory placed the reader in the center of the reading transaction. 
Rosenblatt (1938) placed the reader at the center of the reading event which she called a transaction; this is why reader response theory is also known as transactional theory. The transaction refers to the reading event where a specific reader engages a specific text. Dewey and Bentley (1949) introduced the concept of transaction to counter positivism's view of reality where the observer and observed are separated and the observer has no effect on the observed. Dewey's transaction described a reciprocal relationship between the observer and the observed; Rosenblatt credits Dewey's work with providing her with the term (Rosenblatt, 2005, p. X). Rosenblatt's transaction gave the reader a place at the table by espousing a view of reading where meaning was created by the interrelationship between the reader and the text during the reading event.

Rosenblatt's importance on the reader is echoed by Iser (1978) who argues that the readers' role is central to the reading event. The reader must interpret text, evaluate text, and examine potential meanings in order to experience a text in its entirety. The reader's role is further analyzed by Beach (1993) who argues that reader responses primarily occur in one of five theoretical perspectives: (a), textual, which focuses on the reader's knowledge of conventions; (b), experiential, which focuses on the reader's personal experience with the text including identification with elements of the work and relating to the text personally; (c), psychological, which focuses on cognitive and subconscious processes according to individual differences in personality and developmental level; (d), social, which focuses on the reader's social role in responses such as classroom discussions; and (e), cultural, which focuses on how a reader's cultural roles, attitudes, values, and historical context shape responses to literature. These perspectives are important in classrooms because these teacher-valued, theoretical 
perspectives can influence the responses that students offer. Furthermore, while reader response theory places a premium on the reader's role, responses to literature will also be greatly affected by the texts that are read by readers.

Iser (1974) postulates that texts offer a "horizon of meanings" through explicit writing and through "gaps" in the text. In this paradigm, the text provides a wide array of possible meanings that a reader can derive. Iser's model of interaction (Iser, 1974, p. 274) defines literary work as the meaning derived from a transaction between the text and the reader. Limits and gaps in the text offer a horizon of possible meanings for the reader to discover. The reader brings to literary work his/her own personal repertoire which includes personal and social knowledge. The meeting between the reader and the text produces, in this conceptualization, literary work. While not subscribing to the doctrine of New Criticism, Iser argued that text offers readers invitations to various meanings that are sometimes rejected and sometimes explored. Nodelman and Reimer (2003) compared a reader to an actor who must play a role from a script in that the actor is free to improvise, but their performance is guided by the script. For example, in a reading of The Absolutely True Diary of a Part Time Indian, there are many interpretations that a reader could make as the text deals with issues of racism, poverty, coming age, violence, and substance abuse; however, there are some interpretations that could not realistically be gleaned from the text because the text does not deal with them.

Iser's view takes into account the common sense notion that texts do have some permanent characteristics that would lead readers to similar conclusions, but also acknowledges the reader's individuality as a mediating variable on the transaction, or as Iser calls it, literary work. Rabinowitz and Smith (1998) suggest that students complete 
"authorial readings" of texts where they analyze the text in a traditional manner indicative of New Criticism, as well as responding to the text in a reader response journal or discussion. This view point is valuable because English/Language Arts teachers must also instruct students in literary techniques, terms, and rhetorical devices during readings, in addition to eliciting personal responses. An example of this would be a teacher leading students to discover symbolic elements in Lord of the Flies while at the same time allowing for personal responses to the text. Responses to text can occur in many formats, but most all English/Language Arts classes will find themselves in discussions of texts.

Responses and discussions of responses do not take place in a vacuum. Aside from the personal characteristics a reader brings to a transaction, Fish (1980) puts forth the concept that readers are members of interpretive communities which shape their interpretation of texts which he views as having many possible meanings. Fish (1980) defines interpretive communities as groups that are:

...made up of those who share interpretive strategies not for reading (in the conventional sense) but for writing texts, for constituting their properties and assigning their intentions. In other words, these strategies exist prior to the act of reading and therefore determine the shape of what is read, rather than, as is usually assumed, the other way around. (p. 171) The strategies readers bring to a transaction are learned and taught; these include assumptions, practices and goals the readers deem as necessary to engage texts. Most secondary students will have had numerous English/Language Arts teachers by the time they reach graduation and each of these teachers will have had an effect on developing students' membership in interpretive communities. Students are members of the 
interpretive community of their immediate classroom; however, students will also be members of various other interpretive communities dictated by personal characteristics such as sex, race, culture, sexual orientation, and socio-economic status (Fish, 1980). Thus, while the students of a class may form one collective interpretive community, in a reading of Krik Krak!, a female first generation Caribbean immigrant may respond from a different interpretive community than a male fifth generation European American would, although both are in the same classroom.

The intersection of students and their interpretive communities is critical to meaningful discussions of texts, and teachers are responsible for making students aware of certain conventions that authors use in order to recognize what the author may have intended (Rabinowitz \& Smith, 1997). Fish (1980) recommends that members of different interpretive communities discuss texts because the opposing positions that readers may take allow real dialogue to occur. These types of discussions can open up the minds of students who belong to various and/or multiple interpretive communities to opinions different or even oppositional to their own and may expand students' knowledge, increase their tolerance for others and even help them embrace new ideas. For instructors focused on social justice, critical literacy, feminist theory or queer theory this is a desired end result as knowledge of others and tolerance for others is often a byproduct of such interactions.

This perspective on classroom discourse is echoed in the work of Bleich (1988) who looks at classroom discussion as a chance for students to share ideas in a format that reduces the traditional authoritarian role of the teacher in classroom discourse. This is noteworthy as it legitimizes oral literacy which is often minimized or completely absent 
from typical American classrooms. Many students, especially those of color and/or nonnative speakers of English, may have grown up in an environment which allowed them to excel at oral fluency; however, these students, who may have rich and deep ideas, are rarely given a chance to utilize this form of literacy (Heath, 1983). Oral fluency will help students in classroom discussions, and in small group discussions, which Bleich contends are safe havens where ideas and beliefs may flourish without being overly influenced by the authoritarian presence of the teacher. Simply put, students are more apt to be honest about their opinions and to discuss them freely in a small group because they may not be worried about how their responses appear to the teacher. This is critical to this study because some research has shown a backlash in boys rape myth acceptance where they become more accepting of rape supportive beliefs post intervention (Jaffe et al., 1992). This may be because of the authoritarian structure of a didactic lecture which many interventions utilize. Following Bleich's argument, it would be reasonable to expect that classroom and small group discussions of reader responses to literature would circumnavigate elements that contribute to backlash and may increase the probability of attitudinal changes in rape myth acceptance toward less accepting views of rape myths.

The major theoretical stances of reader response lead to the conclusion that teacher initiated and led responses to literature could allow for aesthetic readings. These aesthetic readings could lead to personal responses that could be shared through writing and discussion with the class, which serves as an immediate interpretative community. This would foster literary experiences where students could not only vicariously experience situations and conflicts through the text, but could see other students' points of view through discussions. When dealing with a topic such as rape myths, this can be 
critical because the backlash against interventions described in not only studies on rape but in studies on racism (Bigler, 1999) may be because of the didactic nature of authority figures lecturing a student that the views he/she current holds are bad. By learning from a text and from friends, students may be able to change their views about such topics without feeling demonized and becoming defensive.

\section{Date Rape}

Rape has historically been defined and understood as a property crime against a father or a husband. A woman was viewed as a commodity which provided various benefits to her owner, whether her father or husband, and rape was the unauthorized use of a man's property (Fleck, 1998). Until the 1970s, explanations of rape were dominated by a psychopathology model. Under the psychopathology model, rape is viewed as a symptom of a psychiatric disorder (Murphy, Coleman, \& Haynes, 1986). Therefore, rapists are viewed as deviants who do not represent what society views as "normal" males. The writings of the 1970's feminist movement redefined the perception of who could be a rapist, enlarged rape as a cultural phenomenon and refined definitions of rape.

Brownmiller (1975) postulated that rapists "cloaked in myths that obscure their identity" and are not "society's abberants" but are the "front line masculine shock troops" who serve an important function in a patriarchal society - to keep women subservient to men (p. 209). This defines rape, as not sexual in nature, but as an "exercise in power" (Brownmiller, 1975, p. 256). Brownmiller's removal of rapists from the category of psychological deviants was groundbreaking because it allowed for the examination of rape as an instrument of violence against all women, not just those who are raped, used in order to maintain male dominance in a patriarchal society. Through rape and the threat of 
rape, women are unable to ever be truly free as the threat of rape keeps women "in a constant state of intimidation" (p. 209). According to Brownmiller, men who do not rape benefit from the actions of rapists as women are held in a subservient position. Because any man can be a rapist, women are in constant danger, even from men whom they know or with whom they may be romantically involved.

In her chapter on institutional power and authority, Brownmiller (1975) introduces the category date rape. She described rapists who have had a prior relationship with their victims as having "elements of coercive authority that militates against decisive resistance" (p. 257). She blames the expectations of feminine behavior on society for many date rapes as they demand that women remain polite and "gracefully endure" or "wriggle away" from a rapist in the context of a date rape but that a "direct confrontation falls outside of the behavioral norms" (p. 257). Brownmiller discusses the difficulty of prosecuting date rape cases as police may believe that a date rape accusation is just a woman who has "changed her mind afterward" (p. 257). In addition to this myth, Brownmiller discusses many more rape myths including the "beautiful victim" (p. 333), the black man as a rapist (p. 223), the socially solitary rapist (p. 182), that a woman could not really be raped if she did not want it (p. 235), that fighting back may get a woman killed (p. 206), that sexual intercourse is normally painful (p. 316), and that "she was asking for it” (p. 311). Rape myths are embraced by not just men, but also by women, and the endorsement of these rape myths functions to deny rapes as real and to shift blame for rape from the rapist to the victim (Lonsway, \& Fitzgerald, 1994).

Women's adherence to rape myths was examined in a study by Koss and Oros (1982) who sampled 2,016 female college students and asked them questions relating to 
their sexual history in reference to date rape. Her findings became part of the now famous Ms. Magazine article I Never Called it Rape, which is credited with bringing the crime of date rape to national attention. In their 1982 study, Koss and Oros found that $13 \%$ of her sample had been victims of rape, but of these, $43 \%$ did not label their experience as rape. The percentage of rape victims who do not acknowledge their rapes as such have been found to range from 73\% (Koss, et al., 1988; Layman, Gidycz, \& Lynn, 1996), to $64 \%$ (Bondurant, 2001), to $62 \%$ (Peterson \& Muhlenhard, 2004) and 48\% (Kahn, Mathie, \& Torgler, 1994). According to Koss (1985) these unacknowledged rape victims have had an experience that meets the legal criteria for rape but do not identify themselves as victims. Peterson and Muhlenhard (2004) averred that these women are influenced by rape myth acceptance and in a study of 86 college women who were unacknowledged rape victims, they found that there was a statistically significant $(p<.05)$ interaction between items on the Illinois Rape Myth Acceptance Scale (Payne, et al., 1999) indicating belief in the myths that a woman who is sexually teasing deserves to be raped, that their own actions were sexually teasing, and that it is not really rape if a woman does not fight back. These findings are significant because they show that the acceptance of rape myths by women is a critical element in perpetuating the domination of women in society (Brownmiller, 1975). Brownmiller described the expected behavior for a woman is to be passive and the adherence to this sociocultural expectation and the belief in the myth that if a woman does not fight back it is not rape combine to influence a large percentage of date rape victims into denying the reality of their own rapes. While date rapes are more likely to become unacknowledged rapes (Koss, Dinero, Seibel, \& Cox, 1988), the effects of these rapes are no less damaging than those of stranger rape. 
The psychological damage to victims from date rape was found to be the same as the psychological damage from stranger rape in a national study by Koss (1988). Burt and Katz (1988) found that date rape victims up to three years post trauma self-rated themselves as less recovered from sexual assault than those who were victims of stranger rape. Both of these studies found that women who blamed themselves for the rapes were less likely to call the police, seek counseling, or tell anyone about their experience and were more likely to experience higher levels of psychological distress (Burt \& Katz, 1988; Koss, 1988). The damaging effects of date rape are intensified by the acceptance of rape myths by women as victims of date rape blame themselves for the way they dress, for leading their attackers on, and for not fighting back enough. While the adherence to rape myths mediates the way women may behave during and after a date rape, the acceptance of rape myths by men may be a precursor to committing sexual assault.

Rape myth acceptance in men has been hypothesized to be a predictor of proclivity to commit future sexual assault by numerous researchers (Abrahms, Viki, Masser, \& Bohner, 2003; Bohner, Jarvis, Eyssel, \& Siebler, 2005; Bohner, Reinhard, Rutz, Strum, Kerschbaum, \& Effler, 1998; Bohner, Siebler, \& Schmelcher, 2006; Krahe, Bieneck, \& Scheinberger-Olwig, 2007; Malamuth, 1981, 1989; Malamuth \& Check, 1985; Maxwell, Robinson, \& Post, 2003; Murphy, Coleman, Haynes, 1986; Quackenbush, 1989). The linking of rape myth acceptance and future proclivity to rape is a critical connection to make because if research can show that there is a connection between the two, then a logical next step would be to experiment with ways to reduce rape myth acceptance in men in order to reduce rape proclivity (rape proclivity). Malamuth (1981) defines rape proclivity as "the relative likelihood for men to rape under 
various conditions that may or may not actually occur" (p. 139). That is, rape proclivity is the probability that a man may attempt rape in future hypothetical situations.

\section{Research on Rape Myth Acceptance and Rape Proclivity}

The following section examines research related to the proclivity of males to commit rapes and studies which have attempted to link rape proclivity and rape myth acceptance. Most studies conducted have used university students and share some common elements such as the use of vignettes depicting some form of rape, a self-report questionnaire to assess the participants' proclivity to commit a similar rape if assured they would not be caught, and a measure of rape myth acceptance. As studies developed, the rape vignettes diverged into two types: acquaintance rape vignettes and stranger rape vignettes. Recall that an acquaintance rape is a rape between two people who know each other while a date rape is a rape that occurs within a dating context or a romantic or potentially romantic situation. Simply put, a date rape implies a relationship beyond that of merely being acquaintances such as classmates, coworkers, or neighbors; both the victim and the perpetrator in a date rape are at some point interested in each other beyond the platonic level. As most researchers examined rape situations where there is a male assailant and a female victim, women are often absent from studies attempting to link high rape myth acceptance with high levels of rape proclivity.

\section{Early Studies}

Early studies of rape proclivity often looked at participants' arousal to various audio and visual depictions of rape. Abel, Barlow, Blanchard and Guild (1977) hypothesized that rape proclivity can be measured by examining the arousal level of males who listen to audio depictions of rape; in their study they found that rapists were 
more sexually aroused by depictions than were non-rapists. Malamuth, Heim and Feshbach (1980) used written depictions of rape and mutually consensual intercourse to measure sexual arousal in a sample of 135 male and 159 female undergraduates. The second part of the study used only a written rape depiction and manipulated the level of pain and/or pleasure of the victim via changes in the scenario to determine sexual arousal in a sample of 68 female and 55 male undergraduates. Participants in both sections of the study read the depictions to themselves. The rape depiction used appeared to be a stranger rape from various descriptions in the article, although it was not clearly stated as such.

Depictions of stranger rape were used again in a study by Malamuth and Check (1980) who assessed 145 male participants on personality variables, sexual motivations, sexual experience, and rape proclivity. Rape proclivity measured participants' selfprofessed likeliness to commit rape if they were assured they would not be caught. The inventory was researcher created and used a 6-point Likert-style scale ranging from "not at all likely" to "very likely" (p. 58). Participants who indicated that there was no likelihood they would rape, were assigned a score of 1, and were separated into a Low Likelihood to Rape group (LR; 59\%), while those who responded with values above 2 were classified as High Likelihood to Rape (HR; 41\%). Participants then listened to audio recordings of either a scenario of mutually consenting intercourse, or a scenario of a stranger rape which involved a man following a woman home from a disco, breaking into her apartment, and forcibly raping her. Results showed that likelihood of raping was significantly correlated with sexual arousal to rape depictions $(r=.38, p<.01)$. 
Malamuth, Haber, and Feshbach (1980) used a depiction of an acquaintance rape in which a male student offers a female student a ride and when she refuses, he proceeds to rape her at knife point. Participants were 38 female and 53 male undergraduate students from a psychology class at the University of California, Los Angeles. Results showed that $17 \%$ of males showed some tendency (at least a 2 on a 5-point Likert-style scale) to behave as the rapist had in the depiction and when another question included the assurance that they would not be caught, the percentage of males who would be at least somewhat inclined to rape increased to $51 \%$. When assured of not being caught, the number of males scoring at least a 3 on the scale was 21\%. Questionnaires also inquired as to the participants' belief that other males would rape in the same situation if assured of not being caught. Rape proclivity and belief in others' rape proclivity was significantly correlated $(r=.49, p<.01)$. Female participants answered questions as to how fearful they would be of being victimized and whether they would enjoy being victimized in a manner similar to the story if they were guaranteed no one would ever find out. This early study is of great value because not only does it start moving from stranger rape depictions to acquaintance rape depictions, but it also introduces the factor of perception of others' rape proclivity as a variable of interest when measuring rape proclivity.

An early study by Tieger (1981) examined self-rated rape proclivity and the social perception of rape in a study with 392 junior college students (179 men, 213 women). Participants were assessed using the Bem Sex Role Inventory (Bem, 1974; 1977) and a researcher made rape questionnaire designed to measure attitudes toward rape, perpetrators of rape, and victims of rape. The rape questionnaire began with a vignette of 
a stranger rape incident with a picture of the victim which was either "attractive" or "nonattractive," and was followed with thirty-two 5-point Likert-style scale questions which measured (a), victim believability; (b), victim precipitation and seductiveness; (c), perceived seriousness of crime; (d), sexual nature of crime; (e), victim enjoyment of rape; and (f), males' rape proclivity if they were assured that they would not be caught.

Results showed that out of 172 males in the study, 64 (37\%) indicated some likelihood of perpetrating rape and $35(20 \%)$ indicated a likelihood of perpetrating rape that was equal or greater than the midpoint of the rating scale. Researchers separated the 35 males into a group labeled high likelihood of raping (HLR) for further analysis.

The HLR group showed a very strong correlation $(r=.92)$ with the subscale of the questionnaire "Rape as Enjoyable Seduction" which assessed the participants' belief of rape as part of normal sexual seduction interactions between men and women. While this is not labeled as rape myth acceptance by the researchers, the myths that "when a woman/girl says no she really means yes," and that "if a woman enjoys it, it is not rape" are two prominent rape myths measured by this subscale. Further analysis showed that the HLR group viewed rape as a less serious crime than female participants. Clearly, these are all part of rape myths as identified by Burt (1980), and the results show that adherence to these myths plays an integral role in developing a personality that is self reportedly highly likely to rape.

Check and Malamuth (1983) investigated rape myth acceptance and rape proclivity in a study which assigned participants to groups which read either a vignette depicting mutually consenting intercourse, a vignette depicting an acquaintance rape, or a vignette depicting a stranger rape. The vignette labeled as an acquaintance rape would 
better fit the definition of a date rape, as the rape involved a man and a woman who were on a first date where they engaged in consensual kissing before a date rape ensued. Participants were 289 male and female introductory psychology students from the University of Manitoba. Participants were assessed using the Sex Role Stereotyping scale (Burt, 1980), one of the three vignettes, a self-reported sexual arousal measure created by the researchers, an assessment designed to measure the participants' perception of the woman in the story in terms of willingness, pleasure and pain, and for male subjects, a self-reported measure of likelihood of rape. The likelihood of rape inventory asked on a 5-point Likert-style scale how likely they would be to commit the same rape depicted in the vignette if they were assured that no one would find out. Results showed that $30 \%$ of males indicated some likelihood of raping. The difference in rape proclivity between the acquaintance rape $(M=1.48)$ and stranger rape group $(M=$ 1.39) were not significant. While there was no significant difference between the acquaintance and stranger rape groups, the results show a high percentage of males who self-indicate proclivity to commit rape. The study is also one of the earliest to separate stranger rape from date rape in examining rape proclivity. This is critical as adolescents who are experimenting with dating behaviors may be more at danger of being a victim of date rape than stranger rape; therefore, attitudes toward date rape are critical to investigate.

The differences between stranger rape and date rape on rape proclivity was examined in a study which investigated the relationship between sex-role orientation and the perception of rape, acceptance of rape myths, and likelihood of committing acquaintance rape and stranger rape (Quackenbush, 1989). Participants were 120 males 
from Washington State University and Eastern Washington University. Participants were assessed using the Bem Sex-Role Inventory (Bem, 1974), the Rape Responsibility Questionnaire (Deitz \& Byrnes, 1981), the Rape Myth Acceptance scale (Burt, 1980), the Acceptance of Interpersonal Violence scale (AIV; Burt, 1980), the Adversarial Sexual Beliefs scale (ASB; Burt, 1980), two rape vignettes adapted from Shotland and Goodstein (1983), and a scale which measured likelihood of raping adapted from Malamuth (1981). The likelihood of raping scale inquired as to how likely the respondent would be to behave as the man in the vignette had if they were guaranteed they would not be caught.

Participants were randomly divided into two equal sized groups which were given either a vignette that depicted an acquaintance rape or a vignette that depicted a stranger rape. The acquaintance rape vignette may be better labeled as date rape as it presents the story of a man and woman who after a date proceed to his apartment and engage in consensual sexual activities, but not intercourse. When the man desires to engage in intercourse and the woman declines, he proceeds to rape her:

Then he slid her dress completely off and removed her underwear. They kissed each other passionately. The phone rang, Lee answered. Just a wrong number; Lee hung up and returned, sitting next to Diane. With Diane totally naked, Lee leaned against her and pushed her back onto the couch until he was on top of her. Diane said, "No, Lee, don't." Ignoring this, Lee responded "It's okay," and quickly unzipped his pants and slid them down. Diane struggled and said, "I don't want to, let me go!" "Relax Diane, don’t worry," Lee answered.

Diane protested once more, "Don't! Stop!” Lee held Diane and said, "Don't worry, I'll take care of everything." He stroked her breasts, "relax, just take it easy," he said. Lee continued to kiss and fondle Diane. Soon, he penetrated her and intercourse had occurred. (Quackenbush, 1989, p. 325) 
Results showed that for participants who read the date rape vignette, $59 \%$ of males responded some likelihood they would commit a similar rape (Quackenbush, 1989). Their rape proclivity was correlated with their rape myth acceptance $(r=.438, p$ $<.01)$, AIV $(r=.490, p<.01)$, and ASB $(r=.451, p<.05)$. These findings lend more support to the hypothesis that there is a relationship between rape myth acceptance and rape proclivity. The correlations of both attitudes toward violence and adversarial sexual beliefs with rape myth acceptance show that acceptance of violence in relationships and belief that relationships are adversarial in nature may underlie rape myth acceptance. Individuals who believe that sexual relations are guided by an adversarial paradigm where potential partners are dishonest, manipulative and exploitative may be more apt to adhere to beliefs which justify rape. Participants in the acquaintance rape vignette group also showed less empathy for the victim and assigned greater responsibility for the rape to the victim, than did readers of the stranger rape vignette. Furthermore, in the date rape vignette, $65 \%$ held the victim responsible for the rape. This further supports the notion that rape myths blame victims for their own victimization and may support the possibility that date rape myths are more deeply entrenched than rape myths in stranger rape situations.

These results lend support to the notion that rape myths include the idea that if a woman consents to any kind of sexual activity before she says no than it is not rape. Specifically, on the Rape Myth Acceptance Scale (Burt, 1980), 35\% agreed with the statement: "If a girl engages in necking or petting and she lets things get out of hand, it is her own fault "if her partner forces sex on her," and 17\% agreed with the statement: "A woman who goes to the home or apartment of a man on their first date implies that she is 
willing to have sex" (Quackenbush, 1989, p. 377). Furthermore, the participants viewed the stranger rape as much more serious than the acquaintance rape and the correlation for rape myth acceptance and rape proclivity was lower, but still significant, in the stranger rape vignette $(r=.365, p<.05)$. Overall this study shows that rape myth acceptance and elements related to rape myth acceptance are related to rape proclivity. Finally, this study shows that males may view date rape as a much different phenomenon than stranger rape and that proclivity to rape may be higher in date rape scenarios than in stranger rape scenarios.

\section{Later Studies}

In a two part study Bohner, Reinhard, Rutz, Strum, Kerschbaum, and Effler (1998) tested the hypothesized link between rape myth acceptance and rape proclivity. Researchers used German versions (VMAS) of Cosin's R scale (Costin, 1985) which measures rape myth acceptance, Malamuth's Attraction Toward Sexual Aggression Scale (ASA; Malamuth, 1989) which measures rape proclivity, and a researcher created 5-point Likert-style scale rape proclivity questionnaire. The researcher created questionnaire asked: "If you could be assured that no one would know and that you could in no way be punished for engaging in the following acts how likely, if at all, would you be to commit such acts?” (p. 260). There were two acts that were used to calculate rape proclivity, "raping a woman" and "forcing a female to do something sexual she didn't want to do" (p. 260). The participants were 125 male students at the University of Mannheim, Germany. Results showed that $33 \%$ of participants indicated at least some likelihood that they would commit sexual assault. Results showed that rape myth acceptance and rape 
proclivity were moderately correlated $(r=.48, p<.01)$ for those who first responded to the rape myth scales and then the ASA scale.

The second part of the study was conducted with 113 male students from the University of Mannheim. In addition to the VMAS and ASA, participants were given written scenarios that described date rapes and asked three 5-point Likert-style scale questions which inquired as to participants' sexual arousal (arousal), probability of behaving the same as the rapist in the vignette (behavioral inclination), and level of satisfaction with "getting your way in this situation" (enjoyment; p. 263). A major difference in the second study was that researchers reworded the ASA rape proclivity scale from "raping a woman" to "forcing a woman to have sexual intercourse against her will" (p. 263). Results showed that $63 \%$ of participants indicated at least some likelihood that they would commit sexual assault. The rewording increased this percentage almost $100 \%$ from the first part of the study. Rape myth acceptance and rape proclivity for participants who first received the rape myth acceptance then the scenarios in order of administration showed significant correlation between ASA rape proclivity and rape myth acceptance $(r=.31, p<.05)$, between rape myth acceptance and rape scenario arousal $(r=.30, p<.05)$, behavioral inclination $(r=.46, p<.001)$, and enjoyment $(r=$ $.52, p<.001)$.

The results show not only the relationship between rape myth acceptance and rape proclivity, but also the increased number of respondents in the second study who reported some likelihood of using sexual violence when the wording of inventories was changed shows how important social desirability can be as a mediator. Furthermore, the power of language is demonstrated by the change in wording from "rape" to "force" and may also 
lend support that it may be socially acceptable to adhere to adversarial sexual beliefs where force and coercion is an accepted part of dating.

Sexual coercion was examined in a two part study which alternated the order of rape myth acceptance and rape proclivity assessments (Bohner, Jarvis, Eyssel, \& Siebler, 2005). The first part was conducted with male undergraduates and employees $(n=107$, mean age $=28.1)$ in East Kent, United Kingdom. Researchers used a modified version of Costin's R-scale (Costin, 1985) to measure rape myth acceptance, five acquaintance rape scenarios (Bohner et al., 1998) used in the previous study, and a modified version (Lisak \& Roth, 1988) of the Sexual Experiences Survey (SES; Koss \& Oros, 1982) to measure previous sexual coercion. Results showed that rape myth acceptance and rape proclivity were correlated $(r=.48, p<.001)$ and that rape myth acceptance was more highly correlated if the rape myth acceptance scale was administered before the rape proclivity scale $(r=.57)$ than after $(r=.31)$. This supports the researchers' hypothesis that the accessibility of rape proclivity is increased by administering rape myth acceptance assessments before rape proclivity assessments. Researchers also discussed the effects the previous engagement in sexual coercion may have on accessibility of rape myth acceptance as participants who had high scores $(n=45)$ for sexual coerciveness had higher rape proclivity $(r=.58)$ than did participants with lower sexual coercion scores $(n$ $=58, r=.26, p=.0026)$.

The second part of the study was conducted with male participants who were mostly students $(n=148$, mean age $=24.2)$ at the University of Bielefeld, Germany. Participants were given a computer administered rape myth acceptance scale, four computer administered rape scenarios, and a printed questionnaire assessing previous 
sexual coercion. rape myth acceptance was measured using the short form of the Sexual Aggression Myths (SAM) scale (Gerger, Kley, Schmidt, Siebler, \& Bohner, 2003; Kley, Gerger, Bohner, Siebler, \& Schmidt, 2004). Researchers used the SAM because of its high correlation $(r=.84)$ with the Illinois Rape Myth Acceptance Scale (Payne, Lonsway, \& Fitzgerald, 1999) and because it showed a low effect of social desirability ( $r$ $=.03$ ) with a German inventory (Musch, Brockhaus, \& Broder, 2002). Sexual coercion was measured using German versions of the modified SES from the first part of the study. Interestingly, this part of the study hypothesized that sexually coercive men would respond faster to computer administered SAM items than non-coercive men. That is, men who were inclined to engage in behavior that is considered aggressive would show less of a need to consider questions and choices of answers before choosing their own answers. Researchers used a baseline reading speed from the time it took participants to read the rape scenarios. Results showed that response times for sexually coercive men were shorter than for non-coercive men on 15 items out of 16 on the $\operatorname{SAM}(p<.005)$. Researchers concluded that the faster response speeds showed a heightened accessibility of rape myth acceptance and therefore a higher level of rape myth acceptance. Researchers concluded that both parts of the study provided more evidence that heightened rape myth acceptance causally affects self-reported rape proclivity, that heightened rape myth acceptance justifies sexual aggression after assault, and that heightened rape myth acceptance increases the likelihood of future assault. In the context of the present study, this research would support the manner in which the antagonist of the novel Speak justifies his actions after the fact and how he remains in denial as to the seriousness of his crime. It also provides an empirical support for his second attempted 
assault of the protagonist at the end of the novel. It would appear that the novel Speak successfully captures the mindset and behavior of a perpetrator of date rape.

In a similar study, Chiroro, Bohner, Viki, and Jarvis (2004) examined the relationship between rape myth acceptance and self-reported rape proclivity, mediated by anticipated sexual arousal and anticipated enjoyment of sexual domination. The three part study was conducted with 113 male students (mean age $=23.9)$ from the University of Mannheim, Germany; 60 male undergraduates (mean age $=21.5$ ) recruited from the University of Kent, England; and 54 non student participants recruited by the author $($ mean age $=35.7)$; and 83 male students $($ mean age $=25.9)$ from five colleges of higher education in Zimbabwe. Researchers used modified versions of Costin's (1985) R-Scale to measure rape myth acceptance while five written date rape scenarios were used to measure rape proclivity and mediators. While the study shows that the relationship between rape myth acceptance and rape proclivity is mediated by anticipated sexual enjoyment but not anticipated sexual arousal, all three parts of the study showed a positive correlation (Germany, $r=.24, p<.01$; England, $r=.53, p<.001$; and Zimbabwe, $r=.28, p=.01$ ) between rape myth acceptance and unmediated self-reported rape proclivity. The results show that rape myth acceptance and self-reported rape proclivity are correlated in samples not only in samples of European males, but also in African males, and support the overall hypothesis that rape myth acceptance is a predictor of rape proclivity. In addition to further supporting the widespread acceptance of date rape myths, the results of this study show that the relationship between rape myth acceptance and proclivity to rape is not limited to European or American societies. 
The relationship between rape myth acceptance and rape proclivity was examined in a two part study using two models of rape proclivity (Chapleau \& Oswald, 2010). The first part of the study investigated the phenomenon of power and sex using 131 college students (54.2\% women; mean age $=20.2, S=3.5)$ from a Midwestern Catholic University. While not directly related to rape myth acceptance and rape proclivity, this part of the study found that the construct of power-sex is different from the construct of domination and enjoyment. Researchers believe this may be related to rape myth acceptance and rape proclivity as it suggests that those who hold the belief that sex is a means to gain or surrender power, may have a different view of rape myth acceptance than those who do not. The first part of the study provided the foundation for the second part which deals directly with rape myth acceptance and rape proclivity.

The second part of the study examined how power-sex association and explicit power-sex beliefs are related to rape myth acceptance and rape proclivity. Participants were 108 males from a Midwestern Catholic University (mean age = 19.1, $S=1.3$; European American, 79.6\%; African American, 2.8\%; Latino or Hispanic, 7.4\%; Asian American, 7.4\%) who were recruited from introductory psychology courses. Participants attitudes were measured with a researcher created inventory to measure implicit powersex association (IAT), a researcher created scale to measure explicit power-sex beliefs, the Illinois Rape Myth Acceptance Scale (IRMA; Payne et al., 1999) to measure rape myth acceptance, and the aggressor version of the SES (Koss et al., 1987; Koss \& Oros, 1982) to measure past sexually aggressive behavior. Researchers replicated the previously reviewed study by Chiroro et al., (2004) and used five different date rape scenarios where participants were asked their likelihood of replicating the rapist's actions 
(0-100\%). All inventories were administered on desktop computers which measured participants' speed of response to items.

Results showed that rape myth acceptance was positively correlated with rape proclivity $(r=.52, p<.01)$. Additionally, power-sex association and explicit power-sex beliefs accounted for $27 \%$ of the variance in rape proclivity. Implicit power-sex was correlated with rape myth acceptance $(r=.19, p<.10)$ and rape proclivity $(r=.20, p<$ $.05)$. Explicit power-sex was correlated with rape myth acceptance $(r=.38, p<.01)$ and rape proclivity $(r=.25, p<.01)$. Researchers averred that these findings provide that implicit power-sex association and explicit power-sex beliefs underlie rape myth acceptance, and that "rape myths are part of a learned system where consensual sex is associated with power" (Chapleau \& Oswald, 2010, p. 75). These findings are important because they continue to add to the evidence linking rape myth acceptance with rape proclivity. They also provide explicit power-sex beliefs as another construct that may be linked with rape myth acceptance and may predict rape proclivity. Moreover, the findings support the assertions of feminists (Brownmiller, 1975) that rape is associated with power and that rape myths are part of a learned system. This is critical because if rape myths are learned in social environments, then it is only natural to assume that through the social environment of education these myths can be dispelled.

The effect of the social environment on individuals' rape myth acceptance and rape proclivity was examined in a study based in social norms theory (Bohner et al., 2006). Social norms theory (Perkins \& Berkowitz, 1986) states that the influence of peers is based more on perceived norms, what one thinks his/her peers do and believe, as opposed to actual norms, what his/her peers' actually do and believe. The disparity 
between the two and the mistaken acceptance of the former in lieu of the latter is the basis of social norms theory. It is believed that by giving accurate information to individuals, the pressure to adhere to perceived norms will decrease and individuals will behave in ways that are more aligned with their true beliefs and attitudes (Berkowitz, 2003; Hillenbrand-Gunn, Heppner, Mauch \& Park, 2010). As it relates to rape myth acceptance and rape proclivity, it is hypothesized that men and/or boys who engage in coercive sexual behavior and/or sexual assault believe that they are acting within the norms of their friends' behaviors, that is, they are acting in the range of their perceived norms.

In their two part study, researchers manipulated participants' perceptions of their peers' rape myth acceptance when measuring rape myth acceptance and rape proclivity. The participants in the first part of the study were all male students $(n=90$, mean age $=$ 24.0) from the University of Mannheim, Germany. Participants were randomly assigned to either no peer rape myth acceptance feedback, low peer rape myth acceptance feedback, or high peer rape myth acceptance feedback. During the assessment of rape myth acceptance using a German adaption of Costin's (1985) R scale, participants in the low rape myth acceptance and high rape myth acceptance feedback conditions were given inventories which had one response underlined for each question that was labeled as having been the most frequently chosen answer in the previous year's survey. For the low rape myth acceptance feedback condition, the values of underlined answers were approximately 1 standard deviation below average male responses from a pilot study and from another study by Bohner (1998). For the high rape myth acceptance feedback condition, the values of underlined answers were approximately 1 standard deviation 
above the aforementioned values. No rape myth acceptance feedback condition participants' R scales did not have any answers underlined nor were there any references to previous respondents' choices. Participants' rape proclivity was assessed using five acquaintance-rape scenarios utilized in previously reviewed studies (Bohner, Jarvis et al., 2005; Chapleau \& Oswald, 2010; Chiroro et al., 2004).

Results from the first part of the study showed means of rape myth acceptance to be 2.21 in the low rape myth acceptance feedback condition, 2.61 in the no rape myth acceptance feedback condition, and 3.18 in the high rape myth acceptance feedback condition. The relationship between rape myth acceptance and high rape myth acceptance feedback was significant $(p<.001)$. High rape myth acceptance feedback was related to higher rape myth acceptance $(r=.26, p<.01)$ while low rape myth acceptance feedback showed a negligible correlation with lower rape myth acceptance scores $(r=.06)$. Thus, the awareness of higher rape myth acceptance scores tended to have more of an influence on higher rape myth acceptance than did the awareness of lower rape myth acceptance scores. These relationships could occur because people who do not buy into rape myths are less easily influenced by those who do embrace rape myths, and, for high rape myth acceptance scores, the high rape myth acceptance feedback provides heightened accessibility to rape myth acceptance. Means of rape proclivity were 1.60 in the low rape myth acceptance feedback condition, 1.70 in the no rape myth acceptance feedback condition, and 1.93 in the high rape myth acceptance feedback condition. Statistical analysis found a marginally significant $(t(80)=1.77, p=$ $.08, \operatorname{MSE}=0.477, r=.19)$ relationship between rape proclivity and high and low rape 
myth acceptance feedback conditions. Researchers concluded there was only weak support for a relationship between rape myth acceptance feedback and rape proclivity.

As in the aforementioned studies, this study's results support the relationship between rape myth acceptance and rape proclivity as in the first part of this study the correlation between rape myth acceptance and rape proclivity was significant $(r=.48, p$ $<.001)$. Overall, researchers concluded that the results of the first study support the hypothesis that rape proclivity is causally moderated by the perceived rape myth acceptance of peers. Therefore, proclivity to rape may be increased or decreased depending on changes in an individual's perception of his or her peers' level of adherence to rape myths. This supports the work of Fish (1980) who suggests that readers are provided with opportunities to discuss reactions to literature in order to allow different interpretive communities to communicate openly. This may allow students to gain a more accurate assessment of their peers' rape myth acceptance and reevaluate their own beliefs. The power of social feedback was further examined in the second part of the study as researchers increased levels of feedback.

The second part of this study expanded rape myth acceptance feedback into four levels: very high rape myth acceptance feedback ( 2 standard deviations above pilot study), high rape myth acceptance feedback (1 standard deviation above pilot study), low rape myth acceptance feedback (1 standard deviation below pilot study), and no rape myth acceptance feedback. It also changed the order of treatments by assessing rape myth acceptance first using the modified version of Costin's (1985) R-scale, then providing manipulated rape myth acceptance feedback of peers, and finally assessing rape proclivity using the five scenario rape proclivity scale used in the first part of the 
study. Researchers hypothesized that the higher the level of perceived rape myth acceptance of peers, the higher participants' rape myth acceptance will be; and that rape proclivity is positively correlated with rape myth acceptance. Participants were 158 male students at the University of Mannheim (mean age $=22.6$ ) who were randomly assigned to one of the four rape myth acceptance feedback conditions. Results showed that means of rape proclivity were 1.57 for low rape myth acceptance feedback condition, 1.63 for no rape myth acceptance feedback condition, 1.66 for high rape myth acceptance feedback condition, and 1.92 for very high rape myth acceptance feedback condition. Very high rape myth acceptance feedback condition had significantly higher scores on the rape proclivity scenario assessment than did all other three levels of rape myth acceptance feedback $(p=.01)$. Analysis of the main effect of the level of rape myth acceptance feedback condition on rape proclivity was significant across all levels $(p<$ .002). The effect of rape myth acceptance feedback condition increased significantly as the feedback level increased $(p<.01)$. Results also continued to solidify the unmodified relationship between rape myth acceptance and rape proclivity which were significantly correlated $(r=.37, p<.001)$.

The previously reviewed studies have consistently shown that high levels of rape myth acceptance are positively correlated with self-professed proclivity to rape. This correlation is the basis for rape education programs which are instituted in colleges across the United States which attempt to reduce date rapes by increasing awareness of safe dating procedures and by reducing rape myth acceptance in both men and women. The powerful effects of social norms on rape myth acceptance and proclivity to rape (Bohner et al., 2006) support the importance of classroom discussion when addressing the topic of 
rape myth acceptance. It is hoped that by giving students the opportunity to become aware that many of their peers may not have accepting attitudes toward rape myths, they may reevaluate their own beliefs and reduce their own rape myth acceptance levels. Ultimately, the point of all rape myth reduction interventions is to reduce future rapes via a reduction in rape myth acceptance. While all of the aforementioned studies used college students as participants, one study did look at rape myth acceptance in secondary students.

Lanier (2001) developed the nine item Rape Myth Attitude Questionnaire as part of a study to determine if adolescents' attitudes that are accepting of forced sex predict the initiation of sexual assault and if acceptance of rape myths result from the perpetration of sexual assault as a method of justification. The study of 851 males enrolled in junior high schools in rural North Carolina, with an age range of 11 to 17, found that there were significant differences on rape myth acceptance between males who had reported perpetrating forced sex and those who did not $(p<.001)$. Adolescents who scored five points higher on the Rape Myth Attitude Questionnaire had a 1.9 times greater probability of committing sexual assault as an adolescent who had scored five points lower. Results did not support that acceptance of rape myths increased after the commitment of sexual assault by those who adhered to them. The results of this study show that rape myth acceptance and proclivity to rape in secondary populations are not significantly different from the relationship between these constructs in college students. Furthermore, this study developed a specific inventory to measure rape myth acceptance by adolescents, and it established a predictive relationship between rape myth acceptance and future perpetration of sexual assault in secondary students. If the results of this study 
are representative, then college may be too late a starting point to begin efforts to reduce rape myth acceptance because beliefs may already be entrenched and because not all secondary students go to college.

\section{Conclusions about Rape Myth Acceptance and Rape Proclivity}

The aforementioned reviewed studies constitute a solid body of research which supports the hypothesis that rape myth acceptance and rape proclivity are related.

Correlation coefficients for rape myth acceptance and rape proclivity consistently showed positive values across all studies reviewed. While it cannot be said that this relationship is causal, the study by Bohner, et al., (2006) which manipulated levels of peer rape myth acceptance feedback does add to the argument that increased rape myth acceptance leads to increased rape proclivity. Whether or not high levels of rape proclivity lead to actual rapes has not been conclusively proven; however, studies of convicted rapists show that they are more likely to accept rape myths than others including inmates convicted of crimes other than rape (Giacopassi \& Dull, 1986; Malamuth, 1981; Scully \& Marolla, 1986). These studies support Brownmiller's (1975) idea that any man is capable of being a rapist and that proclivity to rape and rape myth acceptance are not general traits shared by all criminals and refutes the notion that only "criminal" types commit rape. It must be considered that rape myth acceptance may serve to justify the behaviors of rapists after they commit a rape, though with the high rates of acquaintance and date rape in society, it seems reasonable that those committing these crimes would have a higher level of rape myth acceptance and may be inclined to self-report higher levels of rape proclivity.

For educators, the task at hand is Herculean. Studies indicate that adolescents are in the most at risk group for date rape and other types of sexual assault (Greenfield, 1997; 
Koss, 1997; Parrot, 1991; Snyder, 2000; Snyder \& Sickmund, 1999; U.S. Department of Justice, 2004). As numerous state legislators include dating violence as a mandatory part of public education (National Conference of State Legislators, 2012), educators must attempt to change attitudes and beliefs that may have been formed over years of exposure to family, peer, and cultural supports for rape myths. The additional factor of the social dimension of rape myths investigated in the study by Bohner et al. (2006) not only lends credence to feminist views that rape myths are part of a system of societal violence against women (Brownmiller, 1975), but also brings about an even larger challenge for educators. It is not enough to change an individual's rape myth acceptance and it may be necessary to influence the peer group of an individual to affect any meaningful change in rape myth acceptance. This means it is necessary to have date rape education that allows students to discuss rape myths and their peers' views toward these myths. The current trend of addressing issues such as sexual violence as part of health classes may not afford students the time or environment which may best facilitate a reexamination of attitudes toward rape.

\section{Date Rape Education and Prevention}

The present study examines the relationship between adolescent literature and rape myth acceptance in a secondary school setting, it is important to briefly examine the research concerning date rape education in colleges and universities because they generally precede efforts and research in secondary settings.

\section{College Date Rape Education}

Date rape education and prevention efforts burgeoned in colleges across America in the 1980's as the incidence of date rape on college campuses rose to the forefront of 
the national consciousness (Klaw, Lonsway, Berg, Waldo, Kothari, Mazurek, \& Hegeman, 2005). The public awareness that followed the publication of the Ms. Magazine article on campus rape (Sweet, 1985) led to the implementation of numerous educational programs on college campuses as date rape gained such national prominence that the federal government began to require all colleges and universities that receive federal aid to provide rape prevention programs (National Association of Student Personnel Administrators, 1994). Educational programs designed to reduce the acceptance of rape myths are the primary method of rape prevention on college campuses (Brecklin \& Forde, 2001). Rape myth acceptance has generally been assessed using selfreport Likert-style inventories and all efforts to reduce rape myth acceptance hinge on having valid and reliable measures.

\section{Inventories}

Rape myth acceptance and correlating constructs that underlie it such as adversarial sex beliefs and acceptance of violence have been the primary dependent variable measured to determine the effectiveness of date rape education programs (Anderson \& Whiston, 2005; Brecklin \& Forde, 2001; Flores \& Hartlaub, 1998). The most commonly used inventory to measure rape myth acceptance in college studies is the Rape Myth Acceptance Scale (Burt, 1980; Anderson \& Whiston, 2005). Other measures that have been used to assess attitudinal changes toward rape myths are the Forcible Date Rape Scale (Giarusso, Johnson, Goodchilds, \& Zellman, 1979), Attitudes Toward Rape Questionnaire (Barnett \& Feild, 1977), Acceptance of Rape Myths Scale (GilmartinZena, 1987) General Attitudes Toward Rape Scale (Larson \& Long, 1988), Rape Supportive Attitudes Scale (Lottes, 1987), RAPE Scale (Bumby, 1996) and numerous 
researcher developed and modified inventories (Brecklin \& Forde, 2001). Clearly the aim of most programs has been to reduce rape myth acceptance in the belief that reduced rape myth acceptance will lead to a concomitant reduction in rape proclivity. The reduction in proclivity to rape generally assumes a date rape where the assailant is male and the victim is female. This has led to discussions as to whether prevention efforts are more successful with single sex or coeducational audiences.

\section{Sex of Participants}

College programs have been implemented in all male, all female, and coeducational settings. A meta-analysis of college and university rape education programs showed that $71.2 \%$ were coeducational, $28 \%$ all male, and only $.7 \%$ all female (Brecklin \& Forde, 2001). Collegiate programs in all male settings are generally focused on reducing rape myth acceptance, rape proclivity, related rape supportive beliefs, and are intended to reduce and prevent the perpetration of sexual assaults. Thus, interventions intended to reduce rape myth acceptance in males often do not have female participants. On the other hand, programs for all female participants are aimed at reducing risk elements for women to avoid situations that are conducive to attempted sexual assault (Brecklin \& Forde, 2001). There appears to be equivocation on whether mixed gender or single gender date rape prevention programs are most effective. Some researchers believe that mixed gender programs give men inappropriate information such as the low level of prosecution for date rape (Brecklin \& Forde, 2001; Yeater \& O'Donohue, 1999) and that coeducational settings may be threatening to men and may discourage them from participation (Brecklin \& Forde, 2001; Ring \& Kilmartin, 1992). This belief is in direct opposition to the findings of Bohner et al. (2006) who found that 
the perceived rape myth acceptance of peers is critical in the formation of individual levels of rape myth acceptance and to the work of Fish (1980) who believed that students benefit from hearing views from different interpretative communities.

While these views may have some validity, there are important benefits from mixed gender programs not only for college aged students, but also for secondary aged students. The most obvious benefit is that the majority of public schools are coeducational and most classes in them have both boys and girls enrolled. Schools may be reticent to jump through the logistical hoops needed to separate classes by gender solely for a date rape prevention workshop, whether it is for one class or one semester. Whether or not there is information about date rape that males should not have is highly debatable. Since anyone can find pertinent information about date rape on the Internet, it appears rather foolish to believe that withholding information from participants would have any benefit. Furthermore, the ability to hear numerous points of view in a discussion, both male and female, can broaden the horizons of all participants to beliefs different from their own (Fish, 1980). Finally, rape myths seriously affect women and girls as they reduce the cognition of their experience of rape as such, reduce reporting rates, reduce help seeking behavior, and increase the psychological trauma from date rape. Women and girls can benefit as much as men and boys from programs that dispel rape myths and it is questionable whether a program that focuses on avoiding risky situations for women would achieve that.

\section{Program Format and Duration}

The programs studied in college populations are instituted in a myriad of formats and are of greatly differing lengths in terms of time. Early research focused on the 
effects of interventions that were part of university level human sexuality courses in which rape prevention was one part of a course that dealt with many sexual topics (Flores \& Hartlaub, 1998). Obviously, in a course such as this, students would have already shown an interest in the course as they registered for it and may have been more open to changing attitudes than those who would not sign up for a human sexuality class. These classes would usually be standard semester courses and this would represent the longest duration of interventions at the university level. A recent meta-analysis found that $9.2 \%$ of reviewed studies were conducted as university courses (Brecklin \& Forde, 2001). The most popular format was a workshop/interactive theater (26.8\%), followed by lecture and/or video plus discussion (23.5\%), video and lecture (14.4\%), lecture (13.7\%) video/play (11.1\%) and brochure (1.3\%; Brecklin \& Forde, 2001). The duration of date rape prevention programs was found to be highly variable as the average length was 142.6 minutes $(S=362.1$; Anderson \& Whiston, 2005). Brecklin and Forde's (2001) meta-analysis found the most popular length of program was between 31 and 60 minutes (53.4\%) followed by 61 to 90 minutes (18.5\%), 91 minutes or more (11.6\%), course length $(9.6 \%)$, and 30 minutes or less $(6.8 \%$; Brecklin \& Forde, 2001). There is a large amount of variation in the format and length of date rape intervention programs and the variations are probably caused by an equally wide amount of reasons such as access to students, resources, budget considerations, and a myriad of other reasons.

While date rape attitudes have been studied extensively at the college level, there are far fewer studies which have been conducted at the secondary level. This could be for numerous reasons including the reticence of school administrators, teachers and parents to examine a topic such as rape myth acceptance, and the general difficulty many 
educational researchers face in gaining access to student populations. While there have been some studies conducted on rape myth acceptance at the secondary level, far more have been conducted in senior high schools than in middle schools or junior high schools.

\section{Secondary Date Rape Education}

This section examines research which has examined the ability of interventions to reduce rape myth acceptance in students. Studies conducted at the senior high school level are examined followed by studies conducted at middle and junior high schools.

\section{Studies Conducted in Senior High Schools}

A dating violence prevention program which was conducted as part of required health classes was the focus of a study which evaluated whether a five session program would reduce attitudes justifying the use of dating violence (Avery-Leaf et al., 1997). The participants were 193 students (male, $n=106$; female, $n=87$; White, $79.8 \%$; Hispanic, 11.1\%; Black, 3.8\%; and Asian, 1.4\%) from all the health classes in a senior high school on Long Island, New York, which was described as serving lower middle class students. Health was a required class for all students regardless of academic level. Researchers used a passive form of consent where parents were allowed to return a form in order to opt their child out of the study. None of the parents returned any forms and there was no reported attrition. Classes were randomly assigned to treatment $(n=102)$ or control $(n=90)$. Control group pretest and posttests were administered two weeks before the treatment group received the program to ensure that there was no diffusion of treatment into the control group. Treatment and control groups did not differ significantly pre-intervention. 
Researchers used the Modified Conflict Tactics Scale (MCTS; Straus, 1979) which was a modified version of the Conflict Tactics Scale (CTS) and measures means of partner conflict resolution; the Justification of Interpersonal Violence questionnaire (AIV) which measures acceptance of violence by participants rating the justification of three physically aggressive acts; the Justification of Dating Jealousy and Violence scale (JDV) which was designed for this study and used 10 vignettes to measure acceptance of jealous, coercive and physically aggressive behavior between romantic partners; and a short form of the Social Desirability scale (SDS; Greenwald \& Satow, 1970) which was used to measure participant bias due to self-deception and other deception. Results showed significant decrease in AIV scores justifying use of dating violence $(p<.03)$. No other significant scores were found. This study does not report attrition and it may be because health was a required class at the school and because the method of parent consent was passive. It is rare for interventions in secondary schools which last more than one session to have insignificant attrition.

Another study conducted as part of required classes was conducted by Fay and Medway (2006) who implemented an acquaintance rape education program to 154 South Carolina high school students from a small rural town. The town was selected because it was considered to have high risk factors for sexual violence as $21 \%$ of the population lived below the poverty rate and the town had a rape incidence rate at $62 \%$ higher than the national average. The intervention was included in the high schools" "Freshman 101" curriculum which was a required three week course for freshmen and was conducted by facilitators from outside the school. The program was delivered over two consecutive days and was two hours long. Three classes were randomly chosen as the experimental 
group and three classes as the control group. The intervention consisted of six activities that dealt with assertive behavior, sexual pressure and mixed messages; communication, gender expectations and dating and drinking; rape myths, victim blaming and sexual violence in the media; and date rape definition, problem solving, rape prevention and treatment. The study utilized pretest, posttest and a five month delayed posttest on a modified version of the RMAS (Burt, 1980) which included supplementary questions measuring belief in acquaintance rape myths, and fifteen questions from the Attitudes Toward Dating Violence Scale (Follingstad, 1999) which was in development at the time of the study. The groups did not differ significantly by gender but did by race, with the experimental group having 57\% African American students versus the control group which had 40\% African American students $(p<.05)$. Results showed that experimental group participants showed a reduction in rape myth acceptance at both posttest and delayed posttest $(p<.01)$. This study is of note as it is one of the few studies that included African Americans in the population and because while it used facilitators from outside the school, the interventions were conducted in a classroom setting. The study did not report any issues with attrition; this may be because it would be more difficult to drop out of an intervention that was conducted as part of required classes. While conducting studies in required classes may control attrition levels, attrition rates also tend to be low in one session interventions.

A one-class session intervention on high school students' rape myth acceptance was chronicled by Proto-campise, Belknap and Wooldredge (1998). Three Cincinnati high schools and a total of 417 students participated. Students were 61\% Euro-American, $29 \%$ African-American; half of the participants were 13 or 14 years old. The study used 
a quasi-experimental pretest-posttest design using classroom clusters randomly assigned to either a treatment or control group. Rape myth acceptance was measured using a researcher created inventory of 24 true-false items which incorporated modified questions and topics from previously used inventories (Burt, 1980; Fonow, Richardson, \& Wemmerus, 1992; Gilmartin-Zena, 1988; Warshaw, 1988). The inventory had a Cronbach's alpha of .69 on pretests and .83 on posttests.

The intervention consisted of a lecture and discussion conducted by an outside facilitator which covered topics including legal definitions of rape, effects of rape, rape statistics, rape myths, rape culture, gender roles, and sexuality. Inventories were administered immediately before and after treatment. Separate t-tests conducted on the control group and the treatment group revealed that there was no significant change in the control group posttest while the treatment group showed significantly lower rape myth acceptance posttest $(p<.0001)$. Chi square tests conducted on individual test items showed that the experimental group scored significantly better than the control group on 15 test items $(p<.05)$. The lack of attrition in this study is typical of one-session interventions, though this study is notable as it incorporated a control group design which lends more credence to the generalizability of results.

A one-session intervention which did not use a control group was investigated by Smith and Welchans (2000) who studied a peer led intervention on attitudes toward rape. Participants were 253 students (boys 39\%, girls 46\%, 15\% declined to identify sex) who were mostly in $12^{\text {th }}$ grade from a predominantly White middle class Detroit high school. The 45-minute session was primarily didactic and was implemented by trained high school students. Information was presented concerning sexual assault prevention, rape 
culture, law, providing assistance to victims of sexual assault and male responsibility in preventing sexual assault. The presenters were recruited from the school's student council and peer mediation group. The study utilized a 20 question 4 point Likert-style questionnaire to measured rape attitudes. Pretests revealed that girls had significantly less accepting attitudes toward rape than boys $(p<.001)$. Analysis of treatment effect was done by conducting a separate $t$ test on each item for boys and girls. Results showed that males significantly improved on five items while girls showed statistically significant improvement on 11 items. This study supports previous researchers who have found that girls have lower initial levels of rape myth acceptance than boys. The article did not provide an overall analysis of effect size, so while it is admirable that significant improvement was made on a number of items, it remains unknown as to the size of the effect.

While the previous studies (Avery-Leaf et al., 1997; Fay \& Medway, 2006; Protocampise et al., 1998; Smith \& Welchans, 2000) did not report any issues with attrition, the following reviewed studies were all affected by the loss of subjects during interventions. Beyond reporting attrition, whether a study includes analysis of students who drop out may be an important consideration when judging the effectiveness of an intervention.

\section{High Attrition Studies}

Knowledge and attitudes were examined in a study by Hilton, Harris, Rice, Krans and Lavigne (1998). Participants were $35011^{\text {th }}$ grade students from four high schools from a mixed urban and rural region of a central county in Ontario, Canada. The program consisted of a 1 hour long general assembly where students were given 
information about abusive relationships, options for victims of violence, and laws on assault. Participants then attended two, 1 hour workshops in smaller group formats. Participants were allowed to choose two workshops from a choice of six that were available. The workshops featured programs on sexual assault, verbal aggression, how to help friends experiencing sexual assault, a video presentation on dating violence and two on with coping with anger.

Participants completed pretests, posttests and follow up tests six weeks post intervention. Tests were surveys that measured knowledge of rape, attitudes toward date rape, and self-reported experiences as a perpetrator or victim of sexual violence. The study used a researcher created multiple choice test to measure participants' knowledge of dating violence. Date rape attitudes were measured using a scale adapted from Goodchilds, Zellman, Johnson, and Giarrusso (1988). Self-reported experiences with sexual violence were measured with a questionnaire which also used 10 items from the Modified Conflict, Tactics Scale, Physical Violence subscale (Straus, 1979) and eight questions from a study instrument by Koss and Oros (1982).

The study did not use control groups and attrition played a major factor in this research. Authors reported that attendance was not taken at all of the sessions, so it appeared as if students were free to attend at their leisure. There was a great amount of variation in the number of students who took the pretest $(n=325)$, the posttest $(n=370)$ and follow-up test $(n=489)$. The authors explain that students were confused as to the location of the assembly and missed the administration of the pretest because they arrived late. The actual number of students who actually completed all three tests was 123 $($ female $=50.4 \%$, mean age $=16.5, S=.75)$. 
Data were analyzed using 3 (time) x 2 (sex) repeated-measures ANOVA. Results showed that boys' scores significantly increased from pretest to posttest $(p<.05)$ but not at the follow up test. Pre-tests revealed girls had significantly lower levels of rape supportive attitudes than boys $(p<.05)$. Girls' scores did not significantly change at posttest or follow up test. This may be due to a floor effect as their scores were significantly lower pretest. Attrition rates were high in this study as only $46.5 \%$ of students taking the pretest completed the posttest. Students who did not complete the posttest had lower pretest scores in knowledge than those who completed. The authors conclude that the study did not find the attitude backlash that had been found in other studies; however, due to the high level of attrition the findings related to backlash are equivocal. It could be that the students who would have shown a backlash in scores were more likely to be the ones who dropped out of the study. This idea is supported by the fact that students who completed pretests but not posttests, that is, students who dropped out of the study, had lower pretest informational scores than those who remained. The attrition rate in this study raises serious questions as to the effectiveness of programs that are voluntary. It may be that the students who most need to attend may be the most likely to eschew them. It makes a strong case for the inclusion of date rape education prevention programs in the regular curriculum to be conducted in traditional classroom settings with required attendance.

Attrition rates reduced a study's sample size by $25 \%$ in an examination of social norms theory which was the basis for a study by Hillenbrand-Gunn et al. (2010). The study investigated the effects of a Men as Allies based intervention on high school students' acceptance of rape myths and behaviors. The study began with a sample size of 
283 students from two Midwest high schools, but due to incomplete data sets, analysis was conducted on only 212 participants. The final treatment group size was 124 (58.5\%) and the final control group size was 88 (41.5\%). No information was given regarding the original sizes of each group, nor was any statistical analysis conducted comparing participants who dropped out (25\%) to those who completed the study. The interventions took place in health classes at the schools and were conducted by a sexual violence presenter from outside the school.

The study measured experimental and control groups pretest, posttest and four week follow up scores on the Illinois Rape Myth Acceptance scale - Short Form (IRMASF; Payne et al., 1999), and the What Would You Do? (WWYD; Hillenbrand-Gunn, 2003) which measures male participation in rape supportive behaviors and male willingness to intervene in rape-supportive situations. All participants were also administered Typical Guy (IRMA-T; WWYD-T) variations on the IRMA and WWYD inventories which added "what do you think the typical guy at your school would answer?" to questions in order to determine levels of perceived norms. Participants were also given the Discomfort With Sexist Situations-revised (DSS-R) and the Discomfort With Sexist Situations-Revised Typical Guy (DSS-R-T) which was developed by Kilmartin, Conway, Friedberg, McQuoid, and Tschan (1999). These inventories measured how comfortable participants would be in seven situations that are sexist or rape supportive. Results showed that boys and girls in the experimental group showed significantly lower levels of rape myth acceptance post treatment than both boys and girls in the control group $(p<.05)$. Girls in the experimental group showed significantly greater willingness to behave in rape-preventative and self-protective behaviors post 
intervention $(p<.01)$. The experimental group was also significantly more accurate in their assessment of their peers' attitudes and behaviors post-intervention, which lends support to the hypothesis that a social norms based intervention could decrease perceived norms $(p<.01)$.

This study is worthy of examination as it continues to add to the literature showing attrition rates are a recurring problem in the research. Perhaps of greater importance in this instance, is that this study looks at perceptions of others' rape myth acceptance in the belief that the perceptions of peers' rape myth acceptance may increase individual rape myth acceptance. By showing that the program was effective in reducing incorrect perception of peers' levels of rape myth acceptance, it supports the importance of classroom dialogue that allows for discussion involving student to student exchanges of ideas.

The two previously reviewed studies (Hillenbrand-Gunn et al., 2010; Hilton et al., 1998) show that attrition is a major obstacle for researchers conducting interventions longer than one-session in secondary schools. While research design issues such as whether or not to have control groups also has an important effect on the generalizability of results, researchers in the following reviewed studies attempted to gain a more accurate estimate of effect size by partitioning out subjects according to pretest scores on main analysis of effect.

\section{Studies Using Pretests as Filters for Statistical Analysis}

Researchers examined the effect of an interagency collaborative program on rape knowledge and attitudes (Lowe, Jones, \& Banks, 2007). The intervention was a four day program conducted across four consecutive class periods in two health classes at two 
semi-rural high schools in the south-east United States. Outside facilitators were from a faith-based counseling agency, a rape response center, an agency focused on preventing teen pregnancy, and a counseling agency for sexual abuse victims and perpetrators. The sessions utilized lecture, group discussion and film. Participants were 106 students (age range 14 to 21 years; mean $=15.4$, boys $45.9 \%$, girls $54.1 \%$; White $54.1 \%$, Latino $24.3 \%$, African-American 18.9\%, Asian 2.7\%) from four health classes at the two high schools in the study. Of the 106 original students, only 74 students completed both pretest and posttests resulting in an attrition rate of $30 \%$. No analysis was conducted on students who dropped out of the study.

The study used a researcher created a 4 point Likert-style survey to measure rape attitudes, behavior and knowledge. There were 11 items related to attitudes about sexual activity and sexual harassment and the reliability score for this subscale of the survey was .67. The study used pretests and posttests but did not have a control group. Pretests revealed that boys had higher levels of rape accepting attitudes than girls.

Results of initial t-tests showed no significant reduction in rape accepting attitudes post treatment. Post-hoc, researchers used pretests to divided the students into a Low Tolerance group (scores of 0 to $7 ; n=38$ ) and a Moderate Tolerance group (scores of 8 to $18 ; n=36$ ) and then conducted an ANOVA which revealed a significant reduction in posttest attitudes for the Moderate group when compared to the Low group $(p=.02$, $\eta 2=.07)$. The division of students into groups by pretest is important as it addresses the floor effect which may exist in attitudinal constructs such as rape myth acceptance. By partitioning students by pretest, researchers were able to find a difference that was 
masked by the presence of students whose pretest scores indicated levels of rape acceptance which were already so low as to be unable to be significantly decreased.

A program designed to prevent violence in adolescent dating relationships was evaluated by Lavoie et al. (1995). Participants were $10^{\text {th }}$ grade students $(n=517$; girls, 298; boys, 222; School S mean age 14 years 11 months; School L mean age 15 years) at two high schools in a large city with a majority of French speaking population in the province of Quebec. Schools were randomly assigned to either short form (School S) or long form (School L) intervention. The short form intervention consisted of two class sessions (120-150 minutes) which focused on distinguishing self-control from abusive control, identifying and denouncing social control and blackmail, understanding dating violence, establishing individual rights in relationships, and understanding that responsibility for abuse is not attributed to the victim but to the perpetrator. The instructional methods for the short program were not described; however, the authors noted that the long form consisted added a film on dating violence and an activity where participants wrote fictional letters to a victim and to an aggressor of dating violence.

A 25 item researcher created questionnaire which measured knowledge about violence in dating relationships ( 9 questions) and attitudes toward dating violence (17 questions) was used as pretests and posttests. The attitudinal questions were found to have a Cronbach's alpha of .67. Knowledge items and attitudinal items were analyzed separately.

Analysis showed that there was no significant difference between control and treatment groups at School S or School L. Both schools had pretest scores for girls that were higher (less accepting of dating violence) than boys. Posttest scores showed 
significant increases in scores for both boys and girls on attitudinal items at both schools $(p<.001)$. Analysis also revealed that girls had significantly lower acceptance of dating violence than boys at both pretest and posttest $(p<.001)$. Analysis of knowledge items was conducted individually for each question $(p=.05)$ and used a Bonferroni adjustment. Significant $(p<.0028)$ differences between pre- and posttest scores were found for 5 of 9 knowledge items. Researchers also analyzed attitudinal questions by splitting participants into high and low scoring groups according to pretest scores on the measures of attitudes toward dating violence. The low scoring group (more accepting of dating violence) scored at least 1 standard deviation below their school's mean (School S, $n=$ 44: 2.78 or less; School L, $n=32: 2.62$ or less) while the high scoring group (less accepting of dating violence) scored at least 1 standard deviation above their school's mean (School S: 3.44 or more; School L: 3.28 or more). The researchers purport that results showed "low scorers improved on 16 of the 17 items and that some items, mainly about sexual violence, discriminated the high and low-scoring groups better than others" (Lavoie et al., 1995, p. 521). Unfortunately, the study does not report statistical analysis of the comparison or an item by item analysis as it did with the knowledge questions.

The results of this study show that short interventions can affect secondary students' knowledge and attitudes toward dating violence. It also reinforces other studies' findings that girls generally show lower levels of acceptance of dating violence and rape supportive beliefs than do boys. Finally, it shows that separating participants by pretest scores into low and high scoring groups for statistical analysis can be used to adjust analysis for floor effects to gain a more accurate assessment of significance and effect size. 
In addition to using pretests to separate participants, drop out analysis was conducted in a study which examined adolescent's attitudes toward sexual coercion (Pacifici, Stoolmiller, \& Nelson, 2001). Researchers found that students who were older $(p=.048)$, were more sexually experienced $(p=.026)$, and who had higher levels of selfprofessed use of coercive sexual behavior $(p=.011)$ were significantly less likely to participate in the program. Overall, participants $(n=458)$ were mostly $(93 \%) 10^{\text {th }}$ grade students (mean age 15.6 years, $S=.6$ ) from health education classes in two high schools in the Pacific Northwest. The intervention was conducted through health education classes $(n=23)$ which were randomly assigned to treatment or control. The intervention lasted four class periods and was conducted by classroom teachers. Pretests were conducted on the first class period, while post tests were given at the period following the last period of instruction. The intervention included video materials, role plays, definitions of sexual coercion, identification and discussion of rape supportive attitudes, discussion of risk factors such as drugs and alcohol, a continuum of coercive behavior for different types of relationships, and modeling of appropriate behavior through video and interactive materials. Researchers used the Rape Myth Acceptance Scale (RMAS; Burt, 1980); the Adversarial Sexual Beliefs subscale (ASB; Burt, 1980); the Sex Role Stereotyping subscale (SRS; Burt, 1980); and the Acceptance of Interpersonal Violence subscale (Burt, 1980) as pretests and posttests. Results showed significant reductions in scores (less rape supportive) on the RMAS, ASB, and SRS for treatment groups versus control groups $(p=.026)$. Post-hoc analysis of effect size revealed that participants who had higher pretest scores (more rape supportive) had higher effect sizes. Participants at the pretest mean had small effect size (.25), at 1 standard deviation above the mean had 
moderate effect size (.50), and at 2 standard deviations above the mean had large effect size (1.00). Students whose scores were below the mean (less rape supportive) at pretest did not significantly change post intervention.

This study has several important ramifications for date rape prevention education research. First, by analyzing differences in participants who dropped out, the results of the study make a strong case for implementing dater rape prevention education as part of the regular curriculum in required classes so the students who may need the intervention the most will actually receive it. Secondly, the post hoc analysis shows that future studies should consider separating participants' scores for analysis according to varying levels of pretest scores in relation to the mean. This would allow for more accurate analysis as it could be expected that participants with low levels of rape supportive beliefs may not show as strong effect sizes as those who show higher levels of rape supportive beliefs.

\section{Studies Conducted in Middle or Junior High Schools}

While the above reviewed studies were all conducted at the senior high school level, little research has been conducted on younger students. The following two reviewed studies were conducted with students in junior high or middle schools and continue to show the effects of attrition.

Attrition played a major role in a study conducted by Macgowan (1997) who examined the effect of a 5-session program on knowledge and attitudes toward dating violence using a wait-list control group design. The study, which was conducted at a middle school in the Miami-Dade County School System, began with 802 students from 
sixth, seventh, and eighth grade classes. Students were Black non-Hispanic 72.3\%, Hispanic 18\%, White non-Hispanic 8.3\%, and Asian/Native American 1.3\%.

Researchers eliminated students with learning disabilities, students who missed more than one session, and students who left more than 3 items of the 22 item inventory blank. There were 440 students left after elimination, which equates to a $40 \%$ attrition rate of students who took the pretest. No analysis was conducted on the pretest scores of the dropouts. Posttest completers were 247 girls (56.1\%) and 193 males (43.9\%) with an age range of 11 to 16 years $($ mean $=12.6)$.

The program was conducted by five teachers who underwent a 3 hour training program and lasted 5 consecutive school days. Classroom clusters were randomly assigned to treatment $(n=241)$ or control $(n=199)$. A researcher created 22-item, 4point Likert-style scale was used to measure: knowledge about relationship violence, attitudes about nonphysical violence, attitudes about physical/sexual violence, and attitudes related with dating violence. The measure had a Cronbach's alpha of .73. Pretest scores revealed significant differences in rape myth acceptance between treatment and control groups $(p \leq .05)$. ANCOVA using pretests scores as a covariate revealed a significant difference between treatment and control on posttest scores, with treatment students holding less accepting attitudes toward violence across the four subscales $(p<$ .001). Individual item analysis revealed that boys showed a significant decrease on an item which asked: "It's O.K. for a boy to force a girl to have sex with him if she has flirted with him or led him on" (Macgowan, 1997, p. 231).

The results of this program, like others with high attrition rates and no analysis of drop out participants, need to be viewed with extreme caution. In addition to the attrition, 
the fact that the groups were not equivalent on pretests greatly diminishes the results. The study does show that research can be conducted on sexual violence prevention with participants as young as sixth grade.

High attrition rates plagued another study which examined the results of an after school dating violence prevention program in an urban Detroit charter school (Weisz \& Black, 2001). Participants were African-American seventh grade students with a mean age of $12.84(S=.54)$. Students who volunteered for the after school program for reducing dating violence made up the treatment group while students enrolled in other after school activities were used as a control group. Both treatment and control groups were given pretests, posttests and follow up inventories six months after treatment. Researchers used self-developed instruments to measure knowledge, attitudes, behavior/anticipated behavior and incidence of victimization or perpetration. Questions were drawn from various instruments such as the Knowledge of Sexual Assault (RAVE, 1997), the Rape Attitude Scale (Hall, Howard, \& Boezio, 1986), the Youth Dating Violence Survey (Foshee, 1994) and the Teen Life Relationship Questionnaire (Kantor, 1996). The program was based on the "Reaching and Teaching Teens to Stop Violence" (Nebraska Domestic Violence Sexual Assault Coalition, 1995). The attitude questionnaire essentially measured rape myth acceptance as it was made up of questions such as "Often, girls falsely report a rape in order to get attention," and "Many girls make a guy think they want sex when they really don't, just to tease a guy” (Weisz \& Black, 2001, p. 93). The attitudinal scale's Cronbach's alpha was .68.

The intervention was 12 sessions and included lectures, modeling, role-plays, experimental exercises and discussions. Authors report that role-plays were used 
extensively as participants were very responsive to them. Pretest scores revealed significantly higher levels of rape supportive beliefs in the treatment group versus the control group $(p<.05)$. Pretest scores also revealed that girls had significantly higher knowledge levels and less rape supportive attitudes than boys $(p<.05)$. Results showed that students in the treatment group had significantly higher scores (less rape supportive) versus the control group on both knowledge and attitude scores posttest $(p<.10)$.

Attrition rate in this study seriously affects the efficacy of the results and reinforces the belief that date rape education may not be suitable for voluntary activity. Of the 46 students who chose to be in the treatment program, only 27 completed posttests and only 21 completed follow ups. The control group started with 20 students but by the time follow ups were administered, the control group had dwindled to nine students. Authors report numerous incidences of participants, mainly boys, skipping the intervention in order to roam the halls and bathrooms or to leave campus without permission. Students were also able to drop out of the study to join other after school activities. Unlike the previous study, researchers did not analyze the scores of drop outs to determine if they had significantly different pretest scores than those who remained in the study. It could be that students who had higher levels of rape supportive beliefs would be more likely to skip sessions or drop out entirely as the information may make them feel defensive; however, without the aforementioned analysis this is merely conjecture. As in the previous study, this study shows that date rape education may be something that is not suitable for voluntary activities and may be better served being part of the standard curriculum. 


\section{Summary}

Date rape is a subset of acquaintance rape where the victim knows his or her assailant and is in any type of relationship which may be deemed romantic or potentially romantic. Date rape is an underreported crime (Koss \& Oros, 1982; Koss, 1985; Koss et al., 1988) and may be due to adherence to rape myths in women (Peterson \& Muhlenhard, 2004). Rape myth acceptance has also been correlated with men's proclivity to rape in numerous studies (Bohner, Jarvis et al., 2005; Bohner et al., 1998); Check \& Malamuth, 1983; Chiroro et al., 2004; Tieger, 1981). Furthermore, Brownmiller (1975) argued that rape or the fear of rape is a critical element in the domination of women in society and that rape myth acceptance is the cornerstone of this continued hegemony. The impact of peers' perceived levels of rape myths has been shown to have an effect on rape myth acceptance and in proclivity to rape (Bohner et al., 2006). In an effort to reduce date rape, interventions have been conducted in an effort to reduce rape myth acceptance at the college and the secondary school level (Brecklin \& Forde, 2001; Ting, 2009).

Interventions conducted at the secondary level have been primarily didactic in nature and have been plagued by problems with attrition. Some studies have found a backlash effect in boys with high initial levels of rape myth acceptance (Jaffe et al., 1992) and while studies have attempted to reduce rape myth acceptance without backlash, these studies' results are weakened by attrition (Hilton et al., 1998). Most studies have found that girls have lower initial levels of rape myth acceptance than boys and that there is a floor effect in rape myth acceptance which prevents significantly reducing some participants adherence to rape myths (Lavoie et al., 1995; Smith \& Welchans, 2000). 
Researchers have used pretests as filters to gain a more accurate reading of significance and effect size (Lavoie et al., 1995; Lowe et al., 2007; Pacifici et al., 2001).

There are several gaps in the body of research concerning rape myth acceptance reduction. Few research studies have been conducted on interventions as part of required classes other than Health and freshman seminar courses. Dating generally begins while students are at the middle school level (Slep et al., 2001); however, few studies have been conducted at the middle school level (Macgowan, 1997; Weisz \& Black, 2001). Many studies conducted at the secondary level are no longer than one session (Giacopassi \& Dull, 1986; Smith \& Welchans, 2000) while others are plagued by attrition (HillenbrandGunn et al., 2010; Hilton et al., 1998; Lowe et al., 2007; Weisz \& Black, 2001). Moreover, few studies conduct appropriate analysis of subjects who drop out (Pacifici et al., 2001).

This study examined the effect of a reader response based unit of Speak on adolescents' rape myth acceptance. This unit was part of required language arts classes in a middle school and addressed gaps in the research in the following ways:

1. By using a novel students were provided with an extended aesthetic transaction with literature that afforded them the opportunity to reexamine previously held beliefs about date rape. This may also have prevented a backlash in boys with high levels of initial rape myth acceptance as they were afforded the opportunity to vicariously experience the trauma a victim of date rape suffers.

2. By utilizing small group and whole group discussion which is often absent or minimal in large group presentations, the present study afforded 
students the opportunity to gain accurate estimations of peers' acceptance of rape myths which may have led to reductions in individual levels of rape myth acceptance.

3. By being a full five week instructional unit, the present study sought to have a greater impact on rape myth acceptance than shorter interventions.

4. By being part of required language arts classes, the present study sought to reduce the attrition rates that have been endemic to studies lasting more than one session and to studies conducted outside of required academic classes.

5. By using classroom teachers who are regular faculty at the school where the study is conducted, participants may have taken the issue more seriously than interventions which are conducted by outside facilitators whom students may not take as seriously.

6. By using a thorough analysis of participants who drop out of the study, this study attempted to produce results which are more transparent.

7. By using pretest scores as cutoffs for statistical analysis, this study may have had more accurate results related to significance, effect size, and backlash.

8. By designing and validating an inventory specifically designed for modern students in vernacular and situation, this study hoped to get a more accurate estimation of rape myth acceptance in adolescents.

The purpose of this study was to measure the effect of a reader response instructional unit of the novel Speak on adolescents" rape myth acceptance. The 
following chapter will describe the methods this study used to determine the effect of treatment and to address the aforementioned gaps in the literature. 


\section{CHAPTER III}

\section{METHODS}

The purpose of this chapter is to describe the research methods that were used in this study. The chapter discusses design, participants, procedures, instruments, and statistical analysis. The participants in the study are students.

\section{Design}

This study used a quasi-experimental pretest-posttest design with a wait list control group in order to measure the effect of reading the novel Speak on adolescents' rape myth acceptance. A convenience sample of seven eighth grade language arts classrooms was used to create treatment and control groups for the study. The classes in this study were selected because the researcher was a language arts teacher at the school and instructed four of the classes in the study. Another language arts teacher at the school site volunteered to participate and instructed the other three classes that were included in the sample.

\section{Participants}

Participants were 139 eighth grade students registered for language arts, advanced language arts, or inclusion language arts, at a Title I middle school in a large South Florida school district. Participants ranged in age from 13 to 17 years old. The school's population was about 50\% Hispanic/Chicano/a, 37\% African American, and 10\% Caucasian during the year the study was conducted. The free-reduced lunch rate was about $85 \%$. Approximate values are given to protect confidentiality. 


\section{Setting}

The intervention was conducted in eighth grade language arts classes on a 1 hour 45 minute block schedule that met every other school day. All classes were coeducational and consisted of participants in regular or advanced level classes. See Table 1 for detailed information.

\section{Table 1}

Class Details

\begin{tabular}{llllll}
\hline Class & Teacher & Condition & Boys & Girls & Type \\
\hline 1 & A & Treatment & 13 & 8 & Regular \\
2 & A & Treatment & 6 & 7 & Advanced \\
3 & A & Control & 5 & 13 & Advanced \\
4 & A & Control & 12 & 8 & Regular \\
5 & B & Treatment & 19 & 6 & Regular \\
6 & B & Treatment & 11 & 12 & Regular \\
7 & B & Control & 8 & 11 & Regular \\
\hline
\end{tabular}

\section{Procedures}

The classroom clusters were randomly divided into either treatment or control groups using a random number generator. Because there were seven classes available for inclusion in the study, a coin flip was used to determine that four classes were assigned to treatment and three classes were assigned to control. Teacher A had two treatment classes $(n=38)$ and two control classes $(n=34)$, while Teacher B had two treatment 
classes $(n=48)$ and one control class $(n=19)$. Classrooms ranged in size from 15 to 28 participants.

\section{Informed consent}

Participants in both the treatment and control groups were given parental consent (see Appendix A) and student assent (see Appendix B) forms approximately two weeks before the study began. Both forms explained that the purpose of the study was to examine attitudes toward teen dating violence and that teen dating violence and prevention is a required by the school district where the study was conducted. Both forms explained that the instruction to be provided in the study is a required part of the language arts curriculum and that the consent was only needed to have the participants complete the inventories. Both forms explained that the participants' privacy would be protected by the use of anonymous inventories. Participants were only required to place the last five digits of their student identification number on the inventories used as pretests and posttests. Once the posttest data was entered into SPSS - 19/PASW, the original inventories were destroyed to guarantee participants' privacy.

\section{Development of the Program}

The researcher was one of two teachers who implemented this program. The researcher has taught the novel Speak for 8 years. Over the course of teaching this novel, numerous students have approached him who have been victims of sexual assault. As a result, the school TRUST (To Reach Ultimate Success Together) counselor was invited to conduct classroom presentations on teen dating violence and date rape. In order to assess the effectiveness of the novel unit separately from the TRUST counselor's 
presentation, the TRUST counselor's presentation was conducted at the end of the unit after posttests were completed.

\section{Teachers}

This study was conducted with two teachers at the same school site. Both teachers are male and regularly teach eighth grade language arts as a primary teaching responsibility. Each teacher is described in detail below.

Teacher A. Teacher A is the researcher of this study and has been a public school teacher for 8 years at the school site used in this study and has taught the novel Speak for 8 years. Teacher A has a Master's Degree in English Education from Florida International University and this dissertation is part of the requirements for a doctorate in Curriculum and Instruction with a focus in English Education at Florida International University.

Teacher B. Teacher B has been a public school teacher for $8 \frac{1}{2}$ years at the school site used in this study. Teacher B has taught the novel Speak for 6 years. Teacher B is working toward a Master's Degree in English Education at another South Florida university.

\section{Speak Unit Instruction}

The Speak unit lasted 5 weeks. The school where the study was conducted is on a block schedule, so classes met every other day for 1 hour and 45 minutes. Reading was done in class using copies of Speak that were paid for by a grant from the Adolescent Literature Assembly of the National Council of Teachers of English. Reading consisted of sustained silent reading, jump-in reading, and teacher to class reading.

Comprehension was assessed using short answer questions. It was not possible to have 
the same questions for each class period as variation in the amount of reading completed by each class was affected by numerous factors such as student questions, unplanned discussions, assemblies, fire drills, etc.

The Speak unit used three major reader response assignments. Each assignment was completed in class and written in a writing journal that remained in the participant's possession. Writing time was approximately 45 minutes for each assignment. Writing was followed by small group discussion that lasted approximately 20 minutes. Small group discussions were followed by whole class discussion, which lasted approximately 45 minutes. There were four reader response papers/discussions:

1. Write a letter to Melinda convincing her she was raped and convince her to get help.

2. Completed after page 82 where there is a scene where Melinda passes out during a frog dissection that is symbolic for her rape.

3. Do you think Melinda was raped? Completed after page 136 where Melinda flashes back to her rape in detail.

4. Pretend you are a friend of Andy Evans. Write a conversation where you attempt to convince him that what he did to Melinda was rape. Completed after the novel was completed.

5. If a girl you saw at a party was making out with a guy, and the next day told you that he had raped her, would you believe her? Why or why not? Completed after the novel was completed.

Discussion guidelines. Guidelines were developed for conducting small group and large group discussions. Small group discussions featured three or four participants 
in each group. Discussions began with the participants sharing each of their answers to the reader response prompts. Participants were asked to discuss the topic and to arrive at a group conclusion to the prompt. Teachers did not supervise the small groups in order to allow participants to speak freely as much as was possible in a classroom setting. Participants were asked to pick a group leader who would report their findings to the large group.

Large group discussions began with a student from each group reporting conclusions to the class. Participants were allowed to respond and discussions quickly developed. Powell (1999) avers that classrooms should encourage diverse perspectives through genuine classroom discussions and this was accomplished by teachers encouraging students to explore contradictions, by posing questions that showed alternate perspectives, and by letting the students voices be the main part of the dialogue. In order to create a classroom culture where students could feel free to share opinions that were both supportive and unsupportive of date rape, teachers avoided adopting a superior position where they would "correct" participants for responses deemed unacceptable or undesired. Teachers encouraged participants to be open and informed participants that there were no correct or incorrect answers. Participants were asked to avoid using language which was profane. During discussions, teachers assumed a Socratic role and used questions to draw out differing points of view from other participants and to encourage participants to reconsider positions.

Other instruction. In addition to the reader response assignments, the Speak unit contained instruction and assignments covering traditional literary instruction. A major segment of instruction on Speak addressed symbolism in the novel. Several elements of 
the novel were analyzed in depth including the tree under which Melinda was raped, the tree that was her art project, and the tree on her front lawn. Furthermore, participants wrote papers comparing and contrasting the rape scene in Speak to the rape of Callisto in Ovid's version of the myth and to the source of Original Sin and the Garden of Eden in Genesis. Intertextuality was also examined through the appearance of The Scarlet Letter in Melinda's English class and by the poster of Maya Angelou which hangs in the janitor's closet at Melinda's school. Author's diction was examined in depth in an out loud reading and analysis of the frog dissection scene in Speak. The authenticity of setting in Speak was analyzed with special attention paid to cliques in secondary schools. Additional instruction also covered character, plots and subplots, theme, point of view, and general comprehension.

Control group instruction. Participants in the control group $(n=57)$ participated in a concurrent five week instructional unit of Shakespeare's Julius Caesar. The No Fear Shakespeare version was used. Participants completed instruction covering elements of tragedy, characteristics of the tragic hero, Shakespearean use of the supernatural and omens, and rhetoric. Participants completed the following reader response exercises in writing journals: (a), Do you agree with Brutus's decision to kill Caesar?; (b), Write a conversation where Brutus is convinced not to kill Caesar; and (c), Is Brutus heroic? Write a list of characteristics you think a hero should have. Writing was followed up by small group and large group discussions.

\section{Pretests}

One class before the Speak unit started, participants were given pretest inventories to measure their rape myth acceptance. Participants were asked not to put their names 
on either of the inventories in order to guarantee confidentiality. Participants were asked to place the last five digits of their seven digit student identification number on their inventories. Pretest inventories were the Rape Myth Acceptance Scale (Burt, 1980) and a researcher created scale, the Adolescent Date Rape Myth Scale. The pretest inventories also contained a short demographic questionnaire that asked for the respondent's gender, age, and ethnicity. The instructor for each class read the inventory instructions to the class. Participants were informed that the inventories were confidential, that the inventory answers should be a reflection of their own opinions of date rape, and that there were no correct answers. They were reassured that no one other than the researcher would see their answers, and that their answers would not have any effect on their grades.

\section{Posttests}

Treatment and control groups were posttested after the final unit exams on their respective readings. Testing of the Adolescent Date Rape Myth Scale and Rape Myth Acceptance Scale was conducted between the pretest and posttest dates. Because the Adolescent Date Rape Myth Scale was shown to be correlated with the Rape Myth Acceptance Scale, posttests consisted only of the Adolescent Date Rape Myth Scale (see Chapter 4 for results). Participants were asked not to put their names on either of the inventories in order to guarantee confidentiality. Instead, they placed the last five digits of their student identification number on their inventories. The instructor for each class read the inventory instructions to the class. Participants were informed that the inventories were confidential, that the inventory answers should be a reflection of their own opinions of date rape, and that there were no correct answers. They were reassured 
that no one other than the researcher would see their answers, and that their answers would not have any effect on their grades.

\section{Debriefing}

Treatment groups received a presentation from the school TRUST counselor regarding date rape and teen dating violence. Participants were given information regarding local help centers for victims of rape and were given the opportunity to discuss any issues that arose during the reading of Speak. The numbers of help centers remained on the teachers' walls for the remainder of the school year. The control groups were also given the same presentation at the same time.

\section{Wait List Control Group}

Immediately after the posttests, control group participants began their reading and instructional unit of the novel Speak. The only difference in the Speak unit between the treatment and control groups was that the control group participants received their presentation from the TRUST counselor at the beginning of the unit.

\section{Instruments}

This study used two inventories, the Rape Myth Acceptance Scale (RMAS; Burt, 1980) and the Adolescent Date Rape Myth Scale, a researcher created instrument designed to measure rape myth acceptance specifically in adolescents.

\section{Rape Myth Acceptance Scale}

The Rape Myth Acceptance Scale (see Appendix C) consists of 19 questions that were designed to measure a respondent's level of adherence to rape supportive beliefs such as rape is justifiable in some cases and that victims are often to blame for their own rapes. The first 11 questions give respondents statements that embody common rape 
myths and are answered on a 7-point Likert-style scale $(1=$ strongly disagree to $7=$ strongly disagree). The next two questions use a 4-point Likert-style scale to ask respondents to estimate the percentage of women who lie about rape as a form of revenge and to explain unwanted pregnancies $(1=$ almost none, $2=$ about one-fourth, $3=$ about one-half, and $4=$ almost all). The last 6 questions ask respondents to rate their belief of a rape claim from various types of people on a 5-point Likert-style scale $(1=$ never, $2=$ rarely, $3=$ sometimes, $4=$ frequently, and $5=$ always). Higher scores on the Rape Myth Acceptance Scale are indicative of a higher level of adherence to rape myths.

The RMAS was tested for internal consistency by Burt (1980) who provided a Cronbach's alpha of .875. Subsequent studies have found it to have Cronbach's alpha values of .92 (Marshall \& Hambley, 1996), .90 (Worling, 1995) and .84 (Sawyer, Thompson, \& Chicorelli, 2002). Construct validity has been investigated by Malamuth (1989) who found high Rape Myth Acceptance Scale scores to be correlated $(r=.41, p<$ .00001) with high scores on the Attraction to Sexual Aggression Scale (Malamuth, 1989). The Rape Myth Acceptance Scale has also been significantly correlated with scores on dogmatism $(r=.51, p<.05)$ and significantly inversely correlated with scores on trustworthiness ( $r=-.46, p<.05$; Ashton, 1982). According to Shultz and Whitney (2005), reliability coefficients of over .70 are acceptable scores for an instrument to have achieved internal reliability.

The Rape Myth Acceptance Scale is the seminal inventory for measuring rape myth acceptance and has been used to assess adherence to rape myths in numerous studies (Dallager \& Rosen, 1993; Fonow et al., 1992; Lenihan, Rawlins, Eberly, Buckley, \& Masters, 1992; Linz, Fuson, \& Donnerstein, 1990; Rosenthal, Heesacker, \& Neimeyer, 
1995). The Rape Myth Acceptance Scale has also been used as a measure of the effectiveness of interventions designed to reduce rape myth adherence specifically with secondary level students (Fay \& Medway, 2006; Mandelblatt, 1998; Pacifici et al., 2001). Researchers have also used the Rape Myth Acceptance Scale as a basis for designing new inventories to assess rape myth acceptance with secondary level students (Proto-Campise et al., 1998).

\section{Adolescent Date Rape Myth Acceptance Scale}

This study also used a researcher created instrument, the Adolescent Date Rape Myth Scale which was designed to measure rape myth acceptance in adolescents (see Appendix D). Fink (1999) urges researchers to create survey questions that are easily understood by respondents and the purpose of the Adolescent Date Rape Myth Scale is to provide an inventory that is worded in language that adolescents can understand.

Furthermore, the Adolescent Date Rape Myth Scale presents scenarios which adolescents can relate to in order to get a more accurate measure of rape myth acceptance. The Adolescent Date Rape Myth Scale includes questions that are modified versions of questions from the Rape Myth Acceptance Scale (Burt, 1980), the Illinois Rape Myth Acceptance Scale (IRMAS; Payne et al., 1999), the High School Experiences Scenarios (Fenstermaker, 1989) and the College Date Rape Attitude Survey (CDRAS; Lanier \& Green, 2006). The adaptation of questions that have been used successfully in previous instruments is recommended by Fink (1999) when designing survey questions. The need for adaptation of questions is clear in the following example: the IRMAS asks respondents if "women caught having an illicit affair sometimes claim it was rape" (Payne et al., 1999, p. 49). Many adolescents may not know what an "illicit affair" is and 
may be better served with the use of language that they could easily comprehend.

Moreover, this study is specifically geared toward adolescents and date rape; ergo, an inventory which focused on the target population (adolescents) and the target variable (acceptance of date rape myths) would provide the most accurate estimate of adolescents' rape myth acceptance.

There is ample precedence in the literature of rape myth research which incorporates researcher created inventories for use with secondary students (ClintonSherrod, Morgan-Lopez, Gibbs, Hawkins, Hart, Ball, Irvin, \& Littler, 2009; Hilton et al., 1998; Jaycox, McCaffrey, Eiseman, Aronoff, Shelley, Collins, \& Marshall, 2006; Lavoie et al., 1995; MacGowan, 1997; Lowe et al., 2007; Rayburn, Jaycox, McCaffrey, Ulloa, Zander-Cotugno, Marshall, Shelley, 2006; Smith \& Welchans, 2000; Weisz \& Black, 2001). In fact, in a recent meta-analysis of secondary programs designed to reduce dating violence, nine out of 13 studies reviewed used researcher created instruments to measure rape myth acceptance in adolescents enrolled in secondary schools (Ting, 2010).

The Adolescent Date Rape Myth Scale consisted of 20 questions using a 5-point Likert-style scale for each $(1=$ strongly disagree, $2=$ disagree, $3=$ neither agree nor disagree, $4=$ agree, $5=$ strongly disagree), possible scores ranged from 20 to 80 . Similar to the Rape Myth Acceptance Scale, the Adolescent Date Rape Myth Scale is scored so that higher scores are indicative of a higher level of adherence to rape myths.

\section{Statistical Analysis}

Data were entered into SPSS/PASW statistical program and analyzed using PASW 18. Tests were conducted on null hypotheses using alpha $=.05$. Sample size power analysis reveals that to detect a standardized treatment effect of .5 with a power 
level of .80, sample sizes for two groups should be 20 participants per group. With a conservative estimate of 120 students of the possible 160 students participating, power analysis revealed that at alpha $=.05$, with a power level of .80 , there would be a $99.7 \%$ chance to detect a standardized effect size of .5 , and a $77.5 \%$ chance to detect a standardized effect size of .25 .

\section{Null Hypotheses and Analysis}

Null hypotheses were analyzed utilizing the following statistical procedures:

1. When adjusted for pretest rape myth acceptance, the mean posttest rape myth acceptance for participants who have read Speak will be greater than or equal to the mean posttest rape myth acceptance of participants who do not read Speak $(p<.05)$.

A 2 (group) x 2 (sex) x 2 (instructor) ANCOVA was conducted to measure differences in rape myth acceptance between treatment and control groups, using pretest rape myth acceptance as a covariate.

a. Participants who show a high level of pretest rape myth acceptance and read Speak will have a higher or equal mean myth acceptance scores adjusted for pretest than participants who did not read Speak $(p<.05)$

Participants were divided according to pretest scores into the following groups: High rape myth acceptance: participants with pretest scores 1 standard deviation above the mean of all pretest rape myth acceptance scores; and Low rape myth acceptance: participants with pretest scores 1 standard deviation below the mean of all pretest rape 
myth acceptance scores. An ANCOVA using pretest rape myth acceptance as a covariate was conducted comparing posttest rape myth acceptance for participants in the High rape myth acceptance group who read Speak (High rape myth acceptance Treatment) to participants in the High rape myth acceptance group who did not read Speak (High rape myth acceptance Control; $p<.05)$.

b. Boys who show a high level of pretest rape myth acceptance and read Speak will have a higher or equal mean myth acceptance scores adjusted for pretest than boys who did not read Speak $(p<.05)$.

An ANCOVA using pretest rape myth acceptance as a covariate was conducted comparing posttest rape myth acceptance for boys in the High rape myth acceptance group who read Speak (High rape myth acceptance Treatment Boys) to boys in the High rape myth acceptance group who did not read Speak (High rape myth acceptance Control Boys; $p<.05)$.

c. Participants who show a low level of pretest rape myth acceptance and read Speak will have equal mean myth acceptance scores adjusted for pretest than boys who did not read Speak $(p<.05)$.

An ANCOVA using pretest rape myth acceptance as a covariate was conducted comparing posttest rape myth acceptance for participants in the Low rape myth acceptance group who read Speak to participants in the Low rape myth acceptance group who did not read $\operatorname{Speak}(p<.05)$. 


\section{Null Interaction Hypotheses and Analysis}

The following null interaction hypotheses were tested using a 2 (group; treatment or control) x 2 (sex) x 2 (instructor; A or B) ANCOVA $(p<.05)$.

1. In the population, there will be no interaction between group and sex in posttest rape myth acceptance adjusted for pretest rape myth acceptance $(p<.05)$.

2. In the population, there will be no interaction between group and instructor in posttest rape myth acceptance adjusted for pretest rape myth acceptance $(p<.05)$.

3. In the population, there will be no interaction between sex and instructor in posttest rape myth acceptance adjusted for pretest rape myth acceptance $(p<.05)$.

\section{Statistical Analysis of Adolescent Date Rape Myth Scale}

Because the Adolescent Date Rape Myth Scale is a new inventory, it was examined using several statistical procedures. Scores from the Adolescent Date Rape Myth Scale were correlated with scores from the Rape Myth Acceptance Scale using Pearson Product Moment Correlation to establish content validity. Cronbach's alpha was also calculated for the Adolescent Date Rape Myth Scale to determine internal consistency. Exploratory factor analysis was also conducted on the responses to determine the underlying constructs of the Adolescent Date Rape Myth Scale. Finally, Cronbach's alpha was computed on the factors revealed through factorial analysis. 


\section{Delimitations of Study}

The exclusionary and inclusionary choices of the researcher created several delimitations which may limit the generalizability of the study. The novel used in the study, Speak, deals with a date rape between a non-Hispanic/Latina/o Caucasian male rapist and a non-Hispanic/Latina/o Caucasian female victim. There are many other types

of rapes such as marital rape, gang rape, stranger rape, and acquaintance rape and the results of this study are not intended to be generalized beyond date rape myths. Further, there are female on male rapes, male on male rapes, and female on female rapes, and the results of this study are not intended to be generalized beyond the male on female date rape scenario. Finally, there are rape myths that take into account the racial identity of the rapist and the victim; however, the results of this study are not intended to be generalized to those myths.

As in most secondary date rape research, this study did not examine selfprofessed proclivity to rape. A Likert-style scale was used to measure rape myth acceptance which was designed for this study. This study did not measure knowledge about rape or measure past behavior either in terms of perpetration or victimization. The effect of social desirability is important in studies which use self-report measures but in order to keep the assessments as minimally intrusive as possible, measures of social desirable behavior were not used. Finally, this study did not utilize analysis of student work or discussions, nor did it include interviews with participants or teachers. 


\section{CHAPTER IV}

\section{RESULTS}

The purpose of this chapter is to present the results from the intervention of a reader response based reading of the novel Speak on adolescents' rape myth acceptance. The chapter presents sample data, results of analyses of the Adolescent Date Rape Myth Acceptance Scale, and results of analyses of the null hypotheses.

\section{Sample}

Participants were eighth grade students $(n=139)$ from five language arts classes in a Miami-Dade County Public School System Title I middle school. The sample was $53.2 \%$ boys $(n=74)$ and $46.8 \%$ girls $(n=65)$. Chi square analysis did not reveal any significant difference between number of boys and number of girls in the study $\chi^{2}(1, N=$ $139)=.58, p=.45$. Participants' age (see Table 2$)$ ranged from $13-17$ years $(\bar{x}=14.3, s$ $=.81)$

Table 2

Age of Participants

\begin{tabular}{lcc}
\hline Age & Frequency & Percent \\
\hline 13 years & 19 & 13.70 \\
14 years & 67 & 48.20 \\
15 years & 44 & 31.70 \\
16 years & 8 & 5.80 \\
17 years & 1 & .70 \\
Total & 139 & 100.00 \\
\hline
\end{tabular}


Participants in the study were $52.5 \%$ Hispanic/Latino/a $(n=73), 34.5 \%$ African American $(n=48), 5.8 \%$ Caucasian $(n=8), 2.9 \%$ Caribbean $(n=4), 1.4 \%$ Native American $(n=2)$, and $1.4 \%(n=2)$ Other. One student declined to provide information regarding race/ethnicity.

Four classes (student $n=82$ ) were assigned to treatment and three classes (student $n=57$ ) were assigned to control. There were two teachers (Teacher A and Teacher B) in the study. Teacher A had four classes (total student $n=72$; two treatment classes, student $n=38$; two control classes, student $n=34$ ) and Teacher B had three classes (total student $n=67$; two treatment classes, student $n=48$; one control class, student $n=19$ ).

The treatment group consisted of $59.8 \%$ boys $(n=49)$ and $40.2 \%$ girls $(n=33)$. Chi square analysis did not reveal significant differences in treatment group membership based on $\operatorname{sex} \chi^{2}(1, N=82)=3.12, p=.07$. The control group consisted of $43.9 \%$ boys $(n$ $=25)$ and $56.1 \%$ girls $(n=32)$. Chi square analysis did not reveal significant differences in control group membership based on $\operatorname{sex} \chi^{2}(1, N=57)=.86, p=.35$.

All participants completed the Rape Myth Acceptance Scale (RMAS; Burt, 1980) and the Adolescent Date Rape Myth Acceptance Scale as pretests. Pretests scores on the Rape Myth Acceptance Scale did not differ significantly $(F(1,137)=.21, p=.65)$ between treatment $(\bar{x}=60.39, s=12.37)$ and control $(\bar{x}=59.4, s=12.47)$. Levene's Test of equality of error variances did not reveal significant difference between treatment and control variance on the pretest Rape Myth Acceptance Scale $(F(1,137)=.08, p=$ $.78)$.

Pretest scores on the Adolescent Date Rape Myth Scale did not differ between treatment $(\bar{x}=59.59, s=11.22)$ and control $(\bar{x}=57.11, s=8.42 ; F(1,137)=2.0, p=$ 
.16). Levene's Test of equality of error variances did not reveal significant difference between treatment and control variance on the Adolescent Date Rape Myth Scale ( $F(1$, $137)=3.18, p=.08$ ). Girls showed significantly lower levels of pretest rape myth acceptance than boys on the Rape Myth Acceptance Scale $(p<.05)$ and on the Adolescent Date Rape Myth Scale $(p<.001)$.

\section{Analysis of Inventories}

The following section presents data and analyses of the Rape Myth Acceptance Scale and Adolescent Date Rape Myth Scale.

\section{Rape Myth Acceptance Scale}

Pretest scores on the Rape Myth Acceptance Scale ranged from 29 to 87. The pretest scores on the Rape Myth Acceptance Scale yielded a Cronbach's alpha of .77. Split-half reliability was conducted on the Rape Myth Acceptance Scale. In splitting the items, one half contained items $1,3,5,7,9,11,13,15,17$, and 19; the other half contained items $2,4,6,8,10,12,14,16$, and 18 . Between forms correlation was .65, while Guttman Split-Half coefficient was .78.

\section{Adolescent Date Rape Myth Acceptance Scale}

Pretest scores on the Adolescent Date Rape Myth Scale ranged from 29 to 87. Pretest Adolescent Date Rape Myth Scale scores yielded a Cronbach's alpha of .82. Split-half reliability was conducted on the Adolescent Date Rape Myth Scale. In splitting the items, one half contained items $1,3,5,7,9,11,13,15,17$, and 19; the other half contained items $2,4,6,8,10,12,14,16,18$ and 20. Between forms correlation was .74, while Guttman Split-Half coefficient was .85 . 
Because the Rape Myth Acceptance Scale is a widely tested and accepted measure for rape myth acceptance, bivariate correlation was conducted between the Rape Myth Acceptance Scale and the Adolescent Date Rape Myth Scale. Results revealed a significant correlation value of .60 between the Rape Myth Acceptance Scale and Adolescent Date Rape Myth Scale $(p=.01)$.

\section{Factor Analysis}

Exploratory factor analysis was conducted on the Adolescent Date Rape Myth Scale pretest scores to determine factors underlying the inventory. There were 139 participant cases for the Adolescent Date Rape Myth Scale pretest which consisted of 20 items. Analyses were conducted with SPSS (PASW) version 19.

Kaiser-Meyer-Olkin (KMO) was calculated to determine if the sample size was adequate for factor analysis. Values of over .6 are desirable for quality factor analysis (Tabachnick \& Fidell, 2007). Analysis revealed a KMO of .78; therefore, the sample was accepted as large enough and factor analysis was conducted on Adolescent Date Rape Myth Scale items.

Bartlett's Test of Sphericity was conducted to determine if the correlation matrix is an identity matrix, which would indicate that factor analysis is inappropriate. Achieving significance on Bartlett's under .05 indicates that the correlation matrix is not an identity matrix. Analysis revealed a significant Bartlett's value $(p<.001)$. Factor analysis utilized principal components extraction based on Eigen values greater than 1 with Varimax rotation. Examination of the Scree Plot (Figure 1) revealed two main components with Eigen values over $1($ Component $1=4.84$, Component $2=1.83$ ) before dropping off into a slowly diminishing plateau-like line at Component 3 (1.37). 
Figure 1

Scree Plot

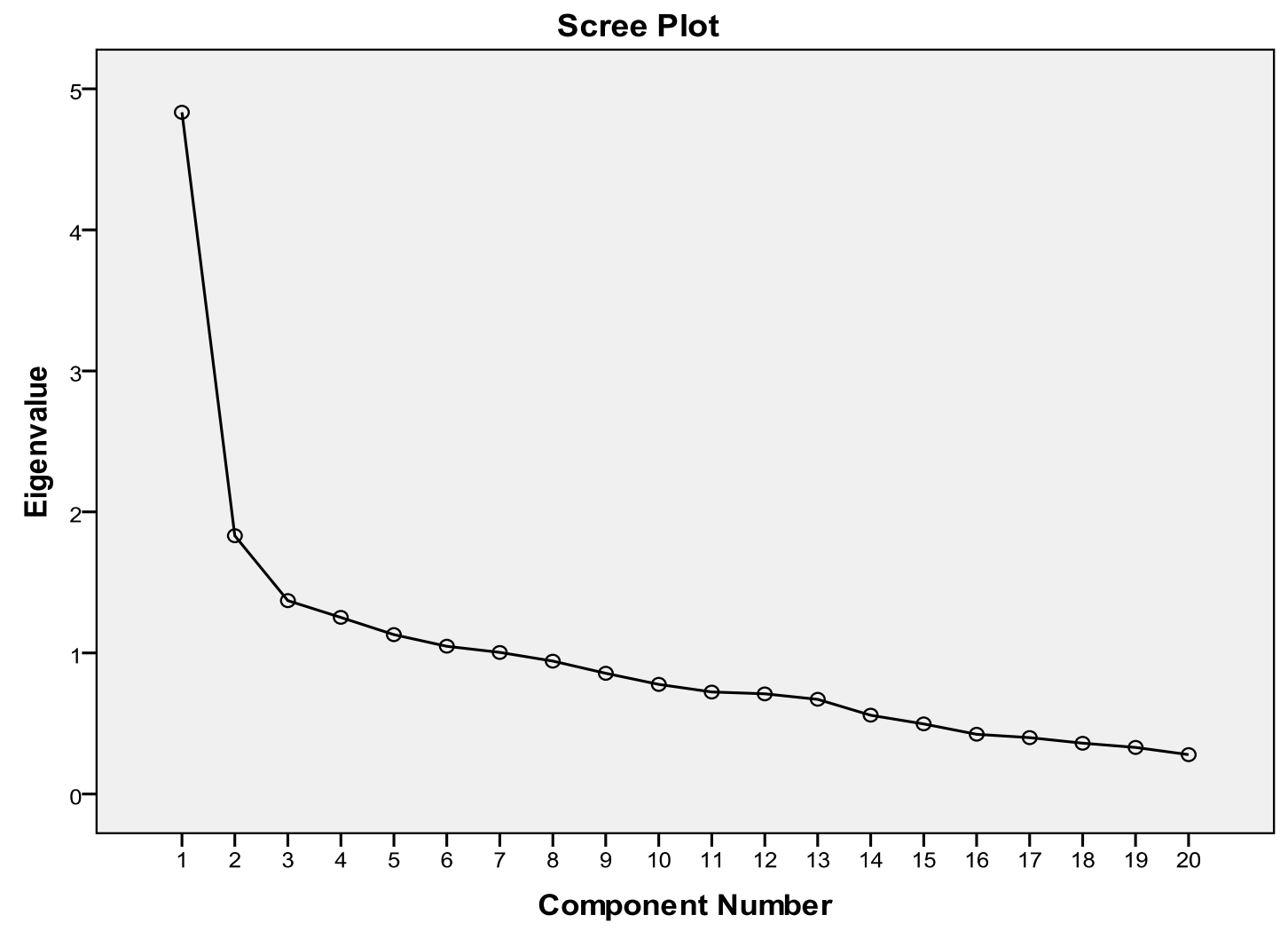

Table 3 provides the factor loadings for Component 1 and Component 2 . 
Table 3

Summary of Exploratory Factor Analysis Results for Adolescent Date Rape Myth Acceptance Scale Using Principal Components Extraction and Varimax Rotation

Factor Loadings

\begin{tabular}{|c|c|c|}
\hline \multirow[t]{2}{*}{ Item } & She & She \\
\hline & Wanted It & Lied \\
\hline Q13 If there are no bruises it is not rape & .68 & .17 \\
\hline Q19 It is important to prove love with sex & .64 & -.01 \\
\hline Q10 Invites him over when parents are not home & .63 & .25 \\
\hline $\begin{array}{l}\text { Q12 Okay to pressure into sex if she has had sex } \\
\text { before }\end{array}$ & .62 & -.01 \\
\hline Q3 She doesn't physically fight back & .61 & .18 \\
\hline $\begin{array}{l}\text { Q7 If she agrees to make out it is not a big deal if he } \\
\text { goes further and has sex }\end{array}$ & .60 & .16 \\
\hline Q18 If she parks with him she wants sex & .59 & .50 \\
\hline Q5 Sneaks out of house to meet him, she wants sex & .57 & .50 \\
\hline Q2 Lets him spend money on date she owes him & .54 & .20 \\
\hline $\begin{array}{l}\text { Q20 If she changes her mind at last moment, not his } \\
\text { fault }\end{array}$ & .45 & -.20 \\
\hline $\begin{array}{l}\text { Q15 Wearing low cut tops and short skirts is asking } \\
\text { for trouble }\end{array}$ & .41 & .23 \\
\hline Q11 Says it was rape to get back at boy & .05 & .67 \\
\hline Q8 Pretends she doesn't want to have sex & .21 & .58 \\
\hline
\end{tabular}


Q4 If she gets drunk, it is partly her fault

Q6 Consents but changes her mind after

Q1 A sexual tease will get in trouble

Q9 Likes to be forced not to appear easy

Q16 Caught by parents having consensual sex and

says it is rape to avoid punishment

Q14 Caught by boyfriend cheating and says it is rape

Q17 Excited boy may not even know girl is resisting

Eigenvalues

$\%$ of variance

Note: Factor loadings over .40 appear in bold.

Component 1 items are displayed in Table 4:

Table 4

Items Included in Component 1: She Wanted It

Question Item

13 If a girl doesn't have any bruises or marks, she wasn't really raped. implying she wants sex. past. 
If a girl sneaks out of her house to meet a boy, she wants sex.

If a girl lets a boy spend a lot of money on her on a date, she owes him something.

If a girl is about to have sex with a boy and she changes her mind at the last minute, it is not his fault if he gets carried away and forces her to have intercourse.

When girls wear low cut tops and short skirts they're just asking for trouble.

Taken together, Component 1 ("She Wanted It") was considered to represent the belief that rape victims actually wanted intercourse and behaved in a way that increased the probability of intercourse occurring.

Component 2 items are displayed in Table 5:

Table 5

Items Included in Component 2: She Lied

\begin{tabular}{ll}
\hline Question & Item \\
\hline 11 & $\begin{array}{l}\text { A lot of times, girls say they were raped in order to get back at a boy } \\
\text { they are mad at. }\end{array}$ \\
8 & $\begin{array}{l}\text { Many girls pretend they don't want to have sex because they don't want } \\
\text { to appear easy. }\end{array}$ \\
4 & $\begin{array}{l}\text { If a girl gets drunk with a boy and he forces her to have sex, she is at } \\
\text { least somewhat responsible for letting things get out of control. }\end{array}$ \\
6 & $\begin{array}{l}\text { Many girls who have sex and then change their minds after say they } \\
\text { were date raped. }\end{array}$ \\
1 & If a girl is a sexual tease, eventually she is going to get into trouble. \\
9 & $\begin{array}{l}\text { Some girls like boys to make them have sex so they don't feel guilty } \\
\text { after. }\end{array}$ \\
& $\begin{array}{l}\text { Many girls who get caught by their parents having sex say it was rape to } \\
\text { avoid getting in trouble. }\end{array}$
\end{tabular}


Some girls who get caught cheating on their boyfriends say it was rape. resisting him.

Taken together, Component 2 (“She Lied”) was considered to represent the belief that girls engage in consensual intercourse and after the fact, falsely proclaim it was rape. Simply put, Component 2 labels many girls who are victims of date rape as liars.

Verification of the two factors derived from factor analysis was conducted utilizing a half sample randomly generated by SPSS to represent $50 \%$ of the sample. The half sample consisted of 70 participant cases. Factor analysis was conducted using Varimax rotation and principal components extraction with two factors set for extraction. Factor analysis of the half sample yielded results very similar to the results of the full factor analysis (see Table 6). The components of the split half factor analysis varied with the full factor analysis only in the placement of two out of 20 items. In the full run, Question 18 had a factor loading of .59 with the first component and .50 with the second component. In the split half factor analysis it had a factor loading of .48 with the first component and .57 with the second component; therefore, it was included in the second component. Question 14, which in the full factor analysis had a factor loading of .11 with the first component and .29 with the second component, was included in the first component in the half sample factor analysis because it had a factor loading of .19 with the first component and a lower factor loading of .02 with the second component. Table 6 shows the factor loadings from the random half sample factor analysis. 
Table 6

Summary of Random Half Factor Analysis Results for Adolescent Date Rape Myth Acceptance Scale Using Principal Components Extraction and Varimax Rotation

Factor Loadings

Item She She

Wanted It

Lied

Q5 Sneaks out of house to meet him, she wants sex

.68 .02

Q10 Invites him over when parents are not home .66 .05

Q19 It is important to prove love with sex

.65

.05

Q13 If there are no bruises it is not rape

.65

Q7 If she agrees to make out it is not a big deal if he

.63

goes further and has sex

Q3 She doesn't physically fight back

.61

.07

Q2 Lets him spend money on date she owes him

.58

Q12 Okay to pressure into sex if she has had sex

.56

before

Q15 Wearing low cut tops and short skirts is asking

for trouble

Q14 Caught by boyfriend cheating and says it is rape

Q20 If she changes her mind at last moment, not his fault Q17 Excited boy may not even know girl is resisting 
Q6 Consents but changes her mind after

Q4 If she gets drunk, it is partly her fault

Q18 If she parks with him she wants sex

Q8 Pretends she doesn't want to have sex

Q1 A sexual tease will get in trouble

Q16 Caught by parents having consensual sex and says it is rape to avoid punishment

Q9 Likes to be forced not to appear easy

Eigenvalues

$\%$ of variance

Note: Factor loadings over .40 appear in bold.

To determine the reliability of the two components derived through factor analysis, Cronbach's alpha was computed. Component 1 ("She Wanted It") yielded a Cronbach's alpha of .82. Analysis of Component 2 (“She Lied") produced a Cronbach's alpha of .61.

The strong similarity of the split half factor analysis to the full sample factor analysis and the derivation of acceptable Cronbach's alpha scores form each component, support the two components derived by the full sample factor analysis.

\section{Attrition Analysis}

Of the 139 participants who took the pretest Adolescent Date Rape Myth Scale, 124 completed the Adolescent Date Rape Myth Scale posttest. Because all tests were anonymously coded, it is not possible to know why each of the 15 participants who took the pretest did not complete the posttest; however, the daily attendance rate at the school 
where the study was conducted for the 2010-2011 school year was about $90 \%$. Of the 15 participants who did not complete the posttest, 11 were from the treatment group (representing an attrition rate of 13.4\%), while 4 were from the control group (representing an attrition rate of 7\%). There were 3 boys and 12 girls in the drop out group. The drop out group $(\bar{x}=14.4, s .74)$ did not differ significantly in age from the posttest completion group, $\chi^{2}(1, N=137)=.18, p=.67$.

To determine if there was any difference in pretest Adolescent Date Rape Myth Scale scores between the drop out group and the posttest completion group, a one way ANOVA was conducted comparing pretest Adolescent Date Rape Myth Scale scores. Results showed the drop out group $(\bar{x}=54.53, s=12.09)$ and the posttest completion group $(\bar{x}=59.06, s=9.90)$ were not significantly different in Adolescent Date Rape Myth Scale pretest scores $F(1,137)=2.66, p=.11$. A one way ANOVA was also conducted on the Rape Myth Acceptance Scale scores to detect any differences in scores between the drop out group and the posttest completion group. Results showed the drop out group $(\bar{x}=54.13, s=15.11)$ was significantly lower than the posttest completion group $(\bar{x}=60.69, s=11.89)$ in Rape Myth Acceptance Scale pretest scores $F(1,137)=$ $3.84, p=.05 ; \dot{\eta}^{2}=.03$.

Analysis was conducted to determine if the attrition of participants from pretest to posttest created any differences in the treatment and control groups. An ANOVA was conducted to compare treatment and control groups adjusted for attrition on Adolescent Date Rape Myth Scale pretest. Results showed that the means of the adjusted treatment group $(\bar{x}=60.51, s=10.74)$ and the adjusted control group $(\bar{x}=57.11, s=8.34)$ was not significantly different in Adolescent Date Rape Myth Scale pretest scores $F(1,122)=$ 
$3.65, p=.06$. An ANOVA was also conducted to compare treatment and control groups adjusted for attrition on the Rape Myth Acceptance Scale pretest. Results showed that the adjusted treatment group $(\bar{x}=60.82, s=12.12)$ and the adjusted control group $(\bar{x}=$ $60.53, s=11.68)$ were not significantly different in Rape Myth Acceptance Scale scores $F(1,122)=.02, p=.89$.

\section{Analysis of Null Hypotheses}

Null Hypothesis 1: When adjusted for pretest rape myth acceptance, the mean posttest rape myth acceptance for participants who have read Speak will be greater than or equal to the mean posttest rape myth acceptance of participants who do not read Speak $(p<.05)$

A preliminary analysis was conducted to evaluate the homogeneity of slopes assumption using Adolescent Date Rape Myth Scale posttest scores as a dependent variable, Adolescent Date Rape Myth Scale pretest scores as a covariate, and Group (treatment or control) as the independent variable. Results show that the relationship between the covariate and the dependent variable did not differ significantly as a function of the independent variable $F(1,120)=.807$, $p=.37$.

A 2 (group) x 2 (sex) x 2 (instructor) ANCOVA using Adolescent Date Rape Myth Scale pretest scores as a covariate and Adolescent Date Rape Myth Scale posttest scores as the dependent variable was conducted to measure differences in rape myth acceptance between treatment and control groups. The ANCOVA was significant for Group, $F(1,115)=20.01, p<.001, \dot{\eta}^{2}=.15$. Thus, we reject the null hypothesis and accept the research hypothesis that when adjusted for pretest 
rape myth acceptance, the mean posttest rape myth acceptance for participants who have read Speak will be significantly lower than the mean posttest rape myth acceptance of participants who do not read Speak $(p<.001)$.

The ANCOVA was also significant for Sex, $F(1,115)=4.03, p=.047, \eta^{2}=$ .03. We can conclude that when adjusted for pretest rape myth acceptance, boys' and girls' posttest scores on the Adolescent Date Rape Myth Scale were significantly different with sex accounting for about $3 \%$ of the variance in scores.

The ANCOVA was not significant for Teacher, $F(1,115)=.43, p=.52$. Thus, we can conclude that the effect of being in classes taught by Teacher A or Teacher B did not significantly affect participants' posttest rape myth acceptance scores.

The results of the ANCOVA also provided analysis of the following interaction hypotheses:

1. In the sample, there will be no significant interaction between group and sex in posttest rape myth acceptance $(p<.05)$. The ANCOVA was not significant for interaction between group and sex, $F(1,115)=.49, p=.49$. Thus, we fail to reject the null and we cannot conclude that the effect of group varied by sex in adjusted posttest rape myth acceptance.

2. In the sample, there will be no significant interaction between group and instructor in posttest rape myth acceptance $(p<.05)$. The ANCOVA was not significant for interaction between group and instructor, $F(1,115)=$ $.09, p=.77$. Thus, we fail to reject the null and we cannot conclude that 
the effect of group varied by instructor in adjusted posttest rape myth acceptance.

3. In the sample, there will be no significant interaction between sex and instructor in adjusted posttest rape myth acceptance $(p<.05)$. The ANCOVA was not significant for interaction between sex and instructor, $F(1,115)=.883, p=.35$. Thus, we fail to reject the null and cannot conclude that the effect of sex varied by instructor in adjusted posttest rape myth acceptance.

For the testing of null hypotheses $2-4$, participants were divided according to pretest Adolescent Date Rape Myth Scale scores into two groups: High rape myth acceptance: participants with pretest scores 1 standard deviation above the mean of all pretest Adolescent Date Rape Myth Scale scores ( $>69)$; and Low rape myth acceptance: participants with pretest scores 1 standard deviation below the mean of all pretest rape myth acceptance scores $(<48)$. Pretest Adolescent Date Rape Myth Scale $\bar{x}=58.57, s=$ 10.21 .

Null Hypothesis 2: Participants who show a high level of pretest rape myth acceptance and read Speak will show either no significant difference or a significantly mean score in posttest rape myth acceptance compared to participants with a high level of pretest rape myth acceptance who do not read Speak $(p<.05)$. An ANCOVA using pretest Adolescent Date Rape Myth Scale scores as a covariate was conducted comparing posttest Adolescent Date Rape Myth Scale scores between participants with high rape myth acceptance in the treatment group (Adolescent Date Rape Myth Scale posttest $\bar{x}=$ 63.21) and participants with high rape myth acceptance in the control group (Adolescent 
Date Rape Myth Scale posttest $\bar{x}=65.75)$. Results showed no statistical significance between group means, $F(1,16)=.35, p=.92$. Thus, we fail to reject the null hypothesis and cannot conclude that there was a difference in posttest rape myth acceptance between participants with high pretest rape myth acceptance who read Speak and participants with high pretest rape myth acceptance who did not read Speak.

Null Hypothesis 3: After reading Speak, boys who show a high level of pretest rape myth acceptance will demonstrate a backlash to treatment and will show significantly higher levels of posttest rape myth acceptance. An ANCOVA using pretest Adolescent Date Rape Myth Scale scores as a covariate was conducted comparing posttest Adolescent Date Rape Myth Scale scores between boys with high rape myth acceptance in the treatment group (Adolescent Date Rape Myth Scale posttest $\bar{x}=62.5$ ) and boys with high rape myth acceptance in the control group (Adolescent Date Rape Myth Scale posttest $\bar{x}=70.5$ ). Results showed no statistical significance between group means, $F(1,10)=.41, p=.54$. Thus, we fail to reject the null hypothesis and cannot conclude that there was backlash to treatment in boys with High pretest rape myth acceptance.

Null Hypothesis 4: After reading Speak, participants who show a low level of pretest rape myth acceptance will show no significant difference or a significant increase in rape myth acceptance posttest. An ANCOVA using pretest Adolescent Date Rape Myth Scale scores as a covariate was conducted comparing posttest Adolescent Date Rape Myth Scale scores between participants with low rape myth acceptance in the treatment group (Adolescent Date Rape Myth Scale posttest $\bar{x}=41.0$ ) and participants with low rape myth acceptance in the control group (Adolescent Date Rape Myth Scale 
posttest $\bar{x}=41.67)$. Results showed no statistical significance between group means, $F(1,13)=1.53, p=.24$. Thus, we fail to reject the null hypothesis and cannot conclude that there was a difference in posttest rape myth acceptance between participants with low pretest rape myth acceptance who read Speak and participants with low pretest rape myth acceptance who did not read Speak.

\section{Post-Hoc Analysis of Factor Analysis Components 1 and 2}

The results of the testing of the main hypothesis showed that participants who read Speak had a significantly lower level of rape myth acceptance posttest than participants who did not read Speak; ergo, post-hoc analysis of the Components derived through factor analysis was conducted to determine if there was any significant difference in reduction of rape myth acceptance between Component 1 ("She Wanted It") and Component 2 (“She Lied"). All pretest and posttest Adolescent Date Rape Myth Scale scores for each participant were recalculated to give a total sum value of the items appearing in Component 1 and a total sum value of the items appearing in Component 2.

An ANCOVA was conducted using the adjusted Component 1 posttest score as the dependent variable, Component 1 pretest scores as a covariate, and group as a fixed factor. Results were significant, $F(1,115)=43.75, p<.001, \dot{\eta}^{2}=.27$. Thus, we can conclude that in treatment group participants, there was a significant reduction in adherence to the rape myth construct that portrays date rape victims as having intentionally behaved in a way to increase chances of intercourse occurring.

An ANCOVA was conducted using Component 2 posttest score as the dependent variable, Component 2 pretest scores as a covariate, and group as a fixed factor. Results were not significant, $F(1,115)=3.41, p=.07$. 


\section{CHAPTER V}

\section{DISCUSSION}

The purpose of this chapter is to discuss the results of this study, which examined the effect of a reader response based instructional unit and reading of the young adult novel Speak, on rape myth acceptance in adolescents. The chapter begins with a brief summary of the study followed by a discussion of the results from the research hypotheses, attrition analysis, and analyses of the Adolescent Date Rape Myth Scale. Implications for practice, implications for future research, and limitations of the study are also discussed.

\section{Summary of the Study}

This study used a quasi-experimental pretest-posttest design to measure the effect of a reader response based instructional unit of the novel Speak on rape myth acceptance in adolescents. The study was conducted in eighth grade language arts classrooms in a South Florida Title I middle school with two teachers and a total of seven classroom clusters. Four classrooms were randomly assigned to treatment and three were randomly assigned to control. Teacher A had two treatment classes and two control classes, while Teacher B had two treatment classes and one control class. Participants were pretested on rape myth acceptance using the Rape Myth Acceptance Scale (Burt, 1980) and an inventory that was created for this study, the Adolescent Date Rape Myth Scale. Analyses were conducted on both scales and established that the Adolescent Date Rape Myth Scale should provide valid and reliable measures of rape myth acceptance in adolescents. 
Treatment group participants participated in a 5 week long instructional unit using the novel Speak. All reading was done in class and in addition to reading comprehension questions and an in depth study of symbolism with the novel, participants completed four major reader response activities which asked participants to: (a) write a letter to the protagonist, Melinda, convincing her to seek help for her rape; (b), write an essay indicting whether they thought Melinda was raped and defending their answers; (c) pretend they are a friend of Andy, the boy who raped Melinda, and write a conversation with Andy where they convince him what he did was rape; and (d) write a personal reaction to the novel and decide whether or not they would believe someone in a similar situation who told them that she had been raped. Each assignment was followed by a student to student small group discussion and then by a whole classroom discussion. Participants in the control group participated in an instructional unit of Julius Caesar, by William Shakespeare.

Participants were posttested on rape myth acceptance using the Adolescent Date Rape Myth Acceptance Scale. Immediately after posttests, participants in both treatment and control groups attended a workshop conducted by the school TRUST counselor on teen dating violence and were provided with information on where to get help for sexual assault or any other kind of abuse. Participants who were in the control group started their unit using Speak at the next class session.

\section{Discussion of Hypotheses}

\section{Hypothesis 1}

Hypothesis 1 stated that treatment group participants who participated in a reader response based instructional unit on the novel Speak would move in the desired direction 
and have a significantly lower level of posttest rape myth acceptance than participants who did not read Speak. This hypothesis was supported by the results as significant differences were found on the posttests between the treatment and control groups as measured by the Adolescent Date Rape Myth Acceptance Scale. The ANCOVA used to test Hypothesis 1 used pretests as a covariate and also provided tests of significance for main effects of teacher and sex, as well as for interaction tests for group and teacher, group and sex, and teacher and sex. Main effect for teacher was not significant. Main effect for sex was significant. Analyses of interaction hypotheses found no significant interactions.

\section{Hypothesis 2}

Hypothesis 2 examined the ability of the intervention to lower rape myth acceptance in participants who had high levels of pretest rape myth acceptance. Recall that participants were divided into high and low rape myth acceptance groups according to pretest scores on the Adolescent Date Rape Myth Acceptance Scale. Participants with scores 1 standard deviation above the mean were included in the High rape myth acceptance group, while participants with scores 1 standard deviation below the mean were included in the Low rape myth acceptance group. Specifically, Hypothesis 2 predicted that High rape myth acceptance treatment group participants would show a significantly lower level of rape myth acceptance posttest when compared to the High rape myth acceptance control group participants. Results did not support this hypothesis as no significant posttest differences in rape myth acceptance were found between groups. 


\section{Hypothesis 3}

Hypothesis 3 tested for the possibility of a treatment backlash which has been found in previous studies (Jaffe et al., 1992; Milhausen, McBride \& Jun, 2006).

Hypothesis 3 predicted specifically that boys in the treatment group would not exhibit a backlash to treatment as demonstrated by a significant increase in posttest rape myth acceptance. Results supported Hypothesis 3 as boys in the treatment group were not significantly higher in posttest rape myth acceptance than boys in the control group.

\section{Hypothesis 4}

Hypothesis 4 examined the floor effect on rape myth acceptance where researchers have previously found that many participants start out at significantly lower levels of rape myth acceptance than others and they many have already reached a point at which there is such little adherence to rape myths that there is little chance of significantly lowering their beliefs (Brecklin \& Forde, 2001; Harrison et al., 1991; Heppner, Humphrey, Hillenbrand-Gunn, \& DeBord, 1995; Lavoie, Piche \& Boivin, 1995; Layman-Guadalupe, 1997). Specifically, Hypothesis 4 predicted that participants who show low levels of pretest rape myth acceptance would not show significant differences in posttest rape myth acceptance. Results supported this hypothesis.

\section{Interpretations and Related Implications}

The results of this study support previous research which has been successful in reducing rape myth acceptance in secondary school settings (Fay \& Medway, 2006; Lavoie, Piche \& Boivin, 1995; MacGowan, 1997; Pacifici et al., 2001; Smith \& Welchans, 2000; Weisz \& Black, 2001); however, due to the nature of the current study, it is critical to point out several important differences between the current study and 
previous research. Perhaps most importantly, this study used an intervention that consisted of reading a fictional novel and completing an accompanying reader response based instructional unit conducted as part of English/Language Arts classes. This is important as previous studies have used outside facilitators (Fay \& Medway, 2006), have often been conducted in general assembly type settings (Hilton et al., 1998), or have even been offered after school (Weisz \& Black, 2001). Even when interventions have been conducted as part of the regular curriculum, they often occur in health classes (AveryLeaf et al., 1997; Pacifici et al., 2001), which many students may not be required to take. For example, AP track students would likely be enrolled in AP Biology as opposed to a health science class. By being part of the English/Language Arts curriculum across regular, advanced, and special education inclusion classes, the current intervention had the potential to reach a more diverse group of students than many previous studies.

This intervention was also unique in that it used regular teachers who are employed at the school full time as opposed to bringing in outside facilitators. This could be meaningful as many students often look at guest lectures as a time to relax and often do not take outside speakers as seriously as they do their regular teachers. Further, by having a regular instructors involved in discussions about date rape, there is more of an opportunity to create a change in culture. This may be because when the unit is completed, the teachers would still be there and subsequent discussions that may refer back to assignments, discussions, and events from the Speak unit would be able to be revisited. The length of the current intervention could also be a factor in the treatment's ability to lower rape myth acceptance. Reading novels is an intimate, long term interaction and the reading and instruction of Speak was no different. The instructional 
unit, including class reading time, lasted for 5 weeks, which translates to 21 hours and 40 minutes of instructional time. This is longer than every study except for one in the most recent meta-analysis on dating violence and rape myth reduction where $77 \%$ of the interventions lasted less than 6 hours (Ting, 2009).

The results of testing Hypothesis 1 are also important because they demonstrate it is possible to reduce rape myth acceptance in middle school students as measured by the Adolescent Date Rape Myth Acceptance Scale. Few previous studies on rape myth acceptance have been conducted in middle schools (MacGowan, 1997; Ting, 2009, Weisz \& Black, 2001). Furthermore, this study was conducted with a majority of Hispanic/Latino/a students (52.5\%) and a large portion of African American students (34.5\%). Much of the previous research on reducing rape myth acceptance has been conducted in schools that serve predominantly Caucasian non-Hispanic students (Hilton et al., 1998; Lavoie et al., 1995; Lowe et al., 2007; Foshee, Linder, Bauman, Langwick, Arriaga, Heath, McMahon, \& Bangdiwala, 1996; Pacifici et al., 2001; Smith \& Welchans, 2000). Few studies have been conducted with predominantly Hispanic/Latina/o students (Jaycox, McCaffrey et al., 2006; Rayburn, Jaycox, McCaffrey, Ulloa, Zander-Cotugno, Marshall, \& Shelly, 2007).

The results of testing Hypothesis 1 clearly show that literature, specifically young adult literature, can be effective in reducing adolescents' date rape myth acceptance. The findings support the work of Rosenblatt (1938) who postulated that affective readings of literature could bring about many changes in readers, including changes in attitudes. The ability to engage in affective reading of text allowed readers to make emotional connections to the main character and to enter the world of the text. This made the 
discussion of rape more than an academic exercise as readers had vicariously lived through the experience that a date rape victim suffered. It is important to note that the intervention included ample opportunities for small group and whole group discussions of the reader response assignments in addition to analysis of plot and symbolism in the novel. The success of the curriculum supports the work of Fish (1980) who advocated using discussions of literature that allow opposing viewpoints to be voiced in order to allow a real dialogue to occur, and the work of Bleich (1988), who advocated small group discussions which allow students to utilize their oral fluency skills and discourse without fear of the authority.

Anecdotal reports from both the teachers included descriptions of discussions which included contradictory points of view regarding date rape. It is believed that these discussions were a critical part of the intervention as both teachers reported that students' attitudes toward date rape were changed during discussions. Due to the nature of the topic, rape, it was critical that both teachers were comfortable orchestrating discussions which often contained views which were rape supportive. For example, one teacher reported that during a discussion a male student responded that "No doesn't mean no, it means go harder." Several female students then verbalized their agreement with the statement. In situations such as these both teachers assumed a Socratic role as opposed to censoring the students and labeling their responses as "wrong." For example, students who voiced pro-rape attitudes were not chastised and corrected; instead, questioning was used to reframe situations and to provide opportunities for reflection and reconsideration. Both teachers reported using the question "But what if it was your sister?" on numerous occasions. Other students would also be called on to provide differing points of view as 
it was deemed critical that students hear oppositional opinions from their peers as opposed to the teachers. Taken together, this study provides empirical evidence for the use of reader response based instruction of young adult literature supplemented with small and whole group discussions as a method for providing students the opportunity to reexamine previously held beliefs and perhaps even embrace more socially acceptable tenets of behavior.

\section{Main Effects for Teacher, Sex, and Interaction Hypotheses}

The use of a $2 \times 2 \times 2$ ANCOVA allowed the study to investigate whether in addition to the effect of treatment (group), there were any main effects for teacher or sex, and if there were any interactions between group and sex, group and teacher, and teacher and sex. The lack of significant differences for main effects of teacher, and interactions between teacher and group, and teacher and sex, support the fidelity of the treatment between the two teachers. Both teachers followed the same unit plan and while it is impossible in an actual classroom setting to have identical discussions and to take the same amount of time when reading a novel, the results are supportive that any differences which may have existed between instruction were not significant.

There was a significant main effect for sex which shows a narrowing of the differences between boys' and girls' rape myth acceptance from pretest to posttest. The main effect demonstrates that boys showed a greater reduction in rape myth acceptance than girls. This is logical as girls showed a significantly lower level of pretest rape myth acceptance than boys and were therefore more susceptible to the floor effect. These results support studies which find girls to have significantly lower initial rape myth acceptance than boys (Hilton et al., 1998; Lavoie, Piche \& Boivin, 1995; Lonsway \& 
Fitzgerald, 1994; Weisz \& Black, 2001). The lack of a significant interaction between sex and group further lend credence to the floor effect as there was no significant interaction in posttest rape myth acceptance between sex and group.

\section{Hypothesis 2}

The mixed results from testing Hypotheses 2, 3, and 4 concerning participants with high and low pretest rape myth acceptance is worthy of discussion. Testing Hypothesis 2 failed to find a significant effect of treatment in lowering high rape myth acceptance treatment group participants', boys and girls, rape myth acceptance when compared to high rape myth acceptance control group participants. The inability to find significant differences between groups may have been a result of regression to the mean as only scores that were 1 standard deviation above the mean on pretests were analyzed, these extreme scores may have moved toward the average on the posttest regardless of group membership. It also may be due to the fact that the sample size of participants categorized as High rape myth acceptance was too small to find significance as there were only a total of 15 participants in the High rape myth acceptance treatment and control groups. Power analysis reveals that an $\mathrm{F}$ test to detect a moderate effect size of .15 at alpha $=.05$ with 15 participants would have an achieved power of .08 . This is a very low power level and it appears that the small number of participants in the High rape myth acceptance group severely limited the power of the test to find significance.

\section{Hypothesis 3}

Hypothesis 3 predicted that boys with High pretest rape myth acceptance would not increase acceptance of rape myths after participating in the program; therefore, the research hypothesis was also the statistical null hypothesis. The failure to reject the null 
is important as it shows that a backlash effect may be avoided in rape myth acceptance reduction interventions. Some previous studies have found that treatment participants increased their overall rape myth acceptance (Jaffee et al., 1992) or important aspects of it (Milhausen et al., 2006) after exposure to intervention. Many interventions aimed at reducing rape myth acceptance are partially or wholly didactic in content and delivery. If a person has a high level of adherence to rape myths, then simply providing contrary information in a lecture type setting may not just be inadequate to reduce rape myth acceptance, but it may actually initiate a defensive reaction where participants embrace their beliefs even more strongly.

The absence of a backlash effect in this study could be due to the nature and duration of the intervention. By providing participants an opportunity to read what surviving a rape is like from the victim's point of view of a period of a fictional school year, there was ample occasion for participants to develop empathy with the main character. Further, the ability to contemplate one's own feelings through reader response assignments provided participants with reflective activities that allowed for a reassessment in belief systems. The continuation of the reader response assignments in small group and whole class discussions allowed participants to share their own views and to hear others views. The contributions of discussions to reduction in rape myth acceptance in the current study support the work of social norms theorists who hypothesize that individuals are influenced by their perception of peers' beliefs (Perkins \& Berkowitz, 1986) and rape myth researchers who have found correlations between peer rape myth acceptance and individual rape myth acceptance (Bohner et al., 2006). The importance of the beliefs of one's peers cannot be overstated for adolescents and 
allowing participants to hear that rape is not socially acceptable to their peers appears to be a powerful attitudinal change agent.

\section{Hypothesis 4}

Hypothesis 4 was another research hypothesis which was also the statistical null hypothesis. The failure to reject the null and to find significant differences between Low rape myth acceptance treatment participants and Low rape myth acceptance control participants supported the belief that a floor effect on rape myth acceptance existed and that the participants who were already unlikely to subscribe to rape myths pretest could not move significantly lower posttest. These results support previous researchers who have found that participants with low levels of rape myth acceptance do not change their beliefs significantly after intervention due to the presence of a floor effect (Brecklin \& Forde, 2001; Harrison, Downes, \& Williams, 1991; Heppner et al., 1995; Lavoie et al., 1995; Layman-Guadalupe, 1996). These results may suggest that in rape myth reduction research statistical analysis of main effects may want to take this into consideration by analyzing participants with low pretest rape myth acceptance separately. For example, in this study, if the $2 \times 2 \times 2$ ANCOVA was recalculated using only participants with pretest rape myth acceptance above -1 standard deviations from the mean, the effect size would increase by $33 \%$ from $\eta^{2}=.15$ to an $\eta^{2}=.20$. Utilizing this partitioning of participants with pretest scores that are either very high or very low could give researchers a more accurate representation of effect size.

\section{Attrition Analysis}

The loss of participants to attrition is a major concern in rape myth reduction research that takes place in secondary schools, as it is important to know if those who 
drop out are significantly different from those who remain. For this study drop outs refer to students who completed the pretests but not the posttests. If the participants who drop out are those with high rape myth acceptance, it may be that the drop outs are reacting defensively to the intervention and their absence from the study casts doubts upon any results from analysis. This effect may be compounded in programs where attendance is voluntary as they tend to have high rates of attrition (Hilton et al., 1998; Weisz \& Black, 2001). In an attempt to control for attrition, few previous studies have included analysis of program drop outs as part of their results (Pacifici et al., 2001).

Analysis of the drop outs revealed that $10.79 \%$ of program participants who completed the pretests did not complete the posttest. Because the inventories were anonymously coded, no attempt was made to determine who the drop outs were or why they did not complete; however, the school site where the study was conducted had a daily attendance rate of about $90 \%$ for the school year in which the research was conducted. Compounding the loss to absenteeism, the school site also has a high student mobility index and a high rate of indoor and outdoor suspensions. Taken together, absenteeism, mobility, and suspension could reasonably explain the attrition rate in a study that lasted 5 weeks. Regardless, analysis was still conducted on pretest data for participants who dropped out to determine if they were different in any way from participants who remained or if their attrition significantly changed the treatment and/or control groups.

Results of attrition analysis showed that the drop outs were not significantly different in age or Adolescent Date Rape Myth Scale pretest scores. The loss of participants did not create any differences in treatment or control groups in terms of 
pretest scores on the Adolescent Myth Rape Acceptance Scale or the Rape Myth Acceptance Scale. The drop outs did have significantly lower scores on the Rape Myth Acceptance Scale pretest scores when compared to participants who completed pretests and posttests; however, considering these differences did not result in any significant difference between treatment and control groups on either pretest measure, it is reasonable to conclude that their absence did not alter the results of the research. Finally, the attrition rate in this study is considerably lower than other studies conducted in secondary settings that report attrition rates.

\section{Adolescent Date Rape Myth Scale}

While the Rape Myth Acceptance Scale (Burt, 1980) is by far the most frequently used scale for rape myth research (Anderson \& Whiston, 2005; Suarez \& Gadalla, 2010; Ting, 2009), researchers have suggested that the Rape Myth Acceptance Scale contains outdated items (Pacifici et al., 2001). Taking this into account and because the Rape Myth Acceptance Scale was designed for adult respondents, this study developed a new scale for use with adolescents using modern language and age appropriate situations. The Adolescent Date Rape Myth Scale used modified versions of questions from several previously used scales such as the Rape Myth Acceptance Scale (Burt, 1980), the Illinois Rape Myth Acceptance Scale (Payne et al., 1999), the Sexual Beliefs Scale (Muehlenhard \& Felts, 1998), the High School Experiences Scenarios (Fenstermaker, 1989), the College Date Rape Attitude Survey (Lanier \& Green, 2006), and researcher created questions developed from theoretical knowledge of rape myths and from experience working with adolescents. 


\section{Validity and Reliability}

The Adolescent Date Rape Myth Acceptance Scale was demonstrated to be a valid measure of rape myth acceptance in adolescents by the significant correlation coefficients achieved between it and the Rape Myth Acceptance Scale (Burt, 1980) as well as the similarities in factor structures obtained using split half samples of the Adolescent Date Rape Myth Scale. The Rape Myth Acceptance Scale has been shown by numerous researchers to be a valid and reliable measure of rape myth acceptance (Ashton, 1982; Malamuth, 1989; Marshall \& Hambley, 1996; Sawyer et al., 2002; Worling, 1995). Results also support the use of the Adolescent Date Rape Myth Scale with adolescents by the very good Cronbach's alpha scores; in fact, the Adolescent Date Rape Myth Scale had higher Cronbach's alpha scores than the Rape Myth Acceptance Scale, and this may indicate that the Adolescent Date Rape Myth Scale is a more consistent measure of rape myth acceptance in adolescents. Anecdotally, both teachers in the study reported that participants were confused by multiple questions during the administration of the Rape Myth Acceptance Scale because they did not understand the terminology used and that questions about the same items were asked repeatedly across all administrations of the Rape Myth Acceptance Scale. There were no reports of confusion or questions from participants regarding the Adolescent Date Rape Myth Scale. The combination of satisfactory statistical analyses and anecdotal reports support the use of the Adolescent Date Rape Myth Scale as a valid and reliable measure of adolescent rape myth acceptance. 


\section{Factor Analysis}

Considering the Adolescent Date Rape Myth Scale is a new scale developed for this study, the relevant aspect of construct validity was addressed through factor analysis to determine the underlying dimensions and structural validity of the structural components of the Adolescent Date Rape Myth Scale. Exploratory factor analysis of the Adolescent Date Rape Myth Scale indicated that a two factor model best represented the sub components of the Adolescent Date Rape Myth Scale. Component 1 was identified as "She Wanted It" and Component 2 was labeled "She Lied." The finding of these two components supports earlier research utilizing factor analysis on rape myth scales which have found highly similar components (Briere, Malamuth \& Check, 1985; Field, 1978; Payne, et al., 1999).

Component 1 "She Wanted It" represents the belief of respondents that rape victims actually wanted to engage in intercourse but chose not to verbalize their desires; instead, they behaved in a way which increased the probability of their engaging in intercourse. Several items which are found in this component relate to the level of physical effort a girl uses to fight off her rapist. It is reasonable to assume that those who scored high on these items believe that if a girl did not want to engage in intercourse, she would have used vigorous physical force to fight off her attacker and she would have bruises and marks afterward to prove it. Thus, by not fighting back enough, she may be viewed by those with high levels of rape myth acceptance as having wanted to engage in intercourse. Another set of items in the "She Wanted It" component relates to girls consenting to engage in activities which those who have high rape myth acceptance view as inviting sexual encounters. Items contain such behaviors as a girl sneaking out of her 
house to meet a boy, consenting to kissing and fondling, inviting a boy over to her house when her parents are not home, and parking with a boy in a car. It is surmised that those with high rape myth acceptance view these actions as implicit invitations for sex and that the boys are merely accepting these requests when date rape occurs in these situations. Anecdotal reports from both teachers confirm that both of these two facets of "She Wanted It" were verbalized by participants in multiple classroom discussions.

Component 2 "She Lied" represents the belief that girls who accuse boys of rape in dating situations actually agree to consensual intercourse but after the fact, they lie by claiming that they were victims of rape. Several items in the component specifically state that girls lie about rape to get revenge on boys, to avoid punishment when caught by parents, to lessen the consequences of being caught cheating on their boyfriends, and because they change their minds after engaging in consensual intercourse.

To determine if either of these factors was more influential in the significant results found in testing Hypothesis 1, further analyses were conducted on "She Wanted It" and "She Lied." Both components were tested to determine if one component contributed more than the other to the rape myth reduction found in the analysis of Hypothesis 1. Results showed that scores on "She Wanted It" items were lower in the treatment group than in the control group. Items on "She Lied" were not significantly lower for the treatment group when compared to the control group. These results may make sense when the nature of the novel Speak is considered. The date rape which occurs in the novel takes place at a summer party. The victim, Melinda, is attracted to the rapist and agrees to go outside behind the house with him. There, she engages in consensual kissing before he wants more, and when she says no, he covers her mouth and 
rapes her. The novel relates her struggle in speaking of the rape and her attempts at denying it was rape. Thus, the novel brings about discussions which are directly related to the items which loaded into "She Wanted It." The reader response assignments addressed this myth directly and anecdotal reports of discussions show that they were often related to whether or not Melinda wanted to engage in intercourse based on her behavior at the party and her acquiescence in going to an isolated spot with the rapist. On the other hand, the only element of a falsely accused rape is at the end of the novel when the rapist confronts Melinda and claims that she had "wanted it" at the party. By this point in the novel, from her recollection of the event, by her attempts to deny it, and due to the psychological damage she suffered as a result, it is clear to most readers that she was raped. Thus, it can be concluded that the novel used is appropriate for changing attitudes which portray girls as desirous of intercourse but unable to verbalize their desires, while it is not effective at dispelling the myth that the majority of rape victims are liars.

\section{Implications for Practice}

The results of this study have implications for the practice of teaching English/Language Arts in numerous ways. Perhaps most importantly, the findings of this study show that reading a young adult novel in conjunction with a reader response based instructional unit can be effectively used to reduce rape myth acceptance in adolescents. Novels, specifically Speak, could be used in other schools and/or other grade levels as part of traditional English/Language Arts instruction and/or as part of curricula designed to reduce rape myth acceptance. The use of reader response activities which include small group and whole group discussion is also supported by the results, and 
English/Language Arts teachers may want to consider how these types of activities and discussions could be integrated into their curriculum regardless of the novel or reading material which is being used.

English/Language Arts teachers may also explore how using similar novels that deal with other topics such as bullying, sexism, racism, homophobia, or religious intolerance, may be included in the curriculum in order to afford adolescents an opportunity to reexamine previously held beliefs and to open their minds to different opinions and attitudes.

Date rape education is mandated by the state of Florida and numerous other states have similar laws in place (Connecticut, Georgia, Illinois, Massachusetts, Nebraska, New Jersey, Ohio, Pennsylvania, Rhode Island, Tennessee, Texas, Virginia, and Washington) or are introducing similar legislation (California, Georgia, Maryland, New York, Oklahoma, Oregon, and Virginia; National Conference of State Legislators, 2012). Considering the widespread efforts at reducing teen dating violence, including date rape, educators at all levels, including state and federal, should consider integrating the reading of Speak into sexual assault prevention education. Furthermore, educators should consider the development of sexual assault prevention curricula which could include English/Language Arts, science, social studies and mathematics - there is no need for dating violence prevention to be relegated to health science classes.

\section{Implications for Research}

The results of this study suggest numerous needs for future research. The finding of significant effects suggests that the study should be replicated. The study was conducted with students who were primarily Hispanic/Latina/o. Future research should 
attempt to replicate the results with a primarily African American population, and with a primarily Caucasian non-Hispanic/Latina/o population. Because this study was conducted toward the end of the school year, follow up administrations of rape myth acceptance were not possible; future studies using Speak should conduct follow up assessments to determine if the effects of treatment are lasting. The study was conducted in eighth grade and future studies should attempt to replicate it at other appropriate grade levels. Future date rape research with secondary students should examine whether adding the use of the novel Speak into existing interventions will make them more or less effective. As the results support the use of literature to change attitudes in adolescents, future research should examine if similar novels can change attitudes toward bullying, sexism, homophobia, disabled persons, racism, Islamaphobia, and general intolerance based on religion.

It is important that researchers investigating rape myth acceptance in adolescents have an inventory which is a reliable and valid assessment; therefore, the inventory developed for this study, the Adolescent Date Rape Myth Scale, should be studied further to replicate reliability findings in students of both middle and senior high school level. The findings derived from factor analysis should also be replicated and future studies should examine whether the Adolescent Date Rape Myth Scale has a different factor structure as determined by sex.

The ultimate goal of date rape prevention education is to prevent date rape; therefore, future research could include longitudinal studies to determine if the rate of perpetration and/or victimization is significantly different for participants than nonparticipants. Future research should also examine how the novel Speak affects not just 
rape myth acceptance, but also self-professed proclivity to rape, and an appropriate measure for rape proclivity should be developed for adolescents.

As the results of this study support the use of full length young adult novels in the official curricula of English/Language Arts classes, future research should examine how the use of novels in English/Language Arts classes has been affected by mandates such as No Child Left Behind and Race to the Top. Furthermore, research should examine if there is a disparity in the use of novels in English/Language Arts classes as determined by race/ethnicity or poverty as less affluent students are more often subjected to drill and test curricula and may be being denied learning opportunities provided by aesthetic transactions with full length novels. Research into teacher training programs should examine whether teachers are trained in how to use novels which deal with topics that some may find uncomfortable such as rape, racism, homophobia, etc.

The statistical analysis of this study also suggests directions for research methodology. Future studies which examine effectiveness in reducing an attitudinal construct should consider using pretests to identify participants who may be subject to a floor or ceiling effect. Because many interventions in education and psychology are aimed at reducing the adherence to a construct such as rape myth acceptance or homophobia, statistical analysis of effect size may be better represented by restricting analysis of main effects to those with medium to high level scores on pretests. It is implicit that most interventions are designed to reduce acceptance levels in people who have medium to high levels of acceptance and by stating hypotheses as such, researchers would have a greater ability to find representative effect sizes. For example, if one were to test an intervention designed to reduce acceptance of bullying behavior, pretests would 
reveal participants who have varying levels of bullying acceptance. It is reasonable to expect that there would be participants whose initial levels of acceptance are so low that it would be unrealistic to expect to be able to significantly reduce their adherence. An acceptable cutoff point would be scores which are 1 standard deviation below the mean. These participants could be removed from the analysis of main effects to obtain a higher estimate of effect size. Follow up analyses should include analyses of the low level adherence participants to determine if there were any significant changes in adherence levels after treatment. A consequence to conducting this type of analyses would be the possible loss of statistical power resulting from decreasing the overall number of participants in the main analysis; however, this loss can be estimated beforehand as removing scores 1 standard deviation below (or above depending on the scoring method) the mean would result in a loss of $15.9 \%$ of participants. After the total number of subjects per group exceeds 110, the loss would not reduce power beneath .80 and as subjects per group increases beyond 110 , the loss of power greatly diminishes. Furthermore, the generalizability of the results of a study using this type of analysis would be restricted to the population that remained after removing subjects who may be subject to a floor or ceiling effect.

Similarly, if research reveals backlash to treatment effects, analysis should be conducted on those who have high (assuming high represents scores in the undesired direction) adherence to a construct demonstrated by a pretest score of 1 standard deviation above the mean. Post intervention analysis could be conducted to determine whether they moved significantly in an undesired direction, or to determine if the intervention was effective in reducing adherence specifically in those with high levels of 
pretest adherence. Unfortunately, by the very nature of taking only those with scores 1 standard deviation above the mean, power is drastically reduced as the sample size is shrunk to $15.9 \%$ of the original size. Future studies which wish to conduct this type of research should use sample sizes large enough to provide a high acceptance group large enough for powerful analysis.

\section{Limitations of Study}

There are several limitations to this study. This study was conducted with a population of participants who were eighth grade students in a South Florida Title I middle school. The sample was comprised of predominantly Hispanic/Latina/o students. Hispanic/Latino/are are the largest ethnic population of Miami-Dade County and are a sizable portion of the population in other South Florida counties; therefore, the results of this study may not be generalizable to other grade levels or to other socioeconomic levels of students. Hispanic/Latino/a culture is not a single culture and this must be considered when generalizing the results of this study to other schools and districts which serve Hispanic/Latino/a students.

Both of the teachers who conducted the intervention in this study were experienced instructors with 8 years of teaching experience each, both were both experienced teaching the novel Speak, Teacher A had taught the novel for 7 years while Teacher B had taught the novel for 5 years, and both were comfortable discussing the topic of rape with students in a classroom setting. These factors could have had an impact on the success of the intervention and should be considered when generalizing the results. 
Finally, sample size in this study limited the achieved statistical power of analyses. Post-hoc power analysis revealed that achieved power was . 38 using a $2 \times 2 \times 2$ ANCOVA with a .05 significance level, an effect size of .15 and 124 subjects.

\section{Summary}

The results of this study provide empirical support for the hypothesis that a reader response based instructional unit of the young adult novel Speak could reduce rape myth acceptance in adolescents. This study also provides empirical support that the use of literature can help avoid a backlash effect in rape myth reduction interventions and the results support earlier studies which found girls to have significantly lower pretest rape myth acceptance than boys. The study developed the Adolescent Date Rape Myth Scale which measures acceptance of date rape myths in adolescents. Future researchers can use this inventory and further analyze its validity and reliability in date rape prevention research. Finally, the results provide empirical support for the use of full length young adult novels as part of English/Language Arts curricula and raise serious questions as to whether scripted curricula and curricula which are no more than practice for standardized tests are denying students unique and valuable learning opportunities. 


\section{REFERENCES}

Abel, G. G., Barlow, D. H., Blanchard, E. B., \& Guild, D. (1977). The components of rapists' sexual arousal. Archives of General Psychiatry, 34, 895-903.

Abrams, D., Viki, G. T., Masser, B., \& Bohner, G. (2003). Perceptions of stranger and acquaintance rape: The role of benevolent and hostile sexism in victim blame and rape proclivity. Journal of Personality and Social Psychology, 84 111-125.

Ackard, D. M., \& Neumark-Sztainer, D. (2001). Health care information sources for adolescents: Age and gender differences on use, concerns, and needs. Journal of Adolescent Health, 29, 170-176.

Anderson, L., \& Whiston, S. (2005). Sexual assault education programs: A meta-analytic examination of their effectiveness. Psychology of Women Quarterly, 25, 374-388.

Anderson, L. H. (1999). Speak. New York, NY: Farrar Straus Giroux.

Anderson, R. C., Fielding, L. G.,\& Wilson. P. T. (1988). Growth in reading and how children spend their time outside of school. Reading Research Quarterly, 23, 285-304.

Anyon, J. (1980). Social class and the hidden curriculum of work. Journal of Education, 162(1), 67-92.

Aristotle. (1905). Politics. (B. Jowett, Trans.). Oxford, UK: Clarendon.

Aristotle. (1954). Poetics. (W. Roberts, Trans.). New York, NY: McGraw-Hill.

Ashley, O. S., \& Foshee, V. A. (2005). Adolescent help-seeking for dating violence: Prevalence, sociodemographic correlates, and sources of help. Journal of Adolescent Health, 36(1), 25-31.

Ashton, N. L. (1982). Validation of rape myth acceptance scale. Psychological Reports, 50,252 - .

Atwell, N. (2010, February 10). The case for literature. Education Week, 32.

Avery-Leaf, S., Cascardi, M., O'Leary, K. D., \& Cano, A. (1997). Efficacy of a dating violence prevention program on attitudes justifying aggression. Journal of Adolescent Health, 21, 11-17. doi:10.1016/S1054-139X(96)00309-6

Barnett, N. J., \& Field, H. S. (1977). Sex differences in university students' attitudes toward rape. Journal of College Student Personnel, Volume, 93-96. 
Beach, R. (1993). Reader response theories. Urbana, IL: National Council of Teachers of English.

Bem, S. L. (1974). The measurement of psychological androgyny. Journal of Consulting and Clinical Psychology, 42, 155-162.

Bem, S. L. (1977). On the utility of alternative procedures for assessing psychological androgyny. Journal of Consulting and Clinical Psychology, 45, 196-205.

Berkowitz, A.D. (2003). Applications of social norms theory and other health and social justice issues. In H.W. Perkins (Ed.), The social norms approach to preventing school and college age substance abuse: A handbook for educators, counselors, and clinicians (pp. 259-279). San Francisco: Jossey-Bass.

Bigler, R.S. (1999). The use of multicultural curricula and materials to counter racism in children. Journal of Social Issues, 55, 687-705.

Bleich, D. (1988). The double perspective: Language, literacy, and social relations. Urbana, IL: National Council of Teachers of English.

Bohner, G. (1998). Rape myths: Social-psychological studies about beliefs that exonerate perpetrators and blame victims of sexual violence. Landau, Germany: Empirical Pedagogy.

Bohner, G., Jarvis, C. I., Eyssel, F., \& Siebler, F. (2005). The causal impact of rape myth acceptance on men's rape proclivity: Comparing sexually coercive and noncoercive men. European Journal of Social Psychology, 35, 819-828.

Bohner, G., Reinhard, M., Rutz, S., Sturm, S., Kerschbaum, B., \& Effler, D. (1998). Rape myths as neutralizing cognitions: Evidence for a causal impact of anti-victim attitudes on men's self-reported likelihood of raping. European Journal of Social Psychology, 28, 257-268.

Bohner, G., Siebler, F., \& Schmelcher, J. (2006). Social norms and the likelihood of raping: Perceived rape myth acceptance of others affects men's rape proclivity. Personality and Social Psychology Bulletin, 32,, 286-297.

Bondurant, B. (2001). University women's acknowledgment of rape. Violence Against Women, 7, 294-314. doi:10.1177/10778010122182451

Brecklin, L. R., \& Forde, D. R. (2001). A meta-analysis of rape education programs. Violence and Victims, 16, 303-321.

Briere, J., Malamuth, N., \& Check, J. V. (1985). Sexuality and rape-supportive beliefs. International Journal of Women's Studies, 8(4), 398-403. 
Brophy, J.E. (1990). Effective schooling for disadvantaged students. In M. Knapp (Ed.), Better schooling for the children of poverty: Alternatives to conventional wisdom (pp. 211-234). Berkley, CA: McCutchan.

Brownmiller, S. (1975). Against our will: Men, women, and rape. New York, NY: Bantam.

Bumby, K. M. (1996). Assessing the cognitive distortions of child molesters and rapists: Development and validation of the MOLEST and RAPE scales. Sexual Abuse: Journal of Research and Treatment, 8(1), 37-54.

Burt, M. R. (1980). Cultural myths and supports for rape. Journal of Personality and Social Pyschology, 38, 217-230.

Burt, M. R., \& Albin, R. S. (1981). Rape myths, rape definitions, and probability of conviction. Journal of Applied Social Psychology, 11, 212-230.

Burt, M. R., \& Katz, B. L. (1988). In Prentky R. A., Quinsey V. L. (Eds.), Coping strategies and recovery from rape. New York, NY: Academy of Sciences.

Campbell, J. (1976). The masks of God. Middlesex, UK: Penguin.

Chapleau, K. M., \& Oswald, D. L. (2010). Power, sex, and rape myth acceptance: Testing two models of rape proclivity. Journal of Sex Research, 47(1), 66-78.

Check, J. V., \& Malamuth, N. M. (1983). Sex role stereotyping and reactions to depictions of stranger versus acquaintance rape. Journal of Personality and Social Psychology, 45, 344-356.

Chiroro, P., Bohner, G., Viki, G. T., \& Jarvis, C. I. (2004). Rape myth acceptance and rape proclivity: Expected dominance versus expected arousal as mediators in acquaintance-rape situations. Journal of Interpersonal Violence, 19, 427-441.

Clinton-Sherrod, A. M., Morgan-Lopez, A. A., Gibbs, D., Hawkins, S. R., Hart, L., Ball, B., Irvin, N., \& Littler, N. (2009). Factors contributing to the effectiveness of four-school based sexual violence interventions. Health Promotion Practice, 10(1, Suppl), 19S-28S. doi:10.1177/1524839908319593

Cornelius, T. L., \& Resseguie, N. (2007). Primary and secondary prevention programs for dating violence: A review of the literature. Aggression and Violent Behavior, 12, 364-375.

Costin, F. (1985). Beliefs about rape and women's social roles. Archives of Sexual Behavior, 14, 319-325. 
Cullinan, B.E. (2000). Independent reading and school achievement. Assessment of the Role of School and Public Libraries in Support of Educational Reform. http://www.ala.org/ala/mgrps/divs/aasl/aaslpubsandjournals/slmrb/slmrcontents/v olume32000/independent.cfm

Cunningham, A. E., and K. E. Stanovich. 1991. Tracking the unique effects of print exposure in children: Associations with vocabulary, general knowledge, and spelling. Journal of Educational Psychology, 83, 264-274.

Dallager, C., \& Rosen, L. A. (1993). Effects of a human sexuality course on attitudes toward rape and violence. Journal of Sex Education and Therapy, 19, 193-199.

Deitz, S. R., \& Byrnes, L. E. (1981). Attribution of responsibility for sexual assault: The influence of observer empathy and defendant occupation and attractiveness. Journal of Psychology: Interdisciplinary and Applied, 108(1), 17-29.

Dewey, J., \& Bentley, A. F. (1949). Knowing and the known. Boston: Beacon Press.

Dill, K. E., \& Thill, K. P. (2007). Video game characters and the socialization of gender roles: Young peoples' perceptions mirror sexist media depictions. Sex Roles, 57(11-12), 851-864. doi:10.1007/s11199-007-9278-1

Edelsky, C. (1991). With literacy and justice for all: Rethinking the social in language and education. London: Falmer.

Fay, K. E., \& Medway, F. J. (2006). An acquaintance rape education program for students transitioning to high school. Sex Education, 6, 223-236.

Feltey, K. M., Ainslie, J. J., \& Geib, A. (1991). Sexual coercion attitudes among high school students: The influence of gender and rape education. Youth \& Society, 23, 229-250.

Fenstermaker, S. (1989). Acquaintance rape on campus: Responsibility and attributions of crime. In Pirog-Good M. A., Stets J. E. (Eds.), Violence in dating relationships: Emerging social issues (pp. 257-272). New York, NY: Praeger.

Fink, A. (1995). The survey kit. Thousand Oaks, CA: Sage.

Fish, S. E. (1980). Is there a text in this class?: The authority of interpretive communities. Cambridge, MA: Harvard University.

Fisher, B. S., Cullen, F. T., \& Turner, M. G. (2000). The sexual victimization of college women (NCJ Publication No. 182369). Washington, DC: U.S. Department of Justice. 
Flores, S. A., \& Hartlaub, M. G. (1998). Reducing rape-myth acceptance in male college students: A meta-analysis of intervention studies. Journal of College Student Development, 39, 438-448.

Florida Statutes, 794.011H. (1997).

Follingstad, D. R., Bradley, R. G., Laughlin, G. E. \& Burke, L. (1999) Risk factors and correlates of dating violence: The relevance of examining frequency and severity levels in a college sample. Violence and Victims, 14, 365-380.

Fonow, M. M., Richardson, L.,\& Wemmerus, V. A. (1992). Feminist rape education: Does it work? Gender and Society, 6, 108-121.

Foshee, V. A. (1994). Youth Dating Violence Survey. Unpublished instrument.

Foshee, V. A., Bauman, K. E., Ennett, S. T., Suchindran, C., Benefield, T., \& Linder, G. F. (2005). Assessing the effects of the dating violence prevention program "safe dates" using random coefficient regression modeling. Prevention Science, 6, $245-$ 258. doi:10.1007/s11121-005-0007-0

Foshee, V. A., Bauman, K. E., Ennett, S. T., Linder, G. F., Benefield, T., \& Suchindran, C. (2004). Assessing the long-term effects of the safe dates program and a booster in preventing and reducing adolescent dating violence victimization and perpetration. American Journal of Public Health, 94, 619-624. doi:10.2105/AJPH.94.4.619

Foshee, V. A., Bauman, K. E., Greene, W. F., Koch, G. G., Linder, G. F., \& MacDougall, J. E. (2000). The safe dates program: 1-year follow-up results. American Journal of Public Health, 90, 1619-1622. doi:10.2105/AJPH.90.10.1619

Foshee, V., Bauman, K. E., Arriaga, X. B., Helms, R. W., Koch, G. G., \& Linder, G. F. (1998). An evaluation of safe dates, an adolescent dating violence prevention program. American Journal of Public Health, 88, 45-50. doi:10.2105/AJPH.88.1.45

Foshee, V. A., Linder, G. F., Bauman, K. E., Langwick, S. A., Arriaga, X. B., Heath, J. L., McMahon, P. M., \& Bangdiwala, S. (1996). The safe dates project: Theoretical basis, evaluation design, and selected baseline findings. American Journal of Preventive Medicine, 12(5), 39-47.

Foubert, J. D., \& Perry, B. C. (2007). Creating lasting attitude and behavior change in fraternity members and male student athletes: The qualitative impact of an empathy-based rape prevention program. Violence Against Women, 13, 70-86. 
Freedner, N., Freed, L.H., Yang, Y.W., \& Austin, S.B. (2002). Dating violence among gay, lesbian, and bisexual adolescents: Results from a community survey. Journal of Adolescent Health, 31:469-74.

Freire, P. (1970). Pedagogy of the oppressed. New York, NY: Continuum.

Frese, B., Moya, M., \& Megías, J. L. (2004). Social perception of rape: How rape myth acceptance modulates the influence of situational factors. Journal of Interpersonal Violence, 19, 143-161. doi:10.1177/0886260503260245

Gerger, H., Kley, H., Schmidt, E. A., Siebler, F., \& Bohner, G. (2003). SAM: A scale for assessing contemporary myths about sexual aggression. Poster, presented at the 9th Conference of Social Psychology, Heidelberg, Germany.

Giacopassi, D. J., \& Dull, R. T. (1986). Gender and racial differences in the acceptance of rape myths within a college population. Sex Roles, 15, 63-75.

Giarrusso, R., Johnson, P., Goodchilds, J., \& Zellman, G. (1979). Adolescents' cues and signals: Sex and assault. In P. Johnson (Chair), Acquaintance rape and adolescent sexuality. symposium conducted at the meeting of the western psychological association, San Diego, CA.

Gilmartin-Zena, P. (1987). Attitudes toward rape: Student characteristics as predictors. Free Inquiry in Creative Sociology, 15, 175-182.

Goodchilds, J. D., Zellman, G. L., Johnson, P. B., \& Giarrusso, R. (1988). Adolescents and their perceptions of sexual interactions. In A. W. Burgess (Ed.), Rape and sexual assault II (pp. 245-270). New York: Garland.

Goodman, D. (2001). Promoting diversity and social justice: Educating people from privileged groups. Thousand Oaks, CA: Sage Publications.

Goodman, Y. M. (1982). Retellings of literature and the comprehension process. Theory into Practice, 21, 300-307. Retrieved from http://search.proquest.com/docview/63493977?accountid=10901.

Greaney, V. (1980). Factors related to amount and type of leisure reading. Reading Research Quarterly, 15, 337-57.

Greenfield, L. A. (1997) Sex offenses and offenders: An analysis of data on rape and sexual assault: sex offenses and offenders Washington, DC: US Department of Justice.

Greenwald, H. J., \& Satow, Y. (1970). A Short Social Desirability Scale. Psychological Reports. 27, 131-35. 
Guthrie, J. T., and V. Greaney. (1991). Literacy acts. In R. Barr, M. L. Kamil, P. Mosenthal, and P. D. Pearson (Eds.). Handbook of reading research: Vol. II. New York: Longman.

Hall, E. R., Howard, J. A., \& Boezio, S. L. (1986). Tolerance of rape: A sexist or antisocial attitude? Psychology of Women Quarterly, 10, 101-117.

Halpern, C.T., Young, M.L., Waller, M.W., Martin, S.L., \& Kupper, L.L. (2004). Prevalence of partner violence in same-sex romantic and sexual relationships in a national sample of adolescents. Journal of Adolescent Health, 35, 124-131.

Hanson, K. A., \& Gidycz, C. A. (1993). Evaluation of a sexual assault prevention program. Journal of Consulting and Clinical Psychology, 61, 1046-1052.

Harrison, P.J., Downes, J., and Williams, M.D. (1991). Date and acquaintance rape: Perception and attitude change strategy. Journal of College Student Development, 32, 131-139.

Hawthorne, N., \& Gollin, R. K. (2002). The scarlet letter: Complete text with introduction, historical contexts, critical essays. Boston: Houghton Mifflin.

Heath, S. B. (1983). Ways with words: Language, life, and work in communities and classrooms. Cambridgeshire: Cambridge University.

Heppner, M. J., Humphrey, C. F., Hillenbrand-Gunn, T. L., \& DeBord, K. A. (1995). The differential effects of rape prevention programming on attitudes, behavior, and knowledge. Journal of Counseling Psychology, 42, 508-518.

Hickman, L. J., Jaycox, L. H., \& Aronoff, J. (2004). Dating violence among adolescents: Prevalence, gender distribution, and prevention program effectiveness. Trauma, Violence, \& Abuse, 5, 123-142.

Hillenbrand-Gunn, T. L., Heppner, M. J., Mauch, P. A., \& Park, H. (2010). Men as allies: The efficacy of a high school rape prevention intervention. Journal of Counseling \& Development, 88, 43-51.

Hilton, N. Z., Harris, G. T., Rice, M. E., Krans, T. S., \& Lavigne, S. E. (1998). Antiviolence education in high schools: Implementation and evaluation. Journal of Interpersonal Violence, 13, 726-742. doi:10.1177/088626098013006004

Hochstrasser-Fickel, L. (2009). "Unbanking” education: Exploring constructs of knowledge, In L.A. Spears-Bunton \& R. Powell (Eds.), Toward a literacy of promise: Joining the African-American struggle (pp. 1-19). New York, NY: Routledge. 
Irvine, P.D., \& Larson, J. (2007). Literacy packages in practice: Constructing academic disadvantage. In J. Larson (Ed.), Literacy as snake oil: New literacies and digital epistemologies (pp. 49-72). New York, NY: Peter Lang.

Irving, A. (1980). Promoting voluntary reading for children and young people. Paris: UNESCO.

Iser, Wolfgang. (1974). The implied reader: patterns of communication in prose fiction from Bunyan to Beckett. Baltimore, Md: Johns Hopkins.

Jaffe, P. G., Suderman, M., Reitzel, D., \& Killip, S.M. (1992). An evaluation of a secondary school primary prevention program on violence in intimate relationships. Violence and Victims, 7, 129-146.

Jaycox, L. H., McCaffrey, D., Eiseman, B., Aronoff, J., Shelley, G. A., Collins, R. L., \& Marshall, G. N. (2006). Impact of a school-based dating violence prevention program among latino teens: Randomized controlled effectiveness trial. Journal of Adolescent Health, 39, 694-704. doi:10.1016/j.jadohealth.2006.05.002

Johansson-Love, J., \& Geer, J. H. (2003). Investigation of attitude change in a rape prevention program. Journal of Interpersonal Violence, 18, 84-99.

Kahn, A. S., Mathie, V. A., \& Torgler, C. (1994). Rape scripts and rape acknowledgment. Psychology of Women Quarterly, 18, 53-66. doi:10.1111/j.14716402.1994.tb00296.x

Kanin, E. J. (1957). Male aggression in dating-courtship relations. American Journal of Sociology, 63, 197-204.

Kantor, G. K. (1996). A safe place dating violence prevention project. Durham: University of New Hampshire, Family Research Laboratory.

Kilmartin, C., Conway, A., Friedberg, A., McQuoid, T., \& Tschan, T. (1999). Social conformity and sexism in all-male peer groups. Paper presented at the annual convention of the Virginia Psychological Association, Virginia Beach, VA.

Klaw, E. L., Lonsway, K. A., Berg, D. R., Waldo, C. R., Kothari, C., Mazurek, C. J., \& Hegeman, K. E. (2005). Challenging rape culture: Awareness, emotion and action through campus acquaintance rape education. Women \& Therapy, 28, 47-63. doi:10.1300/J015v28n02_04

Kley, H., Gerger, H., Bohner, G., Siebler, F., \& Schmidt, E. A. (2004). Parallel development of German- and English-language scales for assessing contemporary myths about sexual aggression. In T. Rammsayer, S. Grabianowski, \& S. Troche 
(Eds.). Congress of the German Society for Psychology, Göttingen, (p. 327). Lengerich, Germany: Pabst Science Publishers.

Korman, S. K., \& Leslie, G. R. (1982). The relationship of feminist ideology and date expense sharing to perceptions of sexual aggression in dating. Journal of Sex Research, 18, 114-129.

Koss, M. P. (1997). Dealing with date rape. US: American Psychological Association.

Koss, M. P., Dinero, T. E., Seibel, C. A., \& Cox, S. L. (1988). Stranger and acquaintance rape: Are there differences in the victim's experience? Psychology of Women Quarterly, 12, 1-24.

Koss, M. P., Gidycz, C. A., \& Wisniewski, N. (1987). The scope of rape: Incidence and prevalence of sexual aggression and victimization in a national sample of higher education students. Journal of Consulting and Clinical Psychology, 55, 162-170.

Koss, M. P., \& Oros, C. J. (1982). Sexual Experiences Survey: A research instrument investigating sexual aggression and victimization. Journal of Consulting and Clinical Psychology, 50, 455-457.

Krahé, B., Bieneck, S., \& Scheinberger-Olwig, R. (2007). Adolescents'sexual scripts: Schematic representations of consensual and nonconsensual heterosexual interactions. Journal of Sex Research, 44, 316-327.

Krashen, S. D. (1993). The power of reading: Insights from the research. Englewood, CO: Libraries Unlimited.

Irving, A. (1980). Promoting voluntary reading for children and young people. Paris: UNESCO.

Lanier, C. A. (2001). Rape-accepting attitudes: precursors to or consequences of forced sex. Violence Against Women, 7, 876.

Lanier, C.A., \& Green, B.A. (2006). Principal component analysis of the college date rape attitude survey (CDRAS): An instrument for the evaluation of date rape prevention programs. Journal of Aggression, Maltreatment \& Trauma, 13, 79-93.

Larsen, K. S., \& Long, E. (1988). Attitudes toward rape. Journal of Sex Research, 24, 299-304.

Lavoie, F., Vézina, L., Piché, C., \& Boivin, M. (1995). Evaluation of a prevention program for violence in teen dating relationships. Journal of Interpersonal Violence, 10, 516-524. doi:10.1177/088626095010004009 
Layman-Guadalupe, M J. (1997). Evaluation of an acquaintance rape awareness program: Differential impact on acknowledged and unacknowledged rape victims. Dissertation Abstracts International: Section B: The Sciences and Engineering. Retrieved from http://search.proquest.com/docview/619250963?accountid=10901.

Layman, M. J., Gidycz, C. A., \& Lynn, S. J. (1996). Unacknowledged versus acknowledged rape victims: Situational factors and posttraumatic stress. Journal of Abnormal Psychology, 105, 124-131. doi:10.1037/0021-843X.105.1.124

Lenihan, G. O., \& Rawlins, M. E. (1994). Rape supportive attitudes among Greek students before and after a date rape prevention program. Journal of College Student Development, 35, 450-455.

Lenihan, G. O., Rawlins, M. E., Eberly, C. G., Buckley, B., \& Masters, B. (1992). Gender differences in rape supportive attitudes before and after a date rape education intervention. Journal of College Student Development, 33, 331-337.

Linz, D., Fuson, I.A., \& Donnerstein, E. (1990). Mitigating the negative effects of sexually violent mass communications through preexposure briefings. Communication Research, 17, pp. 641-674.

Lisak, D., \& Roth, S. (1988). Motivational factors in non-incarcerated sexually aggressive men. Journal of Personality and Social Psychology, 55, 795-802.

Lonsway, K. A., \& Fitzgerald, L. F. (1994). Rape myths: In review. Psychology of Women Quarterly, 18, 133-164.

Lottes, I. L. (1987). Predictors of attitudes toward rape in a college population. Dissertation Abstracts International. Retrieved from http://search.proquest.com/docview/617455760?accountid=10901.

Lowe, L. A., Jones, C. D., \& Banks, L. (2007). Preventing dating violence in public schools: An evaluation of an interagency collaborative program for youth. Journal of School Violence, 6, 69-87.

Macgowan, M. J. (1997). An evaluation of a dating violence prevention program for middle school students. Violence and Victimization, 12, 223-235.

Malamuth, N. M. (1981). Rape proclivity among males. Journal of Social Issues, 37, 138-157.

Malamuth, N. M. (1989). The Attraction to Sexual Aggression scale: Part I. Journal of Sex Research, 26, 26-49. 
Malamuth, N. M., \& Check, J. V. (1980). Penile tumescence and perceptual responses to rape as a function of victims perceived reactions. Journal of Applied Social Psychology, 10, 528-547.

Malamuth, N. M., \& Check, J. V. (1985). The effects of aggressive pornography on beliefs in rape myths: Individual differences. Journal of Research in Personality, 19, 299-320.

Malamuth, N. M., Haber, S., \& Feshbach, S. (1980). Testing hypotheses regarding rape: Exposure to sexual violence, sex differences, and the "normality" of rapists. Journal of Research in Personality, 14, 121-137.

Malamuth, N. M., Heim, M., \& Feshbach, S. (1980). Sexual responsiveness of college students to rape depictions: Inhibitory and disinhibitory effects. Journal of Personality and Social Psychology, 38, 399-408.

Mandelblatt, A. L. (1999). Date rape and acquaintance rape attitudes among secondary school students: The influence of a date and acquaintance rape prevention education program. Dissertation Abstracts International Section A: Humanities and Social Sciences, 60 (1999-95021-191).

Marolla, J. A., \& Scully, D. (1986). Attitudes toward women, violence, and rape: A comparison of convicted rapists and other felons. Deviant Behavior, 7, 337-355.

Marshall, W. L., \& Hambley, L. S. (1996). Intimacy and loneliness, and their relationship to rape myth acceptance and hostility toward women among rapists. Journal of Interpersonal Violence, 11, 586-592. doi:10.1177/088626096011004009

Matthews, J. (2000). Prepackaged school reform. The School Administrator. Retrieved April 22, 2009, from http://aasa.org/SchoolAdministratorArticle.aspx?id=14476.

Maxwell, Christopher D., Robinson, A. L., \& Post, Lori A. (2003). The impact of race on the adjudication of sexual assault and other violent crimes. Journal of Criminal Justice, 31, 523-538.

Messman-Moore, T., Coates, A. A., Gaffey, K. J., \& Johnson, C. F. (2008). Sexuality, substance use, and susceptibility to victimization: Risk for rape and sexual coercion in a prospective study of college women. Journal of Interpersonal Violence, 23, 1730-1746. doi:10.1177/0886260508314336

Milhausen, R. R., McBride, K. R., \& Jun, M. K. (2006). Evaluating a peer-led, theatrical sexual assault prevention program: How do we measure success? College Student Journal, 40, 316-328.

Miller, F. J. (1916). Ovid: Metamorphoses. London: W. Heinemann. 
Moustafa, M. \& Land, R.E. (2002). The reading achievement of economically disadvantaged children in urban schools using Open Court vs. comparably disadvantaged children using non-scripted reading programs. 2002 Yearbook of the Urban Learning, Teaching, and Research Special Interest Group of the American Educational Research Association, 44-53.

Muehlenhard, C. L. \& Felts, A. S. (1998). Sexual beliefs scale. In C.M. Davis, W.L. Yarber, R. Bauserman, G. Schreer, \& S.L. Davis (Eds.), Handbook of Sexuality Related Measures (pp. 116-118). Thousand Oaks, CA: Sage.

Murphy, W. D., Coleman, E. M. \& Haynes, M. R. (1986). Factors related to coercive sexual behavior in a nonclinical sample of males. Violence \& Victims, 1, 255-278.

Musch, J, Brockhaus, R, \& Broder, A. (2002). An inventory for the assessment of two factors of social desirability. Diagnostica.

National Association of Student Personnel Administrators. (1994). Complying with the final regulations: The Student Right to Know and Campus Security Act. Washington, DC.

National Conference of State Legislators. (2012). Teen dating violence. Retrieved from http://www.ncsl.org/issues-research/health/teen-dating-violence.aspx.

National Organization for Women. (2012). Women deserve equal pay. Htttp:/www.now.org/issues/economic/factsheet.html\#endref1.

Nebraska Domestic Violence Sexual Assault Coalition. (1995). Reaching and teaching teens to stop violence. Lincoln, NE.

Nelson, E. S., \& Torgler, C. C. (1990). A comparison of strategies for changing college students' attitudes toward acquaintance rape. Journal of Humanistic Education and Development. 29, 69-85.

Nodelman, P. \& Reimer, M. (2003). The pleasures of children's literature. Colombus, OH: Allyn \& Bacon.

Noonan, R. K., \& Charles, D. (2009). Developing teen dating violence prevention strategies: Formative research with middle school youth. Violence Against Women, 15, 1087-1105. doi:10.1177/1077801209340761

Nussbaum, M. C. (1990). Love's knowledge: Essays on philosophy and literature. New York: Oxford. 
Pacifici, C., Stoolmiller, M., \& Nelson, C. (2001). Evaluating a prevention program for teenagers on sexual coercion: A differential effectiveness approach. Journal of Consulting and Clinical Psychology, 69, 552-559. doi:10.1037/0022006X.69.3.552.

Parrot, A. (1985). Comparison of acquaintance rape patterns among college students in a large co-ed university and a small women's college. Paper presented at the annual meeting of the Society for the Scientific Study of Sex, San Diego, CA.

Parrot, A. (1991). Acquaintance rape and sexual assault: A prevention manual. Holmes Beach, FL: Learning Publications.

Payne, D. L., Lonsway, K. A., \& Fitzgerald, L. F. (1999). Rape myth acceptance: Exploration of its structure and its measurement using the Illinois Rape Myth Acceptance Scale. Journal of Research in Personality, 33, 27-68. doi:10.1006/jrpe.1998.2238

Perkins, H. W., \& Berkowitz, A. D. (1986). Perceiving the community norms of alcohol use among students: Some research implications for campus alcohol education programming. International Journal of the Addictions, 21, 961-976.

Peterson, Z. D., \& Muehlenhard, C. L. (2004). Was it rape? The function of women's rape myth acceptance and definitions of sex in labeling their own experiences. Sex Roles, 51, 129-144. doi:10.1023/B:SERS.0000037758.95376.00

Post, L. A., Maxwell, C. D., Smith, P. K., \& Korzeniewski, S. J. (2006). Youth dating and sexual violence. In F. A. Villarruel, \& T. Luster (Eds.), The crisis in youth mental health (pp. 257-281). Westport, CT: Praeger.

Powell, R. (1999). Literacy as a moral imperative: Facing the challenges of a pluralistic society. Lanham, MD: Roman \& Littlefield.

Powell, R. (2009). Introduction. In L.A. Spears-Bunton \& R. Powell (Eds.), Toward a literacy of promise: Joining the African-American struggle (pp. 1-19). New York, NY: Routledge.

Probst, R. E. (1988). Response and analysis: Teaching literature in junior and senior high school. Portsmouth, NH: Boynton/Cook.

Proto-Campise, L., Belknap, J., \& Wooldredge, J. (1998). High school students' adherence to rape myths and the effectiveness of high school rape awareness programs. Violence Against Women, 4, pp. 308-328.

Purves, A. C. (1990). Testing literature: The current state of affairs. ERIC digest. No. EDO-CS-90-08).ERIC Clearinghouse on Reading and Communication Skills, 
Indiana University, Smith Research Center, Suite 150, 2805 E. Tenth St., Bloomington, IN 47408-2698.

Quackenbush, R. L. (1989). A comparison of androgynous, masculine sex-typed, and undifferentiated males on dimensions of attitudes toward rape. Journal of Research in Personality, 23, 318-342.

Rabinowitz, P. J., \& Smith, M. W. (1998). Authorizing readers: Resistance and respect in the teaching of literature. New York: Teachers College Press.

Rapes by Country. (2010). Nationmaster.com. Retrieved (2010, August 3) from http://www.nationmaster.com/graph/cri rap-crime-rapes.

RAVE. (1997). Knowledge of sexual assault. Grand Rapids, MI: RAVE of West Michigan.

Rayburn, N. R., Jaycox, L. H., McCaffrey, D., Ulloa, E. C., Zander-Cotugno, M., Marshall, G. N., \& Shelly, G.A. (2007). Reactions to dating violence among Latino teenagers: An experiment utilizing the articulated thoughts in simulated situations paradigm. Journal of Adolescence, 30, 893-915.

Ring, T. E., \& Kilmartin, C. (1992). Man to man about rape: A rape prevention program for men. Journal of College Student Development. 33, 82-84.

Rosenblatt, L. M. (1938). Literature as exploration. New York: Noble and Noble.

Rosenblatt, L. M. (1978). The reader, the text, the poem: The transactional theory of the literary work. Carbondale, IL: Southern Illinois University.

Rosenthal, E. H., Heesacker, M., \& Neimeyer, G. J. (1995). Changing the rapesupportive attitudes of traditional and non-traditional male and female college students. Journal of Counseling Psychology, 42, 171-177.

Sawyer, R.G., Thompson, E.E., Chicorelli, A.M. (2002). Rape myth acceptance among intercollegiate student athletes: A preliminary examination. American Journal of Health Studies, 18, pp. 19-25.

Shotland, R. L., \& Goodstein, L. (1983). Just because she doesn't want to doesn't mean its rape: An experimentally based causal model of the perception of rape in a dating situation. Social Psychology Quarterly, 46, 220-232.

Slep, A. M. S., Cascardi, M., Avery-Leaf, S., \& O'Leary, K. D. (2001). Two new measures of attitudes about the acceptability of teen dating aggression. Psychological Assessment, 13, 306-318. 
Shakespeare, W. (2011). Julius Caesar. New York, NY: Simon \& Schuster.

Shultz, K. S., \& Whitney, D. J. (2005). Measurement theory in action: Case studies and exercises. Thousand Oaks, CA: Sage Publications.

Smith, P., \& Welchans, S. (2000). Peer education: Does focusing on male responsibility change sexual assault attitudes? Violence Against Women, 6, 1255-1268.

Snyder, H.N. (2000). Juvenile arrests 1999. Office of Juvenile Programs, Office of Juvenile Justice and Delinquency Prevention. Washington, DC: US Department of Justice.

Snyder, H.N. \& Sickmund, M. (1999). Juvenile offenders and victims: 1999 national report. Washington, DC: U.S. Department of Justice.

Spears-Bunton, L. A., \& Powell, R. (2009). Toward a literacy of promise: Joining the African-American struggle. New York, NY: Routledge.

Stanovich, K. E., \& Cunningham, A. E. (1993). Where does knowledge come from? Specific associations between print exposure and information acquisition. Journal of Educational Psychology, 85, 211-29.

Straus, M. A. (1996). The Revised Conflict Tactics Scale (CTS2): Development and preliminary psychometric data. Journal of Family Issues. 17, 283-316.

Suarez, E., \& Gadalla, T. M. (2010). Stop blaming the victim: A meta-analysis on rape myths. Journal of Interpersonal Violence, 25, 2010-2035.

Sweet, E. (1985). Date rape. Ms. Magazine, 14, 56.

Tabachnick, B. G., \& Fidell, L. S. (2000). Using multivariate statistics. Boston, MA: Allyn and Bacon.

Taylor, B., Frye, P., \& Maruyama, G. (1990). Time spent reading and reading growth. American Educational Research Journal, 27,442-51.

Tieger, T. (1981). Self-rated likelihood of raping and the social perception of rape. Journal of Research in Personality, 15, 147-158. doi:10.1016/00926566(81)90014-3

Ting, S. R. (2009). Meta-analysis on dating violence prevention among middle and high schools. Journal of School Violence, 8, 328-337.

U.S. Bureau of Justice Statistics. (2000) 2000 Sexual Assault of Young Children as Reported to Law Enforcement. 
U.S. Department of Justice. (1998). 1998 National Crime Victimization Survey.

U.S. Department of Justice. (2004). 2004 National Crime Victimization Survey.

U.S. Department of Justice. (2005). 2005 National Crime Victimization Study.

Ward, C. (1988). The attitudes toward rape victims scale. Psychology of Women Quarterly, 12, 127-146.

Warshaw, R. (1988). I never called it rape. New York: Ms. Magazine/Sarah Lazin Books.

Weisz, A. N., \& Black, B. M. (2001). Evaluating a sexual assault and dating violence prevention program for urban youths. Social Work Research, 25, 89-102.

Wollheim, R. (1983). Flawed crystals. New Literary History, 15, 185-192.

Worling, J.R. (1995). Adolescent sex offenders against females: Differences based on the age of their victims. International Journal of Offender therapy and Comparative Criminology, 39, 276-293.

Yeater, E. A., \& O’Donohue, W. (1999). Sexual assault prevention programs: Current issues, future directions, and the potential efficacy of interventions with women. Clinical Psychology Review, 19, 739-771. 
APPENDICES 
Appendix A

Parent Consent Form 


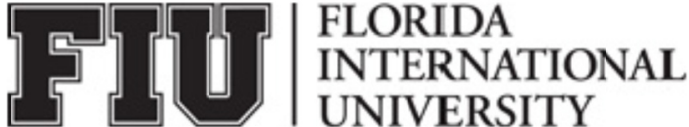

\author{
PARENTAL CONSENT TO PARTICIPATE IN A RESEARCH STUDY \\ The Effect of Young Adult Literature on Teen Dating Violence
}

PURPOSE OF THE STUDY

You are being asked to give your permission for your child to be in a research study. The purpose of this study is to investigate the relationship between reading the novel Speak and adolescents' attitudes toward dating violence.

\section{NUMBER OF STUDY PARTICIPANTS}

If you agree to allow your child to participate in this study, he/she will be one of 160 people in this research study.

\section{DURATION OF THE STUDY}

Your child's participation will require normal class attendance for a period of three weeks.

\section{PROCEDURES}

If your child participates in this study, we will ask your child to do the following things:

1. Fill out two surveys before and after reading a novel in class.

2. Read the novel Speak during class time and do normal academic assignments involving reading.

\section{RISKS AND/OR DISCOMFORTS}

The following risks may be associated with your child's participation in this study: Your child will be asked to consider his/her attitudes toward dating violence and myths about date rape.

\section{BENEFITS}

The following benefits may be associated with your child's participation in this study: Your child will learn about literary elements that will assist him/her in later English classes. This study may assist educators in designing and implementing educational techniques intended to reduce dating violence and date rape.

\section{ALTERNATIVES}

There are no known alternatives available to your child other than not taking part in this study. However, any significant new findings developed during the course of the research which may relate to your child's willingness to continue participation will be provided to you.

\section{CONFIDENTIALITY}

The records of this study will be kept private and will be protected to the fullest extent provided by law. In any sort of report we might publish, we will not include any information that will

Page 1 of 3 
make it possible to identify your child as a subject. Research records will be stored securely and only the researcher team will have access to the records. All surveys will be confidential identifiable only by a number on the survey. All surveys will be destroyed as soon as the data is input into a computer program and it will be impossible for anyone, including the research team, to link your child to any data after that time.

\section{COMPENSATION \& COSTS}

Your child will receive class credit for filling out the surveys. Your child will not be responsible for any costs to participate in this study.

\section{RIGHT TO DECLINE OR WITHDRAW}

Your child's participation in this study is voluntary. Your child is free to participate in the study or withdraw his/her consent at any time during the study. Your child's withdrawal or lack of participation will not affect any benefits to which he/she is otherwise entitled. The investigator reserves the right to remove your child from the study without your consent at such time that they feel it is in the best interest.

\section{RESEARCHER CONTACT INFORMATION}

If you have any questions about the purpose, procedures, or any other issues relating to this research study you may contact Victor Malo-Juvera at vmalojuvera@dadeschools.net.

\section{IRB CONTACT INFORMATION}

If you would like to talk with someone about your child's rights of being a subject in this research study or about ethical issues with this research study, you may contact the FIU Office of Research Integrity by phone at 305-348-2494 or by email at ori@fiu.edu.

\section{PARTICIPANT AGREEMENT}

I have read the information in this consent form and agree to allow my child to participate in this study. I have had a chance to ask any questions I have about this study, and they have been answered for me. I understand that I am entitled to a copy of this form after it has been read and signed.

Signature of Parent/Guardian

Printed Name of Parent/ Guardian

Printed Name of Child Participant

Signature of Person Obtaining Consent

\section{Date}


PARTICIPANT REFUSAL

I have read the information in this consent form and do NOT want my child to participate in this study. I have had a chance to ask any questions I have about this study, and they have been

answered for me. I understand that I am entitled to a copy of this form after it has been read and signed.

Signature of Parent/Guardian

$\overline{\text { Date }}$

Printed Name of Parent/ Guardian

Printed Name of Child Participant 
Appendix B

Child Assent Form 


\title{
FIU]
}

\section{CHILD ASSENT TO PARTICIPATE IN A RESEARCH STUDY}

The Effect of Literature on Adolescents' Rape Myth Acceptance

\begin{abstract}
WHY ARE YOU DOING THIS STUDY?
We would like for you to be in a research study we are doing. A research study is a way to learn information about something. We would like to find out more about how reading novels may or may not influence the way teens feel about dating violence.
\end{abstract}

HOW MANY OTHERS WILL BE IN THIS STUDY?

If you agree to participate in this study, you will be one of 160 children in this research study.

HOW LONG WILL THE STUDY LAST?

Your participation will require filling out two inventories which will take about 20 minutes before and after a unit of study on the novel Speak. The novel will be read in class over a three week period of class time.

\section{WHAT WILL HAPPEN IN THIS STUDY?}

If you participate in this study, we will ask you to do the following things:

Fill out two surveys about your attitudes toward date rape before and after the unit of study.

\section{CAN ANYTHING BAD HAPPEN TO ME?}

There are no known risks to filling out the surveys.

\section{CAN ANYTHING GOOD HAPPEN TO ME?}

The following benefits may be associated with your participation in this study:

In addition to increasing your literary knowledge by reading a novel, you may increase your selfawareness about your attitudes toward dating violence.

\section{DO I HAVE OTHER CHOICES?}

There are no known alternatives available to you other than not taking part in this study.

\section{WILL ANYONE KNOW I AM IN THE STUDY?}

The records of this study will be kept private and will be protected by the researchers. All surveys will be destroyed immediately after the scores are recorded in a computer program.

\section{WILL I BE GIVEN ANYTHING FOR PARTICIPATING?}

You will receive a payment of one extra credit "A" grade for your participation. You will not need to pay for anything to participate in this study. 


\section{WHAT IF I DO NOT WANT TO DO THIS?}

You do not have to be in this study if you don't want to and you can quit the study at any time. If you don't like a question, you don't have to answer it and, if you ask, your answers will not be used in the study. No one will get mad at you if you decide you don't want to participate.

\section{WHO CAN I TALK TO ABOUT THE STUDY?}

If you have any questions about the research study you may contact Victor Malo-Juvera at vmalojuvera@dadeschools.net. If you would like to talk with someone about your rights of being a participant in this research study, you may contact the FIU Office of Research Integrity by phone at 305-348-2494 or by email at ori@fiu.edu.

\section{PARTICIPANT AGREEMENT}

This research study has been explained to me and I agree to be in this study.

Signature of Child Participant

Printed Name of Child Participant

Signature of Person Obtaining Consent
Date

Date

Page 2 of 2 
Appendix C

Rape Myth Acceptance Scale 


\section{Rape Myth Acceptance Scale}

Directions: Respond to the following items by circling what you feel is the most appropriate answer. Please remember, there are no right or wrong answers.

1. A woman who goes to the home or apartment of a man on their first date implies that she is willing to have sex.

Strongly Agree Agree Somewhat Agree Neutral Somewhat Disagree Disagree Strongly Disagree

2. Any female can get raped.

Strongly Agree Agree Somewhat Agree Neutral Somewhat Disagree Disagree Strongly Disagree

3. One reason that women falsely report a rape is that they frequently have a need to call attention to themselves.

Strongly Agree Agree Somewhat Agree Neutral Somewhat Disagree Disagree Strongly Disagree

4. Any healthy woman can successfully resist a rapist if she really wants to.

Strongly Agree Agree Somewhat Agree Neutral Somewhat Disagree Disagree Strongly Disagree

5. When women go around braless or wearing short skirts and tight tops, they are just asking for trouble.

Strongly Agree Agree Somewhat Agree Neutral Somewhat Disagree Disagree Strongly Disagree

6. In the majority of rapes, the victim is promiscuous or has a bad reputation.

Strongly Agree Agree Somewhat Agree Neutral Somewhat Disagree Disagree Strongly Disagree 
7. If a girl engages in necking or petting and she lets things get out of hand, it is her own fault if her partner forces sex on her.

Strongly Agree Agree Somewhat Agree Neutral Somewhat Disagree Disagree Strongly Disagree

8. Women who get raped while hitchhiking get what they deserve.

Strongly Agree Agree Somewhat Agree Neutral Somewhat Disagree Disagree Strongly Disagree

9. A woman who is stuck-up and thinks she is too good to talk to guys on the street deserves to be taught a lesson.

Strongly Agree Agree Somewhat Agree Neutral Somewhat Disagree Disagree Strongly Disagree

10. Many women have an unconscious wish to be raped, and may then unconsciously set up a situation in which they are likely to be attacked.

Strongly Agree Agree Somewhat Agree Neutral Somewhat Disagree Disagree Strongly Disagree

11. If a woman gets drunk at a party and has intercourse with a man she's just met there, she should be considered "fair game" to other males at the party who want to have sex with her too, whether she wants to or not.

Strongly Agree Agree Somewhat Agree Neutral Somewhat Disagree Disagree Strongly Disagree

12. What percentage of women who report a rape would you say are lying because they are angry and want to get back at the man they accuse?

Almost All About 3/4 About Half About 1/4 Almost None

13. What percentage of reported rapes would you guess were merely invented by women who discovered they were pregnant and wanted to protect their own reputation?

Almost All About 3/4 About Half About 1/4 Almost None 
A person comes to you and claims they were raped. How likely would you be to believe their statement if the person were:

14. your best friend?

Always Frequently Sometimes Rarely Never

15. an Indian woman?

Always Frequently Sometimes Rarely Never

16. a neighborhood woman?

Always Frequently Sometimes Rarely Never

17. a young boy?

Always Frequently Sometimes Rarely Never

18. a black woman?

Always Frequently Sometimes Rarely Never

19. a white woman?

Always Frequently Sometimes Rarely Never 
Appendix D

Adolescent Date Rape Myth Scale 


\section{Research ID:}

\section{Adolescent Rape Myth Acceptance Scale}

Directions: Respond to the following items by circling what you feel is the most appropriate answer. Please remember, there are no right or wrong answers.

1. If a girl is a sexual tease, eventually she is going to get into trouble.

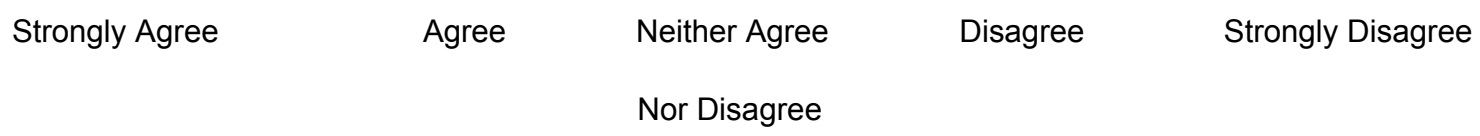

2. If a girl lets a boy spend a lot of money on her on a date, she owes him something.

\begin{tabular}{|c|c|c|c|c|}
\hline Strongly Agree & Agree & Neither Agree & Disagree & Strongly Disagree \\
\hline
\end{tabular}

3. If a girl doesn't physically fight back, you can't really say a boy raped her.

\begin{tabular}{|c|c|c|c|c|}
\hline Strongly & Agree & Neither Agree & Disagree & Strongly Disagree \\
\hline
\end{tabular}

4. If a girl gets drunk with a boy and he forces her to have sex, she is at least somewhat responsible for letting things get out of control.

$\begin{array}{llll}\text { Strongly Agree } & \text { Agree } & \text { Neither Agree } & \text { Disagree } \\ & \text { Nor Disagree } & \end{array}$

5. If a girl sneaks out of her house to meet a boy, she wants sex.

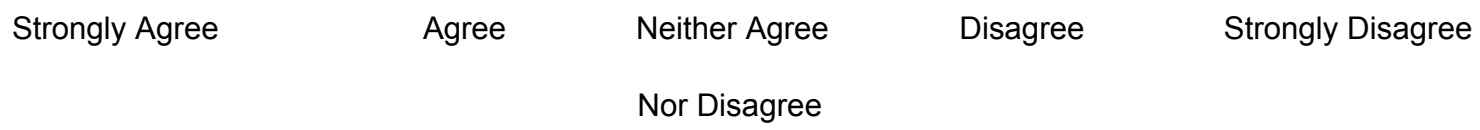


6. Many girls who have sex and then change their minds after say they were date raped.

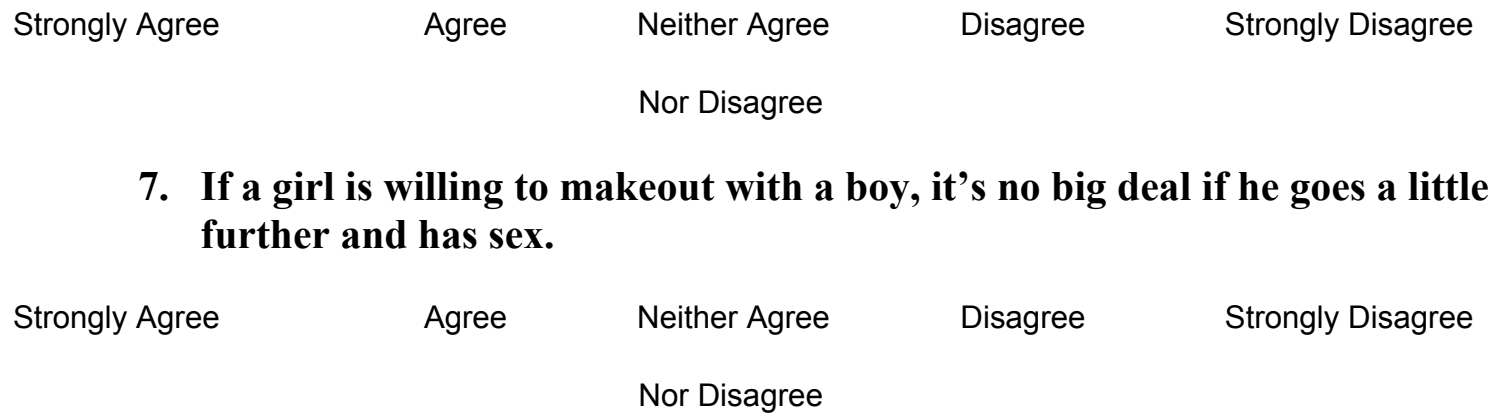

8. Many girls pretend they don't want to have sex because they don't want to appear easy.

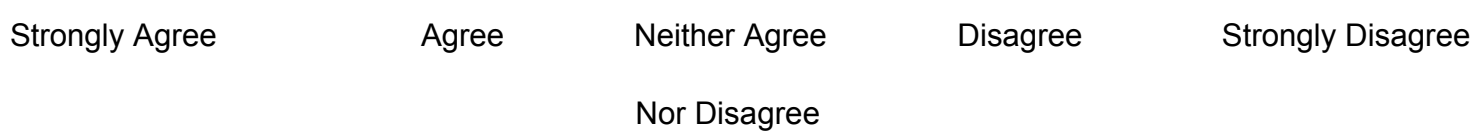

9. Some girls like boys to make them have sex so they don't feel guilty after. Strongly Agree Agree Neither Agree Disagree Strongly Disagree Nor Disagree

10. If a girl invites a boy to her house when her parents are not at home, she is implying she wants sex.

$\begin{array}{llll}\text { Strongly Agree } & \text { Agree } & \text { Neither Agree } & \text { Disagree } \\ & \text { Nor Disagree } & \end{array}$

11. A lot of times girls say they were raped in order to get back at a boy they are mad at.

Strongly Agree

Agree

Neither Agree

Disagree

Strongly Disagree

Nor Disagree 
12. It is okay for a boy to pressure a girl into having sex if she has had sex in the past.

Strongly Agree

Agree

Neither Agree

Disagree

Strongly Disagree

Nor Disagree

13. If a girl doesn't have any bruises or marks, she wasn't really raped.

Strongly Agree

Agree

Neither Agree

Disagree

Strongly Disagree

Nor Disagree

14. Some girls who get caught cheating on their boyfriends say it was rape.

Strongly Agree

Agree

Neither Agree

Disagree

Strongly Disagree

Nor Disagree

15. When girls wear low cut tops and short skirts they're just asking for trouble.

Strongly Agree

Agree

Neither Agree

Disagree

Strongly Disagree

Nor Disagree

16. Many girls who get caught by their parents having sex say it was rape to avoid getting in trouble.

Agree

Neither Agree

Disagree

Strongly Disagree

Nor Disagree

17. If a boy is really sexually excited, he may not even realize the girl is resisting him.

Nor Disagree 
18. If a girl is willing to go parking in a boy's car at night with him, she wants to have sex.

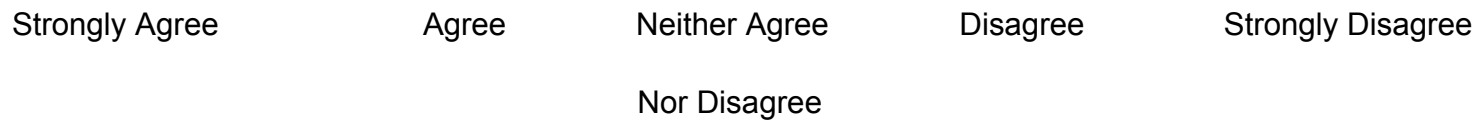

19. To prove her love, it is important for a girl to have sex with her boyfriend.

Strongly Agree

Agree

Neither Agree

Disagree

Strongly Disagree

Nor Disagree

20. If a girl is about to have sex with a boy and she changes her mind at the last minute, it is not his fault if he gets carried away and forces her to have intercourse.

Agree

Neither Agree

Disagree

Strongly Disagree

Nor Disagree 
VITA

\section{VICTOR MALO-JUVERA}

1989

2007

2011

2011-2012
B.F.A., Communications

University of Miami

Miami, Florida

M.S., Curriculum \& Instruction

Florida International University

Miami, Florida

Ed.S., Curriculum \& Instruction

Florida International University

Miami, Florida

Doctoral Candidate

Florida International University

Miami, Florida 